Aus dem anatomischen Institut der Universität Marburg a. L.

\title{
BEITRÄGE
}

ZUR

\section{KENNTNIS DES KOPFES DER WIRBELTIERE.}

I.

\section{DIE ENTWICKELUNG DES PRIMORDIALCRANIUM YON LEPIDOSTEUS OSSEUS.}

VON

OTTO VEIT,

MARBURG.

Mit 1 Textignu und 20 Figuren auf den Tafeln $A-E$. 



\section{Inhaltsuibersicht.}

Neite

I. Beschreibung der Einzelbefunde . . . . . . . . . . . . . . . . . 99

Stadium I, Lepidosteus osseus $8-10 \mathrm{~mm}$. . . . . . . . 99

n II, . , $, 10-11, \ldots . \quad . \quad . \quad . \quad . \quad . \quad .113$

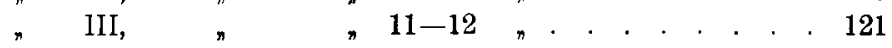

\#IV, $\quad$ IV $\quad 14$. . . . . . . . 135

$\pi$ V, $\quad \pi 20 \pi$. . . . . . . . 152

II. Zusammenfassung und Diskussion der Befunde . . . . . . . . 176

Theoretische Vorbemerkungen . . . . . . . . . . . . 176

Entwickelung des Primordialcranıum . . . . . . . . . . 186

Erste Schädelanlage . . . . . . . . . . . . . . . 186

Labyrinthregion . . . . . . . . . . . . . . . 188

Orbitotemporalregion. . . . . . . . . . . . . . . 195

Ethmoidalregion . . . . . . . . . . . . . . . . 197

Occipitalregion . . . . . . . . . . . . . . . . . 198

Splanchnocranium . . . . . . . . . . . . . . . . 201

Hirnnerven und spinooccipitale Nerven . . . . . . . . . 202

III. Zusammenfassung der Resultate. Der Kopf in seiner Entwickelung als Ganzes betrachtet . . . . . . . . . . . . . . . . 208

T'afelerklärung . . . . . . . . . . . . . . . . . . . . . 219

Literaturverzeichnis . . . . . . . . . . . . . . . . . . . . 222 



\section{Einleitung.}

Irri Laufe der letzten Jahre bin ich in den Besitz eines grösseren, gut konservierten Materiales junger Knochenganoiden gelangt. Ich verdanke es zum Teil der Liebenswürdigkeit von Herrn Geheimrat W i edersheim und besonders Herrn Professor Ga p p, wofür ich auch an dieser Stelle meinen herzlichsten Dank ausdrücken möchte, zum Teil konnte ich das Material in gutem Zustande direkt aus Nordamerika beziehen. Ich beabsichtige nun den Bau und, soweit möglich, die Entwickelung des Kopfes dieser Knochenganoiden zu untersuchen. Denn unsere Kenntnisse des Kopfes der Knochenganoiden sind immer noch recht mangelhaft, was um so mehr zu bedauern ist, als wir in diesen Tieren Übergangsformen zu den Teleostiern erkennen müssen, die noch recht viele primitive Merkmale zeigen. Von neueren Arbeiten besteht nur die ausführliche Abhandlung von E. Ph. Allis (1897) über Amia calva, welche aber im wesentlichen sich auf den Kopf des erwachsenen Tieres beschränkt. Sonst finden sich nur wenige Arbeiten über einige Spezialfragen, aber keine neueren zusammenfassenden Beschreibungen. Von der Arbeit von W. K. Parker (1882), welche die Entwickelung und den Bau des Lepidosteusschädels behandelt, ist der entwickelungsgeschichtliche Teil infolge der nur sehr wenig zweckmässigen Untersuchungsmethode nur in 
beschränktem Masse verwertbar, wie ron vielen Seiten bei anderer Gelegenheit schon betont ist; über den Bau des Schädels des jungen Tieres konnte ich selbst (1907) einige abweichende Beobachtungen mitteilen.

Von allgemeinerem Interesse scheint mir nun eine Untersuchung der Entwickelung des Kopfes der Knochenganoiden zu sein. Die Frage der Phylogenie und die damit eng zusammenhängende Lehre von der Metamerie des Kopfes, die schon für fast gelöst angesehen werden konnte, ist durch die Untersuchungen von A. Froriep, besonders durch seine Mitteilung über die Entwickelung des Kopfes ron Torpedo (1902), ron neuem aufgerollt und bedarf dringend emeuter eingehender Untersuchung. Es wird dabei erwünscht sein, auch noch nicht in dieser Hinsicht untersuchte Formen in den Kreis der Be trachtungen zu ziehen. Es scheint mir demmach der Versuch lohnenswert der kntwickelung des Kopfes der Knochenganoiden einmal genauer nachzugehen. Beror eine solche Untersuchung aber ülserhaupt mit Aussicht auf Erfolg in Angriff genommen werden kann, ist unbedingt eine genaue Kenntnis der Spätentwickelung des Kopfes und zwar besonders der Entwickelung des Primordialcranium zu erstreben, um einen festen genau bekannten Ausgangspunkt zu besitzen. Diesem mehr vorbereitenden Zweck soll die hier rorliegende Abhandlung dienen. Es ist geplant zunächst einmal die Entwickelung des Primordialcranium ron Lepidosteus osseus zu untersuchan, selbstrerständlich unter weitgehender Berücksichtigung der übrigen Organe des Kopfes. Später soll sich an diese Abhandlung die Lntersuchung der ersten Entwickelung des Kopfes anschliessen.

Zweckmässigerweise zerfïllt die Arbeit in zwei Abschnitte. In dem ersten Teile soll eine möglichst objektive Beschreibung der Entwickelung ron Kopf und Primordialcranium von Lepidosteus osseus gegeben werden, ausgehend von einem Stadium, 
das kurz vor der Anlage der Skeletteile steht. In dem zweiten Teile soll alsdann die kritische Besprechung der Befunde erfolgen.

I. Abschnitt.

\section{Beschreibung der Einzelbefunde.}

Stadium I. Gesamtlänge des Tieres 8-10 $\mathrm{mm}$.

(Figur 1. Tafel D.)

Von diesem ersten. Stadium, das der Schädelbildung kurz vorausgeht, stehen mir bisher nur wenige Querschnittserien zur Verfügung. Es soll der Entwickelungsgrad des Kopfes etwas genauer geschildert werden, um einen Ausgangspunkt für die folgenden Stadien zu gewinnen. Die Angabe der Gesamtlängc des Tieres ist zur Beurteilung des Entwickelungsgrades nur in sehr geringem Masse verwendbar, da recht er hebliche Differenzen der Gesamtlänge bei sonst gleich weit entwickelten Tieren bestchen. Zur graphischen Rekonstruktion des Medianschnittes war die Serie eines $91 / 2 \mathrm{~mm}$ langen Tieres benutzt worden, die meisten Exemplare des gleichen Entwickelungsgrades massen ungefähr $8 \mathrm{~mm}$.

Ä us serer En tw i ckel ung g g a d. Das hintere Körperende ist weitgehend rom Dottersack abgehoben, sodass fast die ganze hintere Körperhälfte frei heraussteht. Ein einheitlicher medianer Flossensaum hüllt den Schwanzteil ein, eine Absetzung des Schwanzflossenbezirkes beginnt zunächst auf der ventralen Seite sich einzuleiten. Das vordere Körperende ruht fast in ganzer Ausdehnung auf dem Dottersack, nur der vorderste Teil des Kopfes hat sich abgehoben. Die Mundöffnung 
ist gerade noch frei, stösst aber mit ihrer caudalen Grenze direkt an den Dottersack, sodass eine Unterkieferregion üusserlich nicht sichtbar ist. Vor dem Munde ist das Kopfende ventral und vorn von Saugnäpfen bedeckt, es endet mit stumpfer von Saugnäpfen bedeckter Spitze. Die dorsale Fläche des Kopfes erhebt sich von der Schnauzenspitze rasch, um in einer durch das Mittelhirn bedingten buckeligen Vorwölbung die grösste Höhe zu erreichen und dann nach rückwärts gegen den Rumpf abfallend ohne scharfe Grenze in ihn überzugehen.

Ventral und ein wenig rostral geht die Mittelhirnwölbung nach beiden Seiten in die dorsal vom Mund gelegenen Augenwölbungen ohne scharfe Grenze über. Das Auge wölbt hier zwar die äussere Haut zu cinem diffusen Buckel vor, ist selbst aber am fixierten Objekt in einzelnen Teilen nicht zu crkennen. Von Nase und Ohr ist äusserlich nichts zu sehen. Der Kiemendeckel beginnt nach lateral und hinten auszuwachsen, die Kiemenbögen deckt er noch nicht völlig. In beträichtlichem Abstande hinter Kiemendeckel und Kiemenbögen erhebt sich jederseits seitlich vom Rumpf auf dem Dottersacke die Brustflossenfalte empor.

$\mathrm{K}$ opfdarm. Durch dic Mundöffnung gelangt man in den transversal geräumigen, dorsoventral abgeplatteten Kopfdarm. Anfangs über dem Dottersack dorsalwärts ansteigend, biegt er bald caudalwärts um, verjüngt sich dann beträchtlich, besonders nimmt der transversale Durchmesser rasch ab und geht hinter den letzten Kiemenbögen in einen soliden Epithelzellstrang über. Kiefer- und Zungenbeinbogen sind kaum voneinander abgegrenzt. Der Zungenbeinbogen ist zunächst nur durch den an ihm entspringenden Kiemendeckel gekennzeichnet. Die ersten drei Kiemenbögen sind angelegt, der vierte beginnt sich abzuschnüren, von dem fünften ist noch nichts zu erkennen. Die erste bleibende Kiemenspalte ist in ganzer Länge durchgebrochen, die zweite Spalte ist streckenweise noch 
epithelial verklebt, die dritte Spalte erst an wenigen Stellen geöffnet. Die Kiemenbögen und Kiemenspalten liegen ventral unter der Ohrblase. Die ersten Anzeichen eines Auswachsens von Kiemenanhängen sind am ersten Bogen zu erkennen. Vor der ersten bleibenden Spalte ist an der Grenze von seitlicher und dorsaler Darmwand als Anlage des Spritzlochkanales (Fig. 1, Spr.) ein solider Zellzapfen nachzuweisen, der von dem Epithel der Schlundhöhle ausgehend in dorsolateraler Richtung bis an die äussere Haut zieht. In dem Zellzapfen sind an einer klcinen Stelle die Zellen auseinander gewichen, sodass ein nicht mit dem Kopfdarm kommunizierender Spaltraum entsteht. Der Zellstrang liegt in der Höhe der vorderen Kuppe der Ohrblase: an der Stelle, wo er von dem Schlundepithel ausgeht, ist die Wand des Kopfdarmes zu einer flachen Grube eingezogen. Die äussere Haut wird von dem Zellstrang fast berührt, sie spannt sich unverändert über die Stelle hinweg. Nach den Untersuchungen von Fr. W. Müller (1897) ist der Epithelzellstrang als Spritzlochanlage anzusprechen.

Gehirn. (Fig. 1.) Die einzelnen Himbezirke sind deutlich zu unterscheiden. Das Rückcnmark geht allmählich unter Zunahme des Höhen- und Breitendurchmessers unter Verdünnung und Verbreiterung des Daches in das Nachhirn über. Es entsteht so ein typisches Rautenhirn. Die Kleinhirnanlage besteht aus kleinen paarigen Platten, die am rostralen Ende des Hinterhirndaches gelegen in den Ventrikelraum vorspringen. Die Kleinhirnanlagen sind durch eine mediane Furche getrennt, in derer. Bereich das Hinterhirndach ependymatös ist. Rostralwärts gehen die Anlagen in die aufgebogene Vorderwand des Hinterhirnes über. Die Seitenteile des Hinterhirnes schieben sich unter das Mittelhirn als seitliche Buckel vor, während der mittlere Teil sich in das Mittclhirn fortsetzt. Beim Ubergange von Hinterhirn in Mittelhirn ist in den medianen Partien der Boden des Hinterhirnes fast rechtwinkelig aufgebogen, 
während das Dach diese Lmbiegung nach dorsal nicht nuur nicht mitmacht, sondern noch durch das überlagernde Mitterhirn etwas eingedrückt ist. Der Ventrikelraum des Hinterhirnes ist sehr geräumig, da in den hinteren Partien nur Seitenwand und Boden, im vorderen Gebiete nur der Boden und im Dach die Kleinhirnanlage als nervöse Hirnwand differenziert sind, im übrigen die Hirnwand dagegen aus dünner Ependymmembran besteht. An der Stelle des Überganges zum Mittelhirn ist durch das Aufbiegen der Bodenplatte und das Einsinken des Daches der Ventrikelraum plötzlich erheblich verengt.

Das sich anschliessende Mittelhirn ist ein nicht sehr grosser Hirnabschnitt. Es ist stark nach ventral gegen das Hinterhirn gekrümmt, sodass die Bodenplatte des Mittelhirnes fast direkt der Vorderwand des Hinterhirnes anliegt. Das Vittelhirndach buchtet sich nach rückwärts über das Hinterhirn, dieses überlagernd und eindrückend, aus. Dieser Teil des Mittelhirnes ist der am meisten dorsal gelegene Punkt des ganzen Cehirnes; er bildet den Scheitelpunkt des Mittelhirnhöckers. Durch die Ausdehnung des Wittelhirndaches nach rückwïrts über das Hinterhirn und die daraus folgende Einstülpung des Hinterhirndaches wird an der Grenze ron Hinterhirn und Mittelhirn eine in den Ventrikelraum vorspringende quere Falte des Hirndaches erzeugt. Das Dach des Mittelhirnes fällt vom Scheitelpunkt nach rostral rasch ab, entsprechend der ventralen Krümmung des ganzen Gebietes. Die Seitenteile des Mittelhirnes hängen lateral über und ruhen auf den vorgebuchteten Seitenteilen des Hinterhirmes, davor sich noch über den hinteren Teil der Augenanlage wegschiebend. Der Ventrikelraum des Mittelhirnes ist geräumig, besonders in transversaler Richtung durch das Ausladen der Seitenpartien. Die Wand ist überall von mässiger, ziemlich gleicher Dicke, reine Ependymbezirke existieren nicht.

Ventral geht das Mittelhirn in das Vorderhirn über. Der 
Ubergang erfolgt am Boden des Nittelhimes allmählich, am Dach ist er ein plötzlicher. Hier stülpt sich direkt vor dem Nittelhirn die Epiphyse aus. Diese ist in diesem Stadium eine einfache Ausstülpung mit etwas verhreitertem Ende; das Lumen ist eng, die Wand besteht aus cylindrischen Zellen. Vor der Epiphyse ist das Dach des Vorderhirnes zunächst nur median, dann auch in den Seitenteilen der Dachplatte rein ependymatös. Es ist vor der Epiphyse zunächst ein klein wenig rorgebuchtet, biegt dann scharf nach ventral ab, um die Lamina terminalis zu erreichen. Von einer Anlage des Saccus dorsalis, Paraphyse und Velum transversum findet sich noch nichts.

Die Bodenplatte des Vorderhirnes ist etwas komplizierter gestaltet. Als direkte Fortsetzung des Nittelhimbodens biegt sie zunächst noch weiter caudalwärts um und liegt damit unter dem Boden des Hinterhimes; dann wendet sie sich nach ventral, weiterhin nach ventral und rostral. Hier stösst die Bodenplatte fast bis zur Berührung an das Epithel des Mundhöhlendaches. Hinten an diesem schräg von dorsocaudal nach ventrorostral verlaufendem Teil liegt die Hypophyse dem Hirnboden direkt an. Damit erweist sich die grosse nach ventral und caudal gerichtete Ausbuchtung des Vorderhirnes als Infundibulum. Die Hypophyse ist ein solider scharf abgegrenzter Zellhaufen, der ohne irgendwelches dazwischen liegendes Gewebe einerseits dem Infundibulum, anderseits dem Epithel des Mundhöhlendaches anliegt, aber von beiden Epithellagen scharf abgegrenzt ist. Im Bercich der Anlagerung der Hypophyse ist der Boden des Infundibulum median etwas verdünnt. Die Hirnbodenplatte läuft zunächst direkt nach vorn weiter, biegt dann in zwei Absätzen nach dorsal empor, um in die Lamina terminalis übergehend, sich mit dem Ependym des Daches verbindend das Hirn rostral abzuschliessen. Vor dem Infundibulum ist die Bodenplatte erheblich gegen den Ventrikelraum verdickt, verdünnt sich dann rasch wieder -. Recessus pracopticus - 
und geht schliesslich in die wieder etwas verdickte Vorderwand des Recessus praeopticus, weiterhin in die Lamina terminalis über. Durch eïne Einkerbung zwischen Vorderwand des Recessus praeopticus und Lamina terminalis setzt sich der Recessus praeopticus vom Vorderhirnende scharf ab and er wie das Infundibulum erscheinen somit als Ausbuchtung des Vorderhirnes nach ventral und caudal.

Während das Vorderhirndach demnach ausserordentlich kurz ist und zudem in dem Gebiete vor der Epiphyse zu einer Ependymplatte verdünnt erscheint, ist die Bodenplatte darch die Ausbuchtung des Recessus praeopticus nach ventral, des Infundibulum nach ventrocaudal erheblich verlängert, zwischen Recessus praeopticus und Infundibulum stark verdickt, an der Vorderwand des Recessus pracopticus sowie der Hinterwand des Infundibulum ein wenig verdünnt.

Die Seitenteile des Vorderhimes sind relativ dick, sodass der Ventrikelraum in transversaler Richtung eingeengt, in sagittaler Richtung erheblich ausgedehnt ist. Entsprechend dem ependymatösen Dachbezirke des vordersten Teiles verbreitert sich der Ventrikel hier in der dorsalen Hälfte.

Hirnnerven und Sinnesorgane. Der Nasens a ck liegt seitlich neben dem Vorderhirn. Er ist von der basalen Zellenlage der zweischichtigen Epidermis nach innen gewuchert, ohne dass die oberflächliche Zellage dadurch irgendwelche Veränderungen zeigt; diese verläuft vielmehr unverändert über dic Anlage des Nasensackes weg, sodass auch äusserlich nichts davon zu erkennen war. Im Innern der Organanlage findet sich ein kleiner Hohlraum, um welchen die Zellen radiär angeordnet sind. Mehrere kurze Nervenfaserbündel (Fig. 1, Ol.) verbinden die dorsalen Partien der medialen Wand des Organes mit den Seitenteilen des Vorderhirnes.

Das A u g e liegt scitlich dem Recessus praeopticus und Infundibulum an; der hintere Pol des Auges schiebt sich neben 
resp. unter die seitlich vorgebuchteten Partien des Hinterhirnes, der vordere Pol reicht noch gerade über das Hinterende des Nasensackes nach vorn. Das Auge befindet sich im Stadium des Augenbechers mit weiter von Opticusstiel bis an den Becherrand durchschneidender Augenbecherspalte. Die Linse ist ein Bläschen mit verdickter medialer Wand, von der die Linsenfasern auszuwachsen beginnen. Das Auge wölbt die äussere Haut zu einem äusserlich erkennbaren Buckel vor, ist aber überall durch eine dünne Nesenchymlage von dem Oberflächenepithel getrennt. Dieses letztere zieht unverändert über das Auge hin. Der Opticus (Fig. 1, Opt.) ist hohl, die Bildung ron Sehnervenfasern hat noch nicht begonnen. Der Augenblasenstiel, als welcher der Opticus demnach jetzt noch zu bezeichnen ist, geht hinter dem Recessus praeopticus aus der verdickten Partie der Vorderhimbodenplatte hervor. Er hat nur einen kurzen Verlauf und zwar von der Himbasis etwas ansteigend nach lateral und caudal zum Augenbecher.

Der Oculomotorius (Fig. 1; Ocm.) entspringt ventral aus dem Mittelhirne nahe der Medianebene kurz vor der Grenze von Mittel- und Hinterhirn. Der Nerv verläuft in einem nach vorn leicht convexen Bogen nach ventral und lateral. Es licgt hier zwischen hinterem Teil der Augenblase und Hirn eine grosse von flachkubischem Epithel ausgekleidete Höhle des Mesoderms, welche wohl als Rest der Mesodermhöhle zu betrachten ist, die van Wijhe (1883) bei Selachiern als ersten Somiten beschrieben hat. Aus der lateralen Wand dieser Mesodermhöhle wuchern Mesenchymzellen hervor, welche sich als geschlossene Züge eine kurze Strecke nach dorsolateral, rostral und ventrolateral am Augenbecher entlang verfolgen Iassen. Der Oculomotorius ist bis an die dorsale Wand der Mesodermhöhle zu verfolgen. Die oben erwähnten Züge von Mesenchymzellen dürften als die ersten Anlagen der Muskeln des Oculomotoriusgebietes anzusprechen sein. 
Der Trochlearis ist nicht mit Sicherheit aufufinden. Dorsal auf der hinteren Kuppe des Augenbechers liegt lateral von dem peripheren Ende des Ophthalmicus profundus ein kurzer Zellstrang, welcher dieser Lage wegen als Anlage des Musculus obliquus superior (Fig. 1, Ob.s.) anzusprechen wäre. Gegen Hirn und Augenbecher ist diescr kurze Strang nicht weiter $z u$ verfolgen.

Ophthalmicus profundus (Trigeminus I der Autoren) (Fig. 1, Oph.pr.). Dorsomedial auf dem hinteren Teil des Augenbechers, lateral den Oculomotorius kreuzend, liegt ein Ganglienzellhaufen, der durch kurze feine Fäden mit den schon des öfteren crwähnten rorgebuchteten Seitenteilen des Hinterhirnes verbunden ist. Periphere Ausliufer waren nicht fostzustellen.

Der Abducens ist auch nicht mit Sicherheit fostzustellen. Nedial neben dem Ganglion des Trigeminus, ventral vom Hinterhirn liegt ein Zellstrang hinter dem Augenbecher, welcher beim Vergleich mit späteren Stadien als Anlage des Musculus rectus Iateralis (Fig. 1, R. 1.) gedeutet werden muss. Gegen das Hirn auslaufende Teile, welche als Abducons anzusprechen wären, lassen sich nicht feststellen.

Der Trigemin of a cia I i skom plex gliedert sich schon in diesem Stadium in der für Lepidosteus charakteristischen Weise in Trigeminus, Facialis und Ophthalmicus lateralis. Letzterer Nervenstamm, dem Ophthalmicus superficialis facialis, Buccalis facialis und Oticus facialis entsprechend, ist von dem eigentlichen Facialis abzutrennen.

Der Trigeminus (Fig. 1, Tri.) entspringt mit zwei nebeneinander gelegenen Wurzeln ventral aus den Seitenteilen der Hinterhirnbasis in einiger Entfermung caudal hinter dem Ophthalmicus profundus. Die beiden kurzen Wurzeln vereinigen sich sofort und gehen in ein Ganglion über, das ventral unter dem Hirne, caudal hinter dem Augen- 
becher gelegen ist. Aus dem Ganglion geht ein Nervenstamm hervor, welcher ventralwärts hinter und unter dem Auge herumzieht. Nun teilt sich der Nerv in zwei Ïste, deren einer, der Ramus maxillaris, ventral unter dem Auge noch eine Strecke weit verfolgt werden kann, während der andere, Ramus mandibularis, nach abwärts um die AIundhöhle herum zu verfolgen ist, bis an einen dichten Mesenchymzellhaufen heran, der als Zellplatte in der lateralen Mundhöhlenwand liegt. Irgendwelche Anlagerungen an die Lpidermis finden sich bei dem Trigeminus und seinen Ästen nicht. An einigen Serien aus dieser Entwickelungsperiode war ein kurzer Stumpf zu beobachten, der aus dem Ganglion trigemini hinter dem Auge etwas dorsalwärts anstieg; dieser 1 st muss als Ophthalmicus superficialis trigemini gedeutet werden.

Der $\mathrm{F}$ a $\mathrm{e}$ ia $\mathrm{lis}$ (Fig. 1, Fac.) entspringt beträchtlich weiter caudal aus den Seitenteilen des Hinterhimes medial von der Ohrblase; cr schwillt sogleich zu einem länglichen Ganglion an, welches dem weiter unten zu beschreibenden Ganglion des Ophthalmicus lateralis ventral dicht anliegt und medioventral von der Ohrblase rostralwïrls sich ausdehnt. Hier stösst das Cianglion in der Gegend der Spritzlochanlage an der Wurzel des Zungenbeinbogens resp. Kiemendeckel auf die nach innen vorspringende verdickte Epidermis. Dieser Epidermismasse legt sich der Facialis mit seinem rostralen und ventralen Ganglionrand innig an und ist nicht scharf mehr abzusondern. Hier entspringt ein Nervenast, der caudal um die Spritzlochanlage herum eine Strecke rentralwärts in den Zungenbeinbogen zu verfolgen ist bis an eine dort gelagerte Mesenchymplatte, welche die Inlage der Muskulatur repräsentiert. Finen zweiten ganglionzellhaltigen Fortsatz entsendet der Facialis von seiner Verschmelzungsstelle mit der Epidermis ein kurzes Stück nach rostral.

Deï Ophthalmicus lateralis (Fig. 1, Oph. l.) ent- 
springt etwas mehr dorsal direkt vor dem Facialis. Er geht sogleich in ein grosses Ganglion über, welches dicht dem Facialisganglion aufliegt. Das Ganglion erstreckt sich, anfangs noch medioventral an der Ohrblase gelegen, nach vorn und zieht sich dorsalwärts vor der Ohrblase ansteigend in einen Strang aus, der an einer Seitenorgananlage der Epidermis endet; hicr liegt das Ganglion und sein Ausläufer lateral den Seitenteilen des Hinterhirnes an, in der Höho des dorsalen Randes des Augenbechers, aber in einigem Abstand hinter diesem. Aus dem Ganglion geht ein Zellstrang vor der Spritzlochanlage eine kurze Strecke ventralwärts, ebenfalls an einer Seitenorgananlage der Epidermis endend. Dieser ventrale Ausläufer des Ganglion ophthalmici lateralis entspricht dem Buccalis facialis, besser als Infraorbitalis lateralis bezeichnet, der dorsale Ausläufer repräsentiert den Ophthalmicus superficialis, als Supraorbitalis lateralis $\mathrm{zu}$ bezeichnen.

Der Acusticus (Fig. 1, Ac.) entspringt hart vor und zum Teil noch ventral unter dem Ophthalmicus lateralis aus dem Hinterhirn; er läuft dann über und um die Wurzel dieses Nerven hinweg zwischen den Ganglien des Ophthalmicus lateralis and Facialis hindurch und geht sogleich in sein eigenes grosses Ganglion über. Dadurch, dass zwischen den ohnehin dicht aneinander gelegenen Ganglien des Ophthalmicus lateralis und Facialis sich der Acusticus mit seiner Wurzel und dem Ganglionanfang einschiebt, kommt es hier zu einer innigen Durchflechtung ron Nervenfasern und Ganglienteilen, die das Analysieren dieser Faser- und Zellmassen sehr erschwert. So kann ich auch nicht mit absoluter Sicherheit verneinen, dass nicht doch einige Fasern vom hinteren Teil des Ganglion ophthalmicum laterale zum hinteren Teil des Ganglion faciale ziehen, sodass ein Übertritt von Ophthalmicus-lateralis-Fasern zum Zungenbeinbogennerv des Facialis nicht völlig auszuschliessen ist. Sonst war allerdings die Trennung der verschiedenen Be- 
standteile des Faser- und Ganglienhaufens mit Sicherheit durchzuführen. Das Ganglion acusticum erstreckt sich caudalwärts, der medialen und ventralen Wand der Ohrblase direkt angelagert. Die $0 \mathrm{hrb}$ a s e liegt als grosse einfache Blase neben dem Hinterhirn. Die vordere nach dorsal gerichtete Kuppe erstreckt sich bis in die Höhe der Spritzlochanlage, der Hauptteil der Ohrblase liegt über den Kiemenbögen. Die Wurzeln des Ophthalmicus lateralis, Facialis und Acusticus finden sich medial neben der Ohrblase. An der medioventralen Wand ist die erste Absetzung des Sacculus angedeutet. Von Bogengangbildungen ist noch nichts zu erkennen, ein Ductus endolymphaticus fehlt. Die dorsale Wand der Ohrblase wird grösstenteils von abgeplatteten Zellen gebildet, sonst finden sich überall Zylinderzellen, die in dem Gebiet der Sacculusanlage besonders hoch sind.

Der Gloss ophary g e us (Fig. 1, Gl.) entspringt lateral aus dem Hinterhirn dicht hinter der caudalen Kuppe der Ohrblase. Um diese Kuppe berum, ihr direkt anliegend, verläuft der Nerv naci ventral und rorn und bildet ein kleines Ganglion, welches ventral von der Ohrblase livgt. Ein kurzer Stumpf ist nach vorn bis an die Basis der Kiemendeckelfalte zu verfolgen; hier endet er lateral neben der Ohrblase an einer gegen die Unterlage vorspringenden Verdickung der Epidermis. Ein zweiter Ausläufer des Ganglion geht nach dem dorsalen Ende des ersten Kiemenbogens, ebenfalls an eine gegen die Tiefe verdickte Partie der Epidermis herantretend. Der Nerv ist von hier noch eine kurze Strecke in den ersten Kiemenbogen zu verfolgen.

Der Vagus (Fig. 1, Va.) entspringt mit zwei Wurzeln; die rostrale Wurzel kommt in der direkten Fortsetzung des Glossopharyngeus aus dem Hinterhirn und läuft als starker Stamm nach ventral und caudal. Die hintere Wurzel entspringt mit einer grösseren Zahl von Wurzelfäden, die bei ihrem Ursprung nicht 
immer völlig gegeneinander abzugrenzen sind, in nach caudal etwas anstejgender Linie aus langer Zone der Hinterhirnwand. Die Wurzelfäden werden von einem von dorsocaudal nach ventrorostral verlaufenden Nerrenstamm aufgenommen, der nach dem Eintritt des vordersten dieser Wurzelfäden ventralwärts umbiegt. Die vordere und hintere Vaguswurzel vereinigen sich lateral und ventral vom Hirn zu einem Stamme, der in ein grosses Ganglion übergeht, welches über den dorsalen Enden der Kiemenbögen gelegen ist und hier sich innig mit der nach innen verdickt vorspringenden Epidermis rerbindet. Von Ästen ist nur der nach caudal in der Fortsetzung des Ganglion ragi gelegene Nerrus lateralis vagi aufzufinden, der eine kurze Strecke unter der Epidermis entlang zu verfolgen ist.

Myotomeund Spinalnervendes II interkopfes. Bei der Beschreibung der Hyotome und Spinalnerven des Hinterkopfgebietes kann ich mich kurz fassen und auf die ausführliche Darstellung von K. E. Schreiner (1902) verweisen. Die ersten Spinalnerven (Fig. 1, III, IV.) finden sich ventral unter den letzten Wurzelfäden des Vagus noch im Gebiete des Hinterhirnes. Es sind zwei in geringem Abstande hintereinander gelegene ventrale Nerrenwurzeln, die rostrale ein sehr feines Fïdchen, die caudale ein kräftiger Nervenstamm. Die Nerven treten nach lateral an die Myotome heran. Dorsal oberhalb des letzten Wurzelfadens der hinteren Vaguswurzel liegt neben dem Hirn ein unscharf begrenzter kleiner Haufen epithelialer Zellen. Seine Lago würde der eines Spinalganglion entsprechen, welches der zweiten rentralen Wurzel zuzurechnen wäre. Die beiden ventralen Wurzeln sind die Nerven des III. und IV. Myotomes ron Schreiner (1902) und sollen auch, um Vergleiche zu erleichtern, nach ihm als Nervus IIIv und IVv bezeichnet werden. Da nach Schrein er zu seinem Nervus ventralis IV ein Ganglion spinale gehört, welches frühzeitig wieder rerschwindet, ist der oben erwähnte Zellhaufen wohl als Ganglion- 
rest $z u$ deuten. Nun folgen in regelmässigen Abständen zweiwurzelige Spinalnerren (Fig. 1, V-X.), welche nach Jateral $z u$ den Myotomen herüberlaufen. Die ersten drei dieser Nerven, der 3.-5. der Gesamtreihe, entspringen noch aus dem Grenzgebiete ron Hirn und Rückenmark. Der Rückenmarkskanal beginnt in dieser Region sich zum Hinterhirnventrikel zu erweitern, das Dach ist schon abgeplattet. Dadurch sind die dorsalen Wurzeln etwas länger ausgezogen. Die Nerven entsprechen den Nerven des V.-- YII. Myotomes nach Sch reiner. Der Nervus IV ${ }^{\mathrm{v}}$ und die folgenden zweiwurzeligen Nerven sind durch im wesentlichen gleich grosse Abstände getrennt; der Nervus III ${ }^{\mathrm{v}}$ liegt erheblich nüher an IVv.

bie Reihe der Myotome (Fig. 1, rote Linien) reicht cranial bis über die ganze caudale Wurzel des Vagus. Bis ror den Nerven $V$ sind die Hyotome in typischer Weise entwickelt; sie liegen mit ihren verbreiterten Basen neben der Chorda und reichen mit ihren gegen den dorsalen Rand verjüngten Platten lateral neben dem Centrahnervensystem bis fast zur Mediane herauf. Die trennenden Septa intermuscularia haften der Chorda. scheide lateral an, sie sind schräg nach lateral und caudal gerichtet. Rostral ron dem Septum vor dem Myotom des Nervus $V$ sind keine durchgehenden Scheidewände in der Myotomreihe aufzufinden; nur ventral vor dem Nervus III ${ }^{\mathrm{V}}$ ist noch das basale Stück eines Septum intermusculare zu erkennen. Es mag dieses Fehlen von Scheidewïnden in dem cranialen Teile der Myotomreihe nur scheinbar sein, da in transversalen Serien die Septen überhaupt schwer festzustellen sind, horizontale Serien mir aber bishes nicht zur Verfügung stehen. Jedenfalls müssen etwa vorhandene Septa intermuscularia, die in nur wenig jüngeren Stadien ron Schreiner noch gefunden wurden, erheblich reduziert sein, da sie sonst auch in Transversalserien der Beobachtung sich nicht entzogen hätten. Nervus $I^{\mathrm{v}}$ und die folgenden Nerven treten je an ein einzelnes Myotom heran. 
Nervus IIIv verbindet sich dorsal von dem vordersten Myoseptum mit der Myotomplatte. Die vordere nicht mehr in einzelne Abschnitte zerlegbare Myotomplatte, welche den Myotomen II und III von Schreiner entspricht, schiebt sich medial rom Ganglion vagi über die caudale Wurzel des Vagus, welche mit ihrem Wurzelfasergebiet medial verbleibt, und endet dorsal yon dem vordersten Ursprungsfaden dieser Vaguswurzel.

In der ganzen Myotomreihe sind Muskelfasern gebildet. Dass die vorderste nicht mehr von Nerven versorgte Platte ein vergängliches Gebilde darstellt, findet sich deutlich darin ausgeprägt, dass hier eine Auflösung der Muskulatur in Mesenchymgewebe stattfindet. Das Myotom I von Schreiner, welches er als ventral vom Vagus gelegen und keine Muskelfasern bildend beschreibt, war von mir in diesem Stadium nicht mehr aufzufinden.

$\mathrm{Skelet}$. Die Chorda dorsalis ist in diesem Stadium das einzige nachweisbare Skeletelement. Sie liegt an Hirn- resp. Rückenmarksbasis und reicht cranial bis an das Infundibulum, dessen hintere Wand durch die Chordaspitze etwas eingedrückt wird. Die Chorda hat einen recht erheblichen Dickendurchmesser, sic ist umfangreicher als das ihr aufliegende Rückenmark und verjüngt sich cranialwärts nur sehr langsam; erst von der Höhe der Ohrblase an nimmt sie rasch an Umfang ab und endet an der Hinterwand des Infundibulum mit stumpfer Spitze. In das Mittelhirnpolster steigt die Chorda nicht herauf. Das Bindegewebe, welches die Organe des Kopfes umgibt, zeigt im allgemeinen den Charakter des lockeren embryonalen Mesenchymgewebes. Die Septa intermuscularia besitzen etwas mehr faserige Struktur. Das parachordale Gewebe besteht im Bereiche der Kopfchorda aus verästelten Mesenchymzellen, die in grösseren Abständen liegen als im übrigen Bindegewebe. Irgendwelche sichere Anzeichen beginnender Verknorpelung sind noch nicht zu erkennen. Das Bindegewebe der Kiefer- 
und Kiemenbögen zeigt einen etwas abweichenden Charakter. Hier liegen die rundlichen Mesenchymzellen in dichten Haufen beieinander, den ganzen verfügbaren Raum ausfüllend. Abgesetzte Anhäufungen in bestimmten Gebieten, welche als Vorboten von Skeletstücken angesehen werden könnten, finden sich nirgends.

Stadium II. Gesamtlänge des Tieres $10-11 \mathrm{~mm}$. (Fig 2, Tafel D, Fig. 3-5, Tafel A.)

Der äussere Entwickelungsgrad ist noch nicht viel weiter fortgeschritten. Der Vorderkopf hat sich mehr vom Dottersack abgehoben, sodass hinter der Mundöffnung ein Teil der Unterkieferregion sichtbar geworden ist. Mittelhirnhöcker und Augenbuckel sind stark ausgeprägt, das Auge mit Linse schimmert durch die Haut erkennbar durch. Die Höhle des Nasensackes ist nach aussen durchgebrochen, das Nasenloch liegt lateral am Vorderkopfe kurz vor den Augen, es liegt der Dorsalfläche des Kopfes näher als der Ventralfläche. Der Kiemendeckel ist stärker caudalwärts ausgewachsen, or deckt aber die Kiemenanhänge nicht völlig, die sich zwischen ihm und dem Rumpf hervordrängen. Die Brustflossenfalten sind an den Kiemendeckel scheinbar näher herangerückt.

Der Kopfdarm zeigt im wesentlichen die gleichen Charaktere wie im vorigen Stadium. Der Zungenbeinbogen ist noch kaum vom Kieferbogen abgesetzt. Die vier ersten Kiemenbögen sind länger ausgewachsen. Die Spalten verhalten sich noch wic vorher. Die Kiemenanhänge des ersten Bogens sind länger geworden, sie beginnen am zweiten und auch sch'n am dritten Bogen sich $z u$ entwickeln. Die Kiemenanhänge drängen sich zwischen Kiemendeckel und Rumpf hervor. Die Spritzlochanlage ist im ganzen etwas massiger geworden, im Innern ist zwischen den Zellen ein sehr feiner Spaltraum in grösserer 
Ausdehnung aufgetreten. Die dorsale Wand des Kopfdarmes hat sich in den Zellzapfen etwas tiefer eingestülpt.

Das Gehirn (Fig. 2-5) ist in den rostralen Partien länger ausgewachsen. Die Mittelhirnbeuge ist um ein Weniges geringer geworden, sodass auch das Infundibulum nicht mehr ventral der Hinterhirmbodenplatte anliegt, die Hypophyse nicht mehr ventrocaudal, sondern rein ventral vom Infundibulum sich findet. Die ependymatöse Dachplatte des Vorderhirnes rostral von der Epiphyse buchtet sich an beiden Seiten nach lateral und caudal etwas vor. Im Dach des Vorderhimes ist rostral vor der Ependymplatte cine knopfförmige mediane Verdickung zu erkennen, die erste Anlage der Paraphyse. Das Mittelhirn hat sich caudalwïrts auf das Hinterhirn weiter herauf geschoben.

Hirnnerren und sinnesorgane.

Der $N$ asensack liegt jetzt ausgesprochen neben dem rostralen Ende des Vorderhirnes. Die kleine Nasenhöhle ist nach aussen durchgebrochen.

Das A u g e hat an Grösse zugenommen, es liegt im wesentlichen wie vorher, dorsal reicht es etwas weiter am Hirn herauf. Der rostrale Pol schiebt sich nicht mehr über den Nasensack, da dieser selbst sich rostralwärts vorgeschoben hat. Es beginnt die Differenzierung der einzelnen Retinaschichten einzusetzen. Die Augenbecherspalte ist bis auf einen kleinen Rest am Opticuseintritt geschlossen ${ }^{1}$ ). In den Opticus setzt sich der Hirnventrikel noch etwas fort; am Eintritt in das Auge, welches nach kurzem laterocaudalem Verlaufe bald erreicht wird, ist der Opticus schon völlig solide.

An dem Gehörorgan e lässt sich das Auswachsen der Bogengänge in Form taschenförmiger Ausstülpungen deutlich

1) In der graphischen Rekonstruktion (Fig. 2.) ist die Augenbecherspalte offen gezeichnet, da grade ein Sagittalschnitt mit dem Opticuseintritt in der Projektion gezeichnet ist. 
erkemmen: der Sacculus ist jetzt deutlicher abgesetzt. An der medialen Wand des Ltriculusteiles ist ein kurzer kanalförmiger Recessus superior ausgesprosst.

Die Differenzierung der übrigen Hirnnerven ist weiter fortgeschritten. Es soll hier nur kurz das Wichtigste hervorgehoben werden.

Der Oculomotorius (Fig. 2, Ocm., Fig. 3) ist jetzt bis an den ventralen Imfang des Auges herabgewachsen. Die im vorigen Stadium erwähnte Mesodermhöhle, aus deren Wandung die Augenmuskelanlagen hervorzusprossen begannen, ist verschwunden. Die Muskelanlagen haben sich in zwei Portionen getrennt. Eine dorsale Partie (Fig. 2, R.s.), von dem kurzen Ramus superior oculomotorii versorgt, liegt als dichter dorsalwïrts ansteigender Zellstrang medial am hinteren Abschnitt des Auges. Die ventrale Partie (Fig. 2, R. m., R.i., Ob.i.), von dem längeren Ramus inferior oculomotorii versorgt, liegt am ventralen und medialen Lmfange des Auges. Die dorsale Muskelanlage bildet später den Rectus superior, die ventrale die drei anderen rom Oculomotorius innervierten Augenmuskeln. Von caudal nimmt der Ramus inferior eine Anastomose des Ophthalmicus profundus auf. Ganglienzellen sind im Oculomotorius nicht zu finden.

Der T r o c h l e a r i s konnte noch nicht aufgefunden werden. Die Anlage des Obliquus superior (Fig. 2, Ob.s.) liegt als kompakter Zellstrang dorsomedial über dem Bulbus.

Der Ophthalmicus profundus (Fig. 2, Oph.pr., Fig. 5) ist von seinem Ganglion ansteigend und mediodorsal am Auge hinwegziehend weit rostralwärts zu verfolgen. An der Stelle, wo der Ramus inferior oculomotorii ron dorsomedial schräg vor dem Ganglion ophthalmici profundi entlang lüuft, geht eine Anastomose vom Ganglion an den Oculomotorius von rückwärts heran. 
Der $A b d u c e n s$ konnte nicht sicher festgestell werden. Die Anlage des Rectus lateralis (Fig. 2, R. l.) kreuzt als dichter, gut abgesetzter Zellstrang das Ganglion trigemini an dessen Ventralseite und ist bis an den hinteren Bulbuspol zu verfolgen.

Am Trigeminus (Fig. 2, Tri.) sind jetzt drei Äste weit zu verfolgen. Der Ophthalmicus superficialis steigt dorsalwärts an und läuft dann neben dem Ophthalmicus profundus rostralwärts am Auge vorbei. Der Truncus maxillomandibularis läuft ventralwärts und teilt sich bald in den Ramus maxillaris und mandibularis, welche in das Oberkiefer- und Unterkiefergebiet eintreten und dort besonders an die Muskelanlagen sich anlegen.

Aus dem Facialisganglion, welches verdickten Fpidermisbezirken nicht mehr angelagert ist, geht zunächst caudal um die Spritzlochanlage herum der Truncus hyoideomandibularis hervor. Zum Zungenbeinbogen geht hieraus nach abwärts der Ramus hyoideus (Fig. 2, Hy.f.) hervor, um die Spritzlochanlage rostralwärts läuft der Ramus mandibularis facialis (Fig. 2, Mand.f.), welcher die Sinnesorgane des Mandibularkanales versorgt. Das Facialisganglion liegt dann weiterhin der Spirtzlochanlage direkt auf und entsendet hier einen. kurzen Ast nach lateral an die dorsalen Muskelanlagen des Zungenbeinbogens. Aus dem rostralen Teil-des Ganglion faciale geht der Ramus palatinus (Fig. 2, Pa.f.) ventralwärts hervor, welcher in der Schleimhaut des Mundhöhlendaches rostralwärts weithin verfolgt werden kann. Das rostrale Ganglionende stösst an den Truncus maxillomandibularis trigemini, ohne dass hier ein Übergang von Fasern aus dem Facialis- in das Trigeminusgebiet sicher nachzuweisen wäre.

Aus dem Ganglion ophthalmici lateralis sind der Ramus supraorbitalis und infraorbitalis (Fig. 2, Su. orb., In. orb.) als lange Äste ausgewachsen; sie versorgen die Sinnesorgane der gleichnamigen Seitenkanäle. Ein kurzer Ast geht als Ramus 
oticus (Fig. 2, Ot.) an ein Stück des Seitenkanales hinter dem Auge.

Aus dem Ganglion des G los s oph a r ynge us (Fig. 2, G1., Fig. 5) entspringt ein kurzer Ramus dorsalis (Fig. 2, D.gl.), der zu den Sinnesorganen des Seitenkanales in dieser Region tritt; ein Ramus posttrematicus (Fig. 2, Po.gl.) verläuft abwärts in den ersten Kiemenbogen; ein rostraler Ast kann bis an die Basis des Zungenbeinbogens verfolgt werden und ist wohl als Anlage des Ramus pharyngeus anzusprechen. Die rostrale Partie des Ganglion und der rostrale Ast liegen direkt dem Epithel der Branchialhöhle an, sind aber nirgends mit ihm verschmolzen.

Aus dem Ganglion vagi (Fig. 2, Va., Fig. 5), das durch den Zusammentritt der vorderen und der Ganglienzellen enthaltenden hinteren Wurzeln entsteht, geht nach rückwärts der mächtige an Ganglionzellen reiche Lateralis vagi (Fig. 2, Lat.va.) hervor, welcher die Sinnesorgane des Rumpfseitenkanales versorgt. Vor dem Lateralis vagi senkt sich das Ganglion nach ventral und lateral und ist hier eine kurze Strecke mit der verdickten Epidermis verschmolzen. Ein Ramus dorsalis (Fig. 2, D. va.) geht zu den hier gelegenen Teilen des Seitenkanales. In den zweiten Kiemenbogen ist ein Vagusast abwärts zu verfolgen. Ein rostraler Ganglionausläufer endet am dorsalen Ende des ersten Kiemenbogens, der Epidermis dicht angelagert. Besonders erwähnenswert ist, dass der ganze Vagusstamm die Tendenz zeigt, sich caudalwärts $\mathrm{zu}$ verschieben, was aus der Richtung der vorderen Wurzel leicht zu ersehen ist, die jetzt schärfer von dorsorostral nach ventrocaudal verläuft.

Myotomeund Spinalnervendes Hinterkopfes. Ventral unter dem Vagus findet sich jetzt nur eine ventrale spinale Nervenwurzel, welche, wie weiter unten sich sogleich ergeben wird, dem Nervus $I^{v}$ des vorigen Stadiums 
entspricht. Dann folgt die Reihe der typisch zweiwurzeligen Spinalnerven, deren dorsale Wurzeln, soweit sie noch aus dem Grenzgebiete von Hirn und Rückenmark entspringen, in die Länge ausgezogen sind. Am Nerrus VT -. VIII sind jetzt Äste nachzuweisen, die an die Muskelanlagen der Brustflosse herantreten. Die caudale Vaguswurzel reicht mit ihrem letzten lirsprungsfaden bis zur Berührung an die dorsale Wurzel des Nervus V heran. Bei Vergleichen der Rekonstruktionsfiguren des I. und II. Stadiums erseheinen die spinalen Nerven geradezu von rostral her etwas zusammengeschoben, die Mbstände zwischen ihnen sind rerringert, zudem biegt der Nervus $V$ deutlich um das caudale Vagusende herum, um zu seinem Myotom zu gelangen. Die Reihe der Myotome reicht wiederum bis über die caudale Wurzel des Vagus; der parachordale ventrale Teil stösst noch bis in die Höhe des vordersten Crsprungsfadens der caudalen. Vaguswurzel vor, der dorsale Teil ist etwas zurückgewichen. Der Vagusstamm kreuzt die Myotomplatte bei seinem Verlaufe von medial nach lateral, sodass der dorsale Teil der Myotomplatte lateral auf der caudalen Vaguswurzel liegt, der ventrale Teil dagegen medial rom Vagusganglion sich findet. Dabei zeigt die rostrale Randpartie der Myotomreihe jetzt nicht mehr deutlichen Zerfall in Mesenchymgewebe. Septa intermuscularia sind wiederum bis vor den Nerrus $V$ gut ausgeprägt; ror dem Nervus IV findet sich nur der basale Teil eines Septum intermusculare. Diese Anordnung der Myotome und ihrer Septa intermuscularia weist sofort darauf hin, dass der vorderste Spinalnerv dieses Stadiums dem Nerrus IV des I. Stadiums entspricht. Der Nervus III ${ }^{v}$, der im vorigen Stadium als sehr feiner Faden an die rostrale Myotommasse herantrat, ist jetzt geschwunden 1 ).

$\left.{ }^{1}\right)$ An einer Serie aus dieser Entwickelungsperiode zeigt sich eine eigentümliche Abweichang von dem obenbeschriebenen Verhalten. Es war an einer Seite vom Nervus VIII nur die dorsale Wurzel mit Spinalganglion nachweishar, 
Die wichtigsten Verïnderungen gegen das Stadium I sind also folgende: Der Vagus hat sich caudalwïrts verschoben, wie aus der Richtung der Vaguswurzeln und der Ausdehnung seines Wurzelgebietes caudalwärts zu ersehen ist. Dabei sind die ersten Spinalnerven zusammengeschoben, die erste ventrale Wurzel - Nervus III ${ }^{v}$ - rückgebildet, die Myotomreihe zurückgedrängt unter Schwund der spezifischen Elemente der rostralen Myotome durch Auflösung in Mesenchymgewebe.

Skelet. (Fig. 3-5.) Die Chorda dorsalis zeigt das gleiche Verhalten wie im vorigen Stadium. Da das Infundibulum nicht mehr so weit caudal unter dem Hinterhirn liegt, buchtet die Chorda seine caudale Wand nicht mehr ein.

An der Himbasis sind die ersten knorpeligen Teile aufgetreten. Der Knorpel ist noch typischer Jungknorpel mit wenig Grundsubstanz zwischen den Zellen und entbehrt noch eines abgesetzten perichondrium, er geht also in das ungebende Mesenchymgewebe ohne scharfe Grenze über. Es sind drei Knorpelstücke jederseits nachweisbar. Von der Höhe der Glossopharyngeuswurzel bis an die Wurzel des Trigeminus liegt in dem schmalen Raume zwischen Chorda dorsalis und Ohrblase das Parachordale; rostral verbreitert sich der Knorpel plattenförmig und entsendet einen breiten Fortsatz nach lateral, der in eine Platte auslaufend sich als erste Anlage der Ohrkapsel ventrolateral dem vorderen Teile des Litriculus anlagert an der Stelle, wo an diesem die Anlage des rorderen Bogenganges sich abzugrenzen beginnt. Das Parachordale endet wieder mit verjüngter Spitze kurz hinter dem Trigeminus in einigem Abstande lateral neben der Chorda, da diese schmäler geworden auf einen medianen Streifen beschränkt ist. In der direkten Fortsetzung des Parachordale liegt vor diesem von der Trige-

während eine ventrale Wurzel nicht aufzufinden war. Der periphere Nervenstamm trat aber in typischer Weise an das entsprechende Myotom heran. 
minuswurzel bis neben das caudale Ende des Infundibulum und damit auch lateral in einigem Abstande neben der Chordaspitze eine kurze Knorpelspange. Davor schliesst sich dann als dritter Teil wieder in geradliniger Fortsetzung lateral neben dem Infundibulum die Trabecula an, welche bis vor den Opticus reicht. Das Ende der Trabekel ist ein wenig verbreitert, die beiderseitigen Spangen nähern sich einander vor dem Infundibulum, sind aber immer noch weit getrennt durch die basalen Teile des Hirnes.

V an Wijhe (1905) findet bei Acanthias die erste Anlage des Primordialcranjum sehr ähnlich, er bezeichnet den Knorpel zwischen Parachordale und Trabecula, welcher, soweit es ohne Abbildungen festzustellen ist, genau der oben beschriebenen kurzen Spange neben der Chordaspitze entspricht, als Polknorpel. Mit Rücksicht auf später anzustellende Erwägungen will ich besonders hervorheben, dass die Anlage des Rectus lateralis bulbi, ventral rom Trigeminusganglion gelegen, sich gerade an den Polknorpel anlagert. Sonstige Knorpelteile finden sich nicht.

Als Anzeichen zukünftiger Verknorpelung ballt sich das Mesenchymgewebe im Anschluss an die beschriebene Knorpelplatte an dem ganzen ventralen und lateralen Umfange des Gehörorganes zu einem dichten und ziemlich gut abgesetzten Zellmantel zusammen. Ebenfalls beginnt im Kiefer- und Zungenbeinbogen das vorher diffus dichtzellige Grewebe sich gegen die Stellen der späteren Skeletteile zu konzentricren, d. h. an den anderen Stellen nimmt das Gewebe den Charakter eines lockeren Mesenchymgewebes an. Es kann aber von deutlich abgrenzbaren Vorknorpelanlagen nicht gesprochen werden.

In der caudalen Fortsetzung der Parachordalia ist neben der Chorda das Mesenchymgewebe noch bis caudal von dem Vagusstamme verdichtet. Weiterhin finden sich als festere 
Partien nur die schmalen Septa intermuscularia, welche etwas mehr faserige Struktur zeigen als das übrige Mesenchym. Am cranialen Rande des oben als zurückgewichen beschriebenen dorsalen Teiles der Myotomreihe liegt schalenförmig um den lateralen Umfang des Rückenmarkes ein Streifen verdichteten Gewebes, der bei der Auflösung des noch im I. Stadium hier gelegenen Teiles der Myotomreihe im Bindegewebe entstanden ist. Sonst trägt noch überall das Mesenchymgewebe den Charakter eines lockeren zelligen Füllmateriales.

Stadium III. Gesamtlänge des Tieres $11-12 \mathrm{~mm}$. (Fig. 6. Tafel D, Fig. 7-9, Tafel A.)

Ï usserer Entwickelungsgrad. Durch Verkleinerung des Dottersackes und durch weiteres $\Lambda$ bheben des Vorderkopfes hat das Fischchen im ganzen eine mehr gestreckte Form angenommen. Der Vorderkopf liegt jetzt in ausgesprochenem Masse in der geradlinigen Fortsetzung des übrigen Körpers. Der Mittelhirnhöcker springt weniger stark hervor, da der Kopfbezirk vor ihm sich fast zu gleicher Höhe erhoben hat und die Niveaudifferenz gegen Hinterkopf und Rumpf geringer geworden ist. Die Mundöffnung ist nicht mehr rein ventralwärts, sondern nach ventral und vorn gerichtet. Der Mundhöhlenboden ist vor dem Dottersack bis an die Wurzel des Kiemendeckels frei geworden. Nasenloch und Auge sind deutlich ron aussen zu erkennen. Der Kiemendeckel ist erheblich grösser geworden, er ist ventral- und caudalwärts weiter vorgewachsen. Die Kiemenanhänge werden von ihm jetzt fast völlig gedeckt. Die Brustflossenanlagen, deren rostraler Rand vom Kiemendeckel gerade erreicht wird, sind grösser geworden; ihr caudaler Rand beginnt über die Anheftungsstelle am Rumpf frei caudalwärts auszuwachsen. Anlagen der Bauchflossen sind noch nicht zu erkennen. 
K o p f d a r m. Dic Kiefer- und Zungenbeinbogen sind immer noch kaum voneinander abgesetzt; nur die ventrale Vereinigungsstelle der beiden Zungenbeinbogen --- das Gebiet der hier später gelegenen Hypohyalia - springt in die Mundhöhle als querer Wulst vor und lässt damit am Mundhöhlenboden die Region des Hyalbogens erkennen. Die drei ersten Kiemenbögen sind in allen wesentlichen Teilen angelegt, am Mundhöhlenboden springen ihre ventralen Vereinigungsstellen weit in die Mundhöhle vor. Die Kiemenanhänge sind an diesen drej Bögen lang ausgewachsen. Der vierte Kiemenbogen ist fast in ganzer Länge angelegt, an ihm sind noch keine Kiemenanhänge aufgetreten. Der fünfte Kiemenbogen ist in der ersten Anlage als Leiste an Boden der Mundhöhle zu erkennen. Die ersten drei Kiemenspalten sind vollständig durchgebrochen, die vierte Spalte ist noch grösstenteils, die fünfte in ganzer Ausdehnung epithelial verklebt. Caudal ron dem Kiemenbogengebiet geht der Kopfdarm wieder sogleich in einen soliden Epithelzellstrang über.

Die Spritzlochanlage (Fig. 6, Spr.), in welche die Kopfdarmhöhle sich wieder eine kurze Strecke fortsetzt, ist weniger massig geworden, aber länger ausgewachsen. Sie schiebt sich hart rostral vor der Anlage der Hyomandibel laterodorsalwärts und endet ventrolateral neben der vorderen Kuppe der Ohrkapsel.

Das Gehirn (Fig. 6) zeigt in den einzelnen Abschnitten mannigfache, im ganzen nur geringfügige Veränderungen. Die Kleinhirnanlagen des Hinterhirndaches sind grösser geworden und werden nur durch eine schmale mediane Furche voneinander getrennt. Das Mittelhirn schiebt sich wiederum etwas mehr caudalwärts auf das Dach des Hinterhirnes herauf. Am Vorderhirndach ist die Epiphyse stärker herausgewachsen. Vor der Abgangsstelle der Epiphyse ist das Vorderhirndach noch an einer kleinen Stelle verdickt, dann wölbt es sich zu einer 
Ependymplatte verdünnt dorsal- und lateralwärts heraus und hängt dadurch als dünnwandige Ausbuchtung über die Seitenteile des Vorderhimes etwas über. Vor dieser Ausstülpung, welche die Anlage des Saccus dorsalis darstellt, ist das ependymatöse Dach wieder eingezogen und springt selbst in den Ventrikelraum als quere Falte ein wenig vor; daran schliesst sich eine neue dorsal- und rostralwärts gerichtete Ausstülpung an, in deren Bereich das Dach aber nicht mehr rein ependymatös ist, vielmehr aus einer Lage flachkubischer Zellen besteht. Vor dieser letzten Ausstülpung des Vorderhirndiches, welche aus der knopflörmigen Verdickung, die im vorigen Stadium an dieser stelle sich fand, hervorgegangen ist und die Paraphyse darstellt, geht das Dach dann ventralwärts in die Lamina terminalis über. An der Bodenplatte des Vorderhirnes sind neue Bildungen nicht aufgetreten, die einzehnen Teile haben nur in entsprechender Weise an Grösse zugenommen. Das Infundibulum beginnt stärker caudalwärts über die Anlagerungsstelle der Hypophyse hinweg auszuwachsen, ein Prozess, der die Bildung des Saccus rasculosus einleitet. Am rostralen Ende springen die Seitenteile des Vorderhirnes als schwach algesetzte Lobi olfactorii lateral- und rostralwärts etwas vor.

Hirnnerven und Sinnesorgane. Das Geruchsorgan hat sich weiter rostralwärts rorgeschoben, sodass es jetzt das rostrale Ende des Vorderhirnes eben überragt. Der Olfactorius (Fig. 6, O1.) läuft ron dem Lobus olfactorius noch fast rein transversal an die mediale Wand des Nasensackes und tritt von hier das Organ schalenförmig umgreifend an die Basalseite der Epithelzellen heran.

Das A uge hat an Grösse weiter zugenommen und sich ein wenig rostralwärts vorgeschoben, sodass es mit seinem caudalen Pole nur noch eben neben den vorgebuchteten Seitenteilen des Hinterhirnes erscheint. Es ist aber vom Geruchsorgan durch einen kleinen Zwischenraum getrennt, da letzteres 
sich relativ weiter rostraiwärts vorgeschoben hat. Die Augenbecherspalte ist geschlossen. Der Opticus (Fig. 6, Opt.) ist fast in ganzer Länge völlig solide, der Hirnventrikel setzt sich nur ein sehr klcines Stück in den Nervenursprung fort. Der noch sehr kurze Opticus verläuft wie im früheren Stadium laterocaudalwärts zum Bulbus.

Am G e hörorga n e, welches dorsal und caudalwärts sich weiter ausgedehnt hat, sind die drei Bogengänge ${ }^{1}$ ) jetzt fertig angelegt. Der Sacculus erscheint als scharf abgesetzte ventrale Tasche des Labyrinthorganes. Während in dem vorigen Stadium das Gehörorgan mit dem hinteren Pole sich nur gerade noch über den Gilossopharyngeus fortschob, deckt es jetzt noch die ganze vordere Vaguswurzel von lateral her zu.

Die Ausbildung der vorderen Hirmnerven soll hier nicht im einzelnen angeführt werden, da prinzipielle Änderungen nicht eingetreten sind. Es gelang jetzt den Trochlearis und Abducens aufzufinden. Der Trochlearis (Fig. 6, Tro.) entspringt ventral aus dem Mittelhirn und zwar in einigem Abstande candal hinter dem Oculomotorius aus den Seitenteilen, die über die seitlich vorgebuchteten Teile des Hinterhirns überhängen. Der Nerv war aber seiner Feinheit wegen nur eine kurze Strecke zu verfolgen, es gelang nicht die Verbindung bis zum Obliquus superior herzustellen. Die Deutung dieses Nerven als Trochlearis war nur mter Berücksichtigung des Befundes im nächsten Stadium möglich.

Der A bd u cens (Fig. 6, Abd.) entspringt aus der Hinterhirnbasis nahe der Mediane mit zwei kurz hintereinander gelegenen Wurzelfäden in der Höhe der Glossopharyngeuswurzel. Der feine Stamm war medial längs den Ganglien des Facialis und Trigeminus bis an den Rectus lateralis zu verfolgen.

1) In der Rekonstraktionsfigur 6 sind nur der vordere und hintere Bogengang eingezeichnet. 
Vom Trigeminus und Facialis ist nur zu erwähnen, dass jetzt der Übergang von Fasern aus dem Facialis in den Truncus maxillomandibularis trigemini sicher nachweisbar ist.

Der Glossopharyngeus (Fig. 6, Gl.) verläuft steil nach abwärts um den hinteren Bogengang herum and liegt der caudalen Wand des Sacculus direkt an. Das Ganglion glossopharyngei liegt ventrolateral fast direkt am Sacculus. Aus dem Ganglion gehen wie im vorigen Stadium ein Ramus posttrematicus (Fig. 6, Po.gl.) in den ersten Kiemenbogen, ein Ramus dorsalis (Fig. 6, D.gl.) an die Organe der Seitenlinie dieses Gebietes. Ausserdem tritt jetzt ein kurzer Ast lateralwärts, welcher an dem Epithel des Mundhöhlendaches zwischen den dorsalen Enden des ersten Kiemenbogen und des Hyalbogen endet. Das rostrale Ganglionende liegt unedial von deri dorsalen Kiemenbogenenden dem Epithel des Mundhöhlendaches direkt an. Einen Ramus pharyngeus konnte ich noch nicht auffinden.

Der $\mathrm{Vagus}$ (Fig. 6, Va.) entspringt wie in den bisherigen Stadien mit zwei Wurzeln. Die craniale Wurzel erscheint als Fortsetzung des Glossopharyngeus, sie läuft ventralwärts und in ausgesprochenem Masse caudalwärts. Die caudale Wurzel entspringt wiederum mit einer grösseren Reihe einzelner Wurzelfäden. Der diese Wurzelfäden sammelnde Stamm, welcher Züge von Ganglienzellen enthält, läuft nicht mehr von dem letzten Wurzelfaden bis an die vordersten heran, um dann ventralwärts umzubiegen, sondern er biegt schon früher steil um, sodass die vorderen Wurzelfäden von cranial her in den Stamm eintreten. Caudaler und cranialer Wurzelstamm vereinigen sich bald und gehen als ein grosser ganglienzellhaltiger Nerv ventralwärts in das grosse Ganglion vagi über. Hier entspringt sogleich als erster Ast der Ramus dorsalis vagi (Fig. 6, D. va.), der zu den Seitenorganen dieser Region tritt. Das Ganglion vagi spaltet sich sehr bald in einen branchialen und lateralen Teil. Letzterer 
tritt lateralwirts unter die Epidermis und verläuft nun caudalwärts weiter, die Organe der Seitenlinie versorgend. Der branchiale Teil des Ganglion ragi senkt sich ventrocaudalwärts und lïuft hier hart an dem Epithel des Mundhöhlendaches gelegen längs der dorsalen Kiemenbogenenden entlang. Kurze Stämmchen gehen an die Muskulanlagen, welche an den dorsalen Enden des ersten bis dritten Kiemenbogen sich finden; längere Äste gehen in den zweiten und dritten Kiemenbogen herab. Der Ganglionrest, welcher über das dorsale Ende des vierten Kiemenbogen sich noch wegstreckt, lässt keine abgehenden İste erkenuen.

Die wichtigsten Inderungen des Cilossopharyngeus und Vagus bestehen in der fortgesetzten Verschiebung caudalwärts, die im rorigen Stadium schon angedentet, jetzt deutlicher in der Richtung der Wurzeln und İste hervortritt. Dinse Verschiebung ist als eine direkte Folge der gleichen Erscheinung bei den Kiemenbögen anzusehen, zu denen die Hauptäste des Glossopharyngeus und Vagus herabtreten. Während im ersten Stadium die Kiemenbögen noch rentral unter der Ohrblase lagen, dehnen sie sich jetzt bis fast an die Wurzel der Brustflosse aus. Die Lage der Kiemenbögen ist ohne weiteres aus der der branchialen Äste von Glossopharyngeus und Vagus zu entnehmen, sowie aus der Ausdehnung der offenen Kopfdarmhöhle; denn in gleicher Weise wie im Stadium I geht der Kopfdarm caudal hinter dem letzten Kiemenbogen fast sofort in einen soliden Epithelzellstrang über.

Myotome und Spinalnervendes Hinterkopfes. Ventral unter dem Vagus finden sich jetzt wieder zwei ventrale spinale Nervenwurzeln; diese entsprechen dem Nervus IV und $V^{\mathrm{v}}$ des rorigen Stadiums, wie aus dem folgenden sich sogleich ergeben wird. Der Nervus $I^{\mathrm{V}}$ ist ein ausserordentlich feiner Nerv; in der zur Rekonstruktion benutzten Serie besteht er linkerseits nur aus sehr wenigen Fasern, die nicht mehr bis 
an das Myotom verfolgt werden können. Andere Serien zeigen dagegen den Nervus $I V^{\mathrm{V}}$ beiderseits dentlich bis an das Hyotom herantretend. Es folgen die typisch zweiwurzeligen Spinalnerven. Am Nervus VI bis IX sind jetzt Äste nachzuweisen, die an die Brustflossenanlage herantreten. Die caudale Wurzel des Vagus endet in der Höhe des Nervus $V^{v}$. Hier liegt ventrolateral an der Vaguswurzel beiderseits ein Ganglienzellhaufen, der zunïchst wie zum Vagus gehörig erscheint. Bei genauerem Untersuchen lässt sich aber der Zellhaufen vom Vigus ziemlich gut abgrenzen und besonders entsendet or beiderseits cinige Faserzüge ventralwïts, die auf der einen Seite sich noch bis an den Nerrus $V^{\mathrm{v}}$ verfolgen lassen. Der Ganglienzellhaufen ist demnach als Rest der dorsalen Wurzel des Nervus $V$ zu deuten, welche im jüngeren Stadium um den caudalen Vagusrand herumbog, um zu der dazu gehörigen ventralen Wurzel zu gelangen, jetzt fast völlig rückgebildet ist. Die Reihe der Myotome schiebt sich wieder über den grössten Teil der caudalen Vaguswurzel hinweg. Sic reicht jetzt mit dorsalem und ventralem Rande ungefähr gleich weit rostralwärts ror. Vor der Myotomplatte kreuzt der Vagusstamm von medial nach lateral herüber. Durch den Vagus ist die Myotomplatte hier stärker zurückgedrängt, sodass ihr vorderer Rand an der Kreuzungsstelle hinter dem Vagus zurückgedrängt, dorsal und ventral von dieser Stelle etwas weiter rostralwiirts sich erstreckt; der dorsale Teil liegt wiederum lateral auf der caudalen Vaguswurzel, der ventrale Teil medial vom Vagusganglion. Septa intermuscularia sind bis vor dem Nervus $V^{V}$ gut ausgeprägt; vor dem NerrusIV ${ }^{v}$ ist nur der basale Teil eines Septum intermusculare nachweisbar. Der Vergleich mit dem vorigen Stadium ergibt ohne weiteres die Richtigkeit der oben gegebenen Bezeichnung der beiden spinalen ventralen Nervenwurzeln.

Die wichtigsten Veränderungen gegen das vorige Stadium sind also folgende: Es ist die Rückbildung der Spinalnerven 
und Myotome von rostral her weiter fortgeschritten; sie hat zum fast völligen Schwunde des Nervus $V^{d}$ geführt und zu einem weiteren Zurückweichen des rostralen Randes der Myotomreihe.

Skelet. (Fig. 7-9.) Die Chorda dorsalis zeigt das gleiche Verhalten wie im vorigen Stadium. Zeichen beginnender Rückbildung ihres rostralen Endes finden sich nicht.

Die Bildung des Primordialcraniums ist viel weiter fortgeschritten; es sind in beträchtlichem Grade die Mesenchymmassen verknorpelt, welche als verdichtetes Gewebe sich an die Knorpelspangen im vorigen Stadium anschlossen, zum Teil auch nur an den Stellen späterer Skeletteile lagen. So entsteht das Bild eines Primordialcraniums, welches in hohem Grade an die bekannten Bilder der Kopfskeletanlage bei Teleostiern erinnert (Stöhr [1882], N us baum [1908]).

Neurocranium. Die Parachordalia, Polknorpel und Trabeculae sind miteinander verschmolzen; die lateral vom Labyrinthorgan kräftig weiter entwickelte Ohrkapsel hängt mit den vorderen Teilen der Parachordalia in breiter Ausdehnung zusammen. Das Neurocranium bildet somit ein einheitliches Ganzes, sodass der Beschreibung am besten die bekannte Einteilung in Regionen zu Grunde gelegt wird.

Als Occipitalreg ion ist der hinterste Teil der Schädelanlage zu bezeichnen, der caudal vom Vagusstamm sich findet. Die Parachordalia haben sich bis hierher caudalwärts verlängert, sie liegen als wenig breite Knorpelplatten neben der Chorda. Deutlich ist zu erkennen, dass die Parachordalia am ventralen und besonders am dorsalen Rande verdickte Leisten bilden, während dazwischen nur ein schmaler Knorpelbelag lateral der Chorda anhaftet. Sehr bald endet dieser mittlere Teil eines jeden Parachordale und sitzen nur jederseits eine niedere dorsolaterale und ventrolaterale Knorpelleiste der Chorda an. Die rechte dorsale Längsleiste endet am Nervus VI, die 
drei anderen Leisten schon kurz vorher. Die dorsalen Längsleisten zeigen einige unregelmässige Höcker, welche nach dorsolateral vorspringen. Diese Höcker (Fig. 7) finden sich an den, Ansatzstellen der Septa intermuscularia, sind aber plumper als den schmalen Septen entspricht. An den Vertiefungen zwischen den Höckern liegen die ventralen Nervenwurzeln. Es ist aber besonders zu betonen, dass die Knorpelanlagen durchaus unscharf vom übrigen umgebenden Mesenchymgewebe abgesetzt sind, da ein Perichondrium an ihnen noch nicht ausgebildet ist. So beruhen kleine Unebenheiten des Modelles auf dem Fehlen einer scharfen Absetzung von Knorpel und Bindegewebe. Immerhin lässt sich feststellen, dass zwischen dem Vagusstamm und dem Nervus IV ${ }^{\mathbf{v}}$ ein etwas breiterer Höcker am Parachordale sich bildet, dass kleinere Höcker zwischen den Nerven IV $V^{v}$ und $V, V$ und VI auftreten. Wir dürfen in diesen Höckern wohl Reste dorsaler Wirbelbogen sehen, sodass wir jetzt drei Paar Rudimente dorsaler Bögen gebildet sehen. In der Fortsetzung der vier parachordalen Längsleisten ist das Mesenchymgewebe noch eine Strecke weit caudalwärts verdichtet, dann hört aber auch diese Vorstufe der Skeletbildung auf. Weiterhin im Rumpfgebiet zeigen sich als erste Anzeichen der Wirbelbildung nur ganz geringfügige Mesenchymzellanhäufungen an den Stellen, an welchen die Septa intermuscularia der Chorda ansitzen.

In der Labyrinthregion liegen bis zur Höhe der Facialiswurzel die Parachordalia der Chorda seitlich direkt an. Vor dem Vagusstamm verbreitern sich die Knorpel und springen als dicker Buckel gegen die Ohrkapsel vor. Darauf wird der Breitendurchmesser wieder etwas geringer, schliesslich gehen in der Höhe der Facialiswurzel die Parachordalia breit lateralwärts in die Ohrkapsel über. In diesem Gebiet wird der mediale Teil der Parachordalia, welcher die Verbindung zur Chordaseitenfläche vermittelt, dünner und endet bald mit scharfem 
rostralem Rande (Fig. 7). Es zichen weiterhin die Parachordalia in einigem Abstande neben der Chorda als schmale Knorpelstreifen rostralwärts weiter und gehen in den aus der Vereinigung von Polknorpel und Trabekel entstandenen Knorpelstab der Orbitotemporalregion über.

Die $0 \mathrm{hrkapsel}$ hängt von der Höhe der Facialiswurzel bis fast an die Trigeminuswurzeln breit mit dem Parachordale zusammen. Sie dehnt sich am ventrolateralen Lmfang des Labyrinthorganes caudalwärts aus. An der rostralen Kuppe des Labyrinthorganes reicht die Knorpelwand weit dorsal herauf und bildet hier schon ein Dach auf dem vorderen Teil des Organes (Fig. 7); zugleich wird das Labyrinthorgan von der Ohrkapsel rostral umgriffen. An der linken Seite des Modelles ist dies deutlicher ausgeprägt als auf der rechten. Das caudale Ende der Ohrkapsel beginnt den hinteren Pol des Labyrinthorganes ventrocaudal zu umgreifen; die Ohrkapsel erstreckt sich demnach bis lateral an der Glossopharyngeus- und vorderen Vaguswurzel vorbei caudalwärts. Hier stösst die Ohrkapselanlage medialwärts fast bis an den verdickten Teil des Parachordale an; sie ist mit diesem Teil durch dichtes Vorknorpelgewebe verbunden. $\mathrm{Zu}$ einer knorpelig umrahmten Fenestra basicapsularis, wie sie Stöhr $(1880,1882)$ bei Teleostiern und Amphibien fand, ist es nicht gekommen. Die ihr entsprechende breite Spalte zwischen Ohrkapsel und Parachordale, welche rostral durch die breite Knorpelplatte, die Ohrkipsel und Parachordale verbindet und als $\mathrm{Commis}$ o $\mathrm{ma}$ basicaps ularis anterior zu bezeichnen ist, caudal durch dichtes Vorknorpelgewebe abgeschlossen wird, ist um den ventralen Umfang des Sacculus herum von etwas weniger dichtem Vorknorpelgewebe abgeschlossen. An der linken Seite des Modelles findet sich ein Einschnitt zwischen rostraler Kuppel der Ohrkapsel und Parachordale. Rechts ist dieser Einschnitt zu einer öffnung geschlossen durch eine Knorpelspange, welche von dem Para- 
chordale in ventralwärts vorspringendem Bogen zur Ventralfläche der Ohrkapsel zieht (Fig. 9). Durch den Einschnitt resp. die Öfnung tritt der Truncus hyoideomandibularis facialis zum Zungenbeinbogen herab. Der Ramus palatinus facialis liegt auf seinem Wege vom Facialisganglion rentralwärts zum Mundhöhlendach der lateralen Kante des Parachordale direkt an. Auf der linken Seite des Modelles zeigt hier rostralwärts vor der Conmissura basicapsularis anterior die laterale Kante des Parachordale einen Einschnitt. Der Nerv ist also zum Teil schon von Knorpel umwachsen; rechts ist ein solcher kurzer Einschnitt nicht rorhanden. Es ist an Querschnitten deutlich zu erkennen, dass die Commissura basicapsularis anterior nicht nur durch weitere Ausbildung der schmalen Ohrkapselplatte, wie sie im zweiten Stadium beschrieben wurde, sondern zum Teil sekundär entstanden ist. Es ist nämlich eine kurze Strecke in der caudalen Fortsetzung des eben erwähnten Nervenloches resp. Einschnittes für den Hyalbogennerv eine Nahtfuge zwischen Parachordale und Ohrkapsel zu erkennen, welche beweist, dass die Ohrkapsel zunächst selbständig sich rostralwärts vorentwickelt haben muss, ehe sie mit dem Parachordale verschmolz.

Im rostralen Teil der Labyrinthregion sind die Parachordalia durch ein Perichondrium gut rom umgebenden Gewebe abgesetzt, während bei der Ohrkapselanlage nur an einzelnen Stellen die Bildung eines Perichondriums eingeleitet ist, im übrigen der Knorpel noch unregelmässig und unscharf in das umgebende dichte Vorknorpelgewebe übergeht, sodass besonders der dorsale Rand der Ohrkapsel in einzelne unregelmässige Zacken ausläuft.

Die O r b i t o t e m p o r a l r e g i o n enthält als Skeletelemente zwei Knorpelspangen, die in der Fortsetzung der Parachordalia rostralwärts an der Himbasis entlang ziehen. Zunächst verlaufen die Knorpelspangen in einigem Abstande neben der Chorda, nähern sich dann von der Höhe der Chordaspitze an sehr langsam einander, um schliesslich ventral ror dem Recessus 
praeopticus durch eine Commissur (Fig. 6, 7) sich zu verbinden. Auf diese Weise entsteht eine grosse Offnung, Fe nestra basicranialis, welche caudal von den Parachordalplatten, lateral ron den Parachordalenden, Polknorpeln und Trabekeln, rostral von der Trabecularcommissur umschlossen wird. In dieser Fenestra basicranialis liegt der ventrale Teil des Infundibulum und Recessus pracopticus. Die Chorda ragt in die Fenestra ein gutes Stück rostralwärts hinein. In der Höhe der Chordaspitze springen die Chordaspangen, besonders deutlich rechts, mit geringer Verbreiterung medianwärts vor, sodass eine gewisse Unterteilung der Fenestra basicranialis in zwei Abschnitte erfolgt (Fig. 7, 9). An der verbreiterten Stelle der Knorpelspange setzt der Rectus lateralis bulbi an; diese Stelle entspricht demnach dem Polknorpel, welcher hier im rorigen Stadium als isoliertes Skeletelement lag. Vor ihrer rostralen Vereinigungsstelle sind die Trabekel nur noch ein schr kurzes Stück zu verfolgen. Sie bilden kleine Vorsprünge nach lateral, die Anlagen der sogenannten Trabekelhörner. In der Fortsetzung der Trabekel ist das Mesenchymgewebe am Boden des Vorderhirnes noch eine kurze Strecke zusammengeballt. Die Knorpelspangen der Orbitotemporalregion sind gut ron dem umgebenden Gewebe abgesetzt, zum Teil ist schon ein ausgesprochenes Perichondrium gebildet; nur am rostralen Ende gehen die Knorpelteile wieder ohne scharfe Grenze in das umgebende Gewebe über.

Splanchnocranium (Fig. 8, 9). Es sind jetzt in Kieferund Kiemenbögen die ersten knorpeligen Skeletteile aufgetreten. Sie liegen, noch zum Teil unscharf abgegrenzt, in dem dichtzelligen Gewebe, welches im vorigen Stadium noch fast den ganzen verfügbaren Raum der Kiemenbögen einnahm, jetzt auf die Stellen der zukünftigen Skeletbögen beschrünkt ist, während in den übrigen Teilen ein lockeres embryonales Bindegewebe sich gebildet hat. Die verdichteten Zellmassen bilden 
vollkommen zusammenhängende Spangen, in denen an einzelnen Stellen Knorpelherde aufgetreten sind. Zumeist sind die Knorpelherde noch von dichten Zellmassen umgeben, nur an einzelnen Skeletanlagen ist es zur scharfen Abgrenzung und Bildung eines Perichondriums gekommen. In der lateralen Wand der Mundhöhle in einigem Abstande ventrolateral von den Trabekeln liegt das Palatoquadratum; es crstreckt sich von der Höhe des Opticus bis etwa in die Höhe der Chordaspitze. Im allgemeinen liegt es parallel zur Trabekel, nur der hintere Teil biegt mehr lateralwärts ab. Die Form ist die eines einfachen Knorpelstabes, die mittleren Teile lassen schon deutlicher die spätere Plattenform erkennen. In der rostralen Fortsetzung des Palatoquadratum ist cin kurzer Streifen verdichteten Vorknorpelgewel)es zu verfolgen; der Gewelssstreifen reicht rostral nicht bis in die Höhe der Trabecularcommissur vor. Der Palatoquadratknorpel ist von einem dichten Vorknorpelzellmantel umgeben, der dem Knorpel besonders an der dorsalen und ventralen Kante ansitzt und so dem Ganzen deutlichere Plattenform verleiht. Nur im mittleren Teile, von welchem schon oben gesagt wurde, dass er etwas mehr cine sagittal gestellte Platte darstellt, ist es zur Bildung eines Perichondriums gekommen.

Die M a n d ibula ist kürzer als das Palatoquadratum. Ihr Vorderende beginnt etwas weiter caudal wie der Oberkieferknorpel, sie reicht auch nicht so weit zurück. Das caudàle, etwas dickere Ende liegt im Winkel von Mundhöhlenboden und Seitenwand, das rostrale Ende bicgt medianwärts um. Ein dichter Mesenchymzellmantel hüllt die Mandibula ein, verbindet am Mundhöhlenboden die rostralen Enden der beiderseitigen Knorpel, während am caudalen Ende dichte Zellmassen Mandibula mit Palatoquadratum verbinden.

Im Hyalbogen sind drei skeletelemente aufgetreten. Die Hyomandibula findet sich als grosse Knorpelplatte im dorsalen Teile des Zungenbeinbogens; sie liegt der ventro- 
lateralen Kante der Ohrkapsel etwa in der Höhe der Facialiswurzel direkt an und ist hier mit der Ohrkapsel durch dichtes Jungknorpelgewebe verbunden, sodass eine scharfe Abgrenzung kaum zu treffen ist (Fig. 8). Ein stumpfer Fortsatz erstreckt sich caudalwärts, erreicht aber die Wurzel des Kiemendeckels nicht, ein zweiter Fortsatz läuft ein kurzes Stück ventralwürts. Die Platte der Hyomandibel wird rom Ramus hyoideomandibularis facialis durchbohrt. In der Lmgebung dieses Nervenloches ist es zur Bildung eines Perichondriums gekommen, während sonst ein gegen die Lmgebung nicht scharf abgrenzbarer Žellmantel die Knorpelanlage umhüllt. Rostral geht die Hyomandibel sehr bald in einen dichten Mesenchymzellstreifen über, der in den Zungenbeinbogen ventralwärts zieht. Es tritt hier als Anlage des Interhyale ein sehr kleiner Knorpelherd in dem Streifen auf, sowie weiter ventral- und rostralwärts die Knorpelspange des Kerat ohy ale. Dann zieht der Zellstreifen am Boden der Mundhöhle medianwärts und stösst mit dem entsprechenden Streifen der anderen Seite zusammen. Ein hypohyaler Knorpelherd ist nicht aufzufinden.

In den drei ersten Kiemenbögen sind Knorpelspangen aufgetreten, welche in dem freien Teil der Kiemenbögen, der vom Mundhöhlenboden um die Mundhöhle herum dorsal zieht, gelegen sind. Im ersten Kiemenbogen ist es eine lange Spange, im zweiten ein Stab von zwei Drittel der Lünge des vorigen, im dritten ein sehr kurzes Gebilde. Die Kiemenskeletbögen sind von einem gut ausgebildeten Perichondrium umgeben. Dorsal- und caudalwärts setzen sich die Knorpelstïbe in kurze Vorknorpelstreifon fort, ventral- und rostralwärts in Zellstreifen, welche bis in den ventralen Anfangsteil der Kiemenbögen herab zu verfolgen sind. In dem Zellstreifen, welcher den ersten knorpeligen Kiemenskeletbogen ventralwïrts fortsetzt, tritt am Ursprung des Kiemenbogens aus dem Mundhöhlenboden noch ein sehr kleiner Knorpelherd auf. Die Anlage eines Basibranchiale findet sich nicht. 
Stadium IV. Gesamtlänge des Tieres $14 \mathrm{~mm}$.

(Fig. 10, Tafel D, Fig. 11-15, Tafel A, B.)

Ä usserer Entwickelungsgrad. Der Dottersack hat sich erheblich verkleinert, sodass er nur noch wenig ventral vorspringt. Vor ihm ist an der Ventralfläche des Körpers das Herzgebiet als Vorbuckelung crkennbar geworden. Der Kopf hat im Verhältnis zum übrigen Körper an Grösse stark zugenommen. Der Mittelhirnhöcker ist ausserlich kaum noch zu erkennen. bas stumpfe Kopfende trägt noch eine grosse Zahl Saugnäpfe; diese finden sich aber fast nur an der rostralen Endfläche des Kopfes, auf die Ventralfläche vor dem Mund greifen nur wenige über. Die äussere Nasenöffnung ist rostralwärts vorgeschoben; sie liegt in etwas grösserem Abstande vor dem Auge, nicht mehr rein dorsal, sondem dorsorostral über der Mundöffnung. Die Mundöffnung, welche bisher eine breite viereckige öfnung darstellte, beginnt durch das Auswachsen der Kiefer sich zum Schnauzenspalt (Fig. 10) zu vertiefen. Der Kiemendeckel ist erheblich caudal und ventral ausgewachsen. An der Bauchseite stossen vor dem Herzbuckel die Ränder beider Kiemendeckel aneinander. Die Brustflossenanlagen, deren rostraler Rand vom Kiemendeckel gedeckt wird, springen jetzt caudalwärts als freie Platten vor. Ihre Ansatzlinie am Rumpfe läuft nicht mehr in der Längsrichtung des Körpers, sondern schräg von dorsorostral nach ventrocaudal. Die Bauchflossenanlagen sind als kleine Vorsprünge neben dem Rumpfe auf dem caudalen Pol des Dottersackes zu erkennen.

$\mathrm{K}$ o p f d a rm. Kiefer- und Kiemenbögen sind jetzt in allen wesentlichen Teilen so angelegt, wie sie später beim erwachsenen Tiere sich finden. Sämtliche fünf Kiemenspalten sind durchgebrochen. Die ersten vier Kiemenbögen tragen gut entwickelte Kiemen, nur sind am vierten Bogen die Kiemenblättchen noch relativ einfach gebaut. Am Kiemendeckel findet sich noch keine 
Spur von Kiemenanlagen. Caudalwärts rom Kiemenbogengebiete besitzt der Darm jetzt ein Iumen. Das Kiemenbogengebiet des Kopfdarmes erstreckt sich caudalwärts bis in die Höhe des Nervus $V^{v}$ also gleichzeitig des Endes der caudalen Vaguswurzeln (Fig. 10). Die Spritzlochanlage (Fig. 10, Spr.) hat sich weiter differenziert. Direkt vor dem Zungenbeinbogen senkí sich beiderscits das Dach des Kopfäarmes dorsalwärts zu einer breiten, gegen die Tiefe zu trichterförmig verjüngten Ausbuchtung der Mundhöhle ein. In der Fortsetzung dieser Vertiefung geht ron dem Epithel eine Zellplatte vor dem Zungenbeinbogen lateral- und dorsalwärts. Diese Platte endet mit einem kurzen Ausläufer lateral neben der Hyomandibel, deren Perichondrium dieser Zellstrang direkt anliegt. Ein zweiter längerer Ausläufer steigt dorsalwärts lateral an der vorderen Ohrkapselkuppel an und endet direkt hinter der Stelle, wo der Ramus oticus lateralis aus dem Schädelknorpel herauskommt. Die Zellplatte und ihre beiden Ausläufer bestehen aus Epithelzellen. Lin Lumen in ihrem Imneren ist nicht aufgetreten, nur sind die Zellen am Ende des dorsalen Ausläufers radiär wie um ein virtuelles Lumen angeordnet. Der kurze ventrale Ausläufer, welcher lateral der Hyomandibel anliegt, ist die eigentliche Spritzlochanlage, der dorsale Epithelzellstrang stellt die Anlage des Recessus dorsalis s piracularis dar (Fr. W. Müller [1897]).

Das Gehirn (Fig. 10, 11, 12) zeigt nur geringe Lnterschiede gegen das jüngere Stadium. Dic Kleinhirnanlagen (Fig. 12) des Hinterhirndaches lassen sich in dem Modell jetzt deutlich übersehen; man erkennt, wie die Anlage mit der vorderen verdickten Wand des Hinterhimes in Verbindung steht. Ebenso ist es bei der Betrachtung von innen her zu erkennen, dass dic lateral vorspringenden Teile des Hinterhirnvorderendes, welche in den vorigen Stadien häufig erwähnt werden mussten, tatsächlich vorgebuchtet sind. Der Ventrikel 
zieht sich als tiefer Blindsack in sie hinein. Die wieder verstärkte Überlagerung des Hinterhirnes durch das Mittelhirn kommt in der Querfalte des Daches, welche in den Ventrikel weiter vorspringt, deutlich zum dusdruck. Am Vorderhirndach sind jetzt Epiphyse, Saccus dorsalis, Velum transversum and Paraphyse stärker ausgewachsen. Die Epiphyse, deren Wandung aus Cylinderzellen besteht, beginnt an ihrem freien Ende caudalund rostralwärts Ausbuchlungen auszustülpen. Der Saccus dorsalis hängt nach jeder Seite weit lateral- und caudalwärts üher Vorderhirnteile über und erreicht schon die Grenze von Vorder- und Mittelhirn mit seinem freien caudalen Ende (Fig. 11). Vor dem Saccus dorsalis springt das ependymatöse Dach als Velum transversum rentral und caudal gerichtet in den Ventrikelraum vor. Die Paraphyse schliesst sich in der Form einer kurz gestielten Blase rostralwärts an. Ihre Wand besteht jetzt aus sehr flachkubischen, fast zu einem Lipendym abgeflachten Zellen. Die Lamina terminalis (Fig. 10) ist zunächst in ihrer dorsalen Hälfte stark verdünnt zu einer Ependymmembran, erst der letzte Teil kurz vor der Lmbiegung in die Vorderhirnbodenplatte besteht aus höheren Zellen. Ton der Vorderhimbodenplatte ist nux zu erwähnen, dass das Infundibulum caudalwärts von der Hypophyse weiter rorgewachsen ist, sodass es wieder ventral unter dem Hinterhirnboden liegt. Die Lobi olfactorii (Fig. 11) springen als solide Höcker lateral- und rostralwärts vor, sic liegen mit ihrer Hauptmasse rostral vor der Lamina terminalis.

Hirnnerven und Sinnesorgane. Das Geruchsorgan (Fig. 11) hat sich jetzt erheblich weiter rostralwärts vorgeschoben. Es liegt jetzt völlig rostral vor dem Hirne. Der Olfactorius entspringt ventrolateral aus dem Lobus olfactorius und läuft lateral- und rostralwärts, von caudal her an die mediale Wand des Nasensackes herantretend. Die äussere Nasenöffnung hat sich in einen von rostral nach caudal ver- 
laufenden Schlitz umgewandelt, welcher am rostralen und caudalen Ende weiter ist, als in den mittloren Partien, da diese durch Vorbuchtungen des dorsalen und ventralen Nasenlochrandes verengt sind.

Das A u g e ist auch im ganzen rostralwärts vorgeschoben, aber nur in geringem Masse. Der Abstand zwischen Geruchsorgan und Auge ist dadurch erheblich grösser geworden. Der $\mathrm{O}$ p ticus verläuft jetzt fast rein lateralwärts, nur noch wenig caudalwärts an den Bulbus heran.

Vom Ge hör o rg a n (Fig. 15), dessen einzelne Teile weiter ausgewachsen sind, ist besonders die weitere Entwickelung des Sacculus zu erwähnen. Während im vorigen Stadium der Sacculus als ventrale Tasche am übrigen Labyrinthorgane hing, ist er jetzt caudalwärts über die Stelle der Verbindung mit dem Litriculus vorgewachsen, sodass eine Spalte zwischen caudalem Sacculuspol und Utriculus entsteht. In dieser Spalte liegt der Stamm des Glossopharyngeus. Das Gehörorgan hat sich im ganzen caudalwärts ausgedehnt. Es reicht jetzt schon über die vorderen Teile der caudalen Vaguswurzel hinaus (Fig. 10).

Für die vorderen Hirnnerven sei weiterhin auf die Rekonstruktionsfigur (Fig. 10, Taf. D) verwiesen. Die Beschreibung der wichtigsten Befunde des Hirnnervenverlaufes soll im nächsten Stadium zusammenfassend gegeben werden, sodass, um Wiederholungen zu vermeiden, hier von einer besonderen Besprechung Abstand genommen wird, zumal schon jetzt der definitive Zustand im wesentlichen ausgebildet ist.

Der Glossopharyngeus (Fig. 10, Gl.) ist jetzt mit der vorderen Vaguswurzel zu einem Stamm vereint. Der Vorgang der Vereinigung beider Nervenwurzeln hat sich vom Stadium I, in welchem die Wurzeln rostrocaudal aneinander an. schliessend aus dem Hinterhirn entsprangen, allmählich ausgebildet, dadurch, dass der Glossopharyngeusursprung sich ventral unter den Ursprung der vorderen Vaguswurzel geschoben hat. 
Diese Verschiebung ist wohl als eine Folge der Ausdehnung des Labyrinthes caudahwärts aufzufassen. Die Glossopharyngeuswurzel läuft mit der vorderen Vaguswurzel zunächst caudalwärts, biegt dann scharf ventral um und geht nun an der medialen Wand des Litriculus, speziell des ventralen Schenkels des Canalis semicircularis posterior entlang. Weiterhin geht der Nerv in der oben beschriebenen Spalte zwischen caudalem Sacculuspol und Utriculus lateralwärts, durchbohrt die Wand der Ohrkapsel und geht endlich in das Ganglion glossopharyngei über. Dieses Ganglion (Fig. 11) liegt ventrolateral an der Ohrkapsel über dem dorsalen Ende des ersten Kiemenbogen. Der Ramus dorsalis glossopharyngei (Fig. 10, D.gl.) geht aus dem Ganglion lateral um die Ohrkapsel, deren Perichondrium direkt. anliegend, herum, um zu den Seitenorganen dieser Region zu gelangen. Der Ramus posttrematicus branchialis I fFig. 10, Po.gl.) tritt abwärts in den ersten Kiemenbogen ein. Rostral direkt vor ihm geht ein feiner Ast aus dem Glossopharyngeusganglion, welcher lateralwärts zu verfolgen ist, bis er an der Haut der Branchialhöhle am dorsalen Ende des ersten Kiemenbogen endet. Ein Ramus pharyngeus (Fig. 10, Ph.gl.) ist jetzt deutlich geworden; or läuft aus dem rostralen Ganglionende entspringend dirckt unter dem Epithel des Kopfdarmdaches eine Strecke weit entlang.

Die beiden Wurzeln des $\mathrm{Vag} u$ s (Fig. 10, Va.) vereinigen sich vor dem Austritt aus dem Schädel zu einem Stamm. Die craniale Wurzel, welche dorsal im Anschluss an den Glossopharyngeus entspringt und mit diesem anfangs einen Stamm bildet, läuft neben dem Hirne ventral- und caudalwärts. Die caudale Wurzel sammelt die einzelnen Ursprungsfäden von caudal und cranial her; die vorderen Wurzelfäden laufen dabei, dorsal der cranialen Vaguswurzel anliegend, eine längere Strecke caudalwärts, ehe sie auf den caudalen Wurzelstamm stossen, d. h. der caudale Wurzelstamm ist noch weiter rückwärts ver- 
schoben als in vorigen Stadium. Durch diese Verschiebung des Vagusstammes caudalwärts, welche in der Richtung der beiden Wurzelstämme deutlich zum lusdruck kommt, ist das Ursprungsbild am Hinterhirn so stark verändert, dass auf den ersten Blick die Einteilung des Vagusursprunges in zwei Hauptstämme kaum noch deutlich ausgesprochen erscheint. Der vereinigte Vagusstamm, welcher grössere Züge von Ganglienzellen enthält, tritt hinter der caudalen Ohrkapselkuppel durch einen Schlitz zwischen dieser und dem Occipitalteil des Schädels heraus (Fig. 11, 12, 13). Die Richtung des Vagusstammes ist ventral- und lateralwïrts, zugleich noch ein wenig caudalwärts. Sofort geht nun der Stamm in das grosse Ganglion vagi über, welches caudal von der Ohrkapsel gelegen ist. Noch in dem Schlitze zwischen Ohrkapsel und Occipitatteil des Schädels entspringt der Ramus dorsalis vagi (Fig. 10, D. va.), welcher im Bogen dorsalwärts an die hier gelegeren Seitenorgane herantritt. Das Ganglion vagi zerfällt sehr bald in den Jateralen und branchialen Teil. Der laterale Teil (Fig. 10, Lat.va.), aus welchem auch der Ramus dorsalis entspringt, verläuft caudalwärts als Nervus lateralis vagi und versorgt die Organe der Rumpfseitenlinie. Der branchiale Teil (Fig. 10, Br. va.) liegt am Dache des Kopfdarmes dorsal von den Kiemenbögen. Das rostrale Ganglionende ist vom übrigen Ganglion gut abgesetzt. - Ganglion branchiale II. Aus diesem geht der Ramus posttrematicus branchialis II (Fig. 10, Po.va. II) hervor, welcher abwärts in den zweiten Kiemenbogen tritt; ausserdem geht ein kurzer Nervenast an das Epithel des Kopfdarmes zwischen dem dorsalen Ende des ersten und zweiten Kiemenbogen; ein weiterer $\Lambda$ st läuft auf dem Epithel des Kopfdarmdaches noch eine Strecke rostralwärts - Ramus pharyngeus vagi (Fig. 10, Ph.va.). Die Hauptmasse des branchialen Teiles des Ganglion vagi senkt sich längs der dorsalen Enden der caudalen Kiemenbögen ventralwärts; sie setzt sich caudalwärts als Ramus 
intestinalis ragi fort. In die Kiemenbögen treten die Rami posttrematici vagi herab, am Dach des Kopfdarmes treten cine Reihe kurzer Äste an das Epithel heran. Der branchiale Teil des Vagus ist so weit candalwärts in der Figur eingezeichnet, wie die Kiemenbogenregion reicht; die hinteren Äste sind nicht angegeben.

Myotome und Spinalnervendes Hinterkopfos. Das Bild der Spinalnerven ist sehr ahnlich dem des vorigen Stadiums. Es liegen jederseits ventral von dem Vagusursprung zwei ventrale spinale Wurzeln -... Nervas IV ${ }^{\mathrm{V}}$ und $\mathrm{V}^{\mathrm{V}}$ ohne dazu gehörige Reste dorsaler Wurzeln. Die Nerven treten lateralwïrts durch den knorpeligen Occipitalteil des Schïdels hindurch (Fig. 11, 12, 13) und gelangen dann an dis Myotome heran. Erwihnenswert ist eine Differenz zwischen rechter und linker Scite, welche an der zur Rekonstruktion verwendeten Serie sich fand. Links war nämlich Nervus IV ${ }^{\mathrm{v}}$ nur bis an den Occipitalknorpel heran zu verfolgen. Im Knorpel selbst war aus der Anordnung der Zellen deutlich zu erkennen, dass vor kurzem eine öfmung im Knorpel vorhanden gewesen sein musste, vielleicht führt selbst eine feine öfnung noch hindurch; doch gelang es nicht, dies sicher zu erweisen, da ein durchtretender Nerv nicht zu erkennen war. An anderen Serien aus dieser Entwickelungszeit war aber der Nervus IV ${ }^{\mathrm{v}}$ beiderseits durch den Knorpel nach aussen bis an das Myotom deutlich zu verfolgen. Tom Nervus VI an sind alle Nerven typisch zweiwurzelig. Nervus VI und die folgenden lassen Äste bis in die Brustflossenplatte verfolgen. Die caudale Wurzel des Vagus reicht mit ihren letzten Fäden noch eben über den Nervus $V^{v}$ caudalwärts hinaus.

Die Reihe der Myotome zeigt ebenfalls ungefähr das gleiche Verhalten wie im vorigen Stadium. Der craniale Rand der Myotomplatte ist noch etwas mehr caudalwärts zurückgewichen durch die stärkere Schrägstellung des Vagusstammes. Dieser 
vordere Rand der Myotomplatte zeigt, besonders in den mittleren Partien an der Kreuzung des Vagus, degenerative Verïnderungen der spezifischen Elemente; hier besitzen die Muskelfasern ihren charakteristischen Bau nicht mehr deutlich; die einzelnen Muskelfibrillen sind nicht mehr zu erkennen, der Inhalt der Fasern sieht schollig homogen aus. Auf dem rostralen Rande der Myotomreihe liegt eine Kappe fibrillären Bindegewebes auf. Septa intermuscularia sind bis ror dem Nerrus $V^{v}$ gut ausgeprägt, ror dem Nervus IVv ist ein Septumrest nicht mehr erkennbar.

Die wichtigsten Veränderungen gegen das vorige Stadium sind demnach: Die Stämme des Glossopharyngeus und Vagus verlaufen in verstärktem Masse caudalwärts, um an ihr Ausbreitungsgebiet, die Kiemenbögen, zu gelangen. Die Vorschiebung hat zur Folge ein weiteres Verdrängtwerden des rostralen Randes der Myotomreihe, welche deutliche Zeichen der Degeneration erkennen lässt. Zu einem weiteren Schwunde spinaler Nerven ist es nicht gekommen.

Skelet. (Fig. 11-14, Taf. B.) Die Chorda dorsalis zeigt noch keine deutlichen Rückbildungserscheinungen; ihr Ende ist etwas mehr zugespitzt, die Zellen sind hier plasmareicher als sonst in der Chorda, die Chordahüllen sind aber noch völlig von Chordagewebe ausgefüllt. Relativ hat sich aber das rostrale Ende der Chorda caudalwärts verschoben : es reicht nicht mehr bis in die Höhe des Hinterhirnvorderrandes, sondern endet etwas früher. Unter die Bodenplatte des Hinterhirnes hat sich, wie oben beschrieben, das blinde Ende des Infundibulum rorgeschoben; es bleibt aber noch ein gewisser Abstand zwischen. Infundibulum und Chordaspitze.

Neurocranium. Die Occipitalregion zeigt noch ein prinzipiell sehr ähnliches Verhalten wie im vorigen Stadiım. Die Parachordalia reichen als Knorpelbelag lateral an 
der Chorda bis wenig caudal hinter den Austritt des Nervus IVv, dann laufen sie jederseits in zwei Knorpelspangen aus, welche ventrolateral und dorsolateral bis in die Höhe des Nervus VI der Chorda ansitzen. Die ventrale Spange reicht ein wenig weiter caudal wie die dorsale; sie hat die Form eines ein. fachen Knorpelstreifens, wolcher der Chorda anhaftet, beibehalten. Anders verhält sich der dorsale Teil. Hier ist der Knorpelstreifen zu einer Platte ausgewachsen, welche den ventrolateralen Umfang des Hinterhirnes dieser Region umgreift. Die Knorpelplatte grenzt rostral an den caudalen Rand des austretenden Vagusstammes, den sie von caudal her zu umgreifen beginnt; hier reicht die Knorpelplatte dorsalwärts mit ihrem freien Rande bis in die Höhe des Vagusursprunges herauf. Ventral vom Vagus geht sie in den Boden und Scitenteil der Labyrinthregion über. Caudalwärts nimmt die Höhe der Knorpelplatte rasch ab, sie endet, wie oben schon erwähnt, als schmaler Knorpelstreifen in der Höhe des Nervus VI. Durch diese Knorpelplatte, welche die Seitenwand der Occipitalregion darstellt, treten rechts die Nerven $I^{\mathbf{v}}$ und $V^{\mathbf{v}}$ durch feine, Öffnungen heraus, links verlässt nur der Nervus $V^{v}$ hier den Schädel, während der Nervus IV ${ }^{V}$ nur bis an den Knorpel heran zu verfolgen ist, nicht mehr hindurchtritt. Der Knorpel selbst zeigt in der Anordnung seiner Zellen, dass hier cine Öfnung sich erst kürzlich geschlossen hat (s. oben S. 141). Diese knorpelige Seitenwand der Occipitalregion erinnert in der Form sehr an den Occipitalpfeiler der Teleostier (Stöhr [1882], $\mathrm{N}$ u s b a u m [1908]). Bei Lepidosteus ist der bis jetzt entwickelte Occipitalteil des Schädels drei Skeletmetameren des Rumpfes gleich zu setzen, wie sich aus dem Verhalten der Nerven ohne weiteres ergibt (vgl. S. 129).

In der caudalen Fortsetzung der zwei Knorpelspangen, mit welchen jederseits die Occipitalregion endet, ist das Bindegewebe ventrolateral und dorsolateral längs der Chorda noch 
eine Strecke weit verdichtet. Ais Anlagen von Skeletelementen der Wirbelsäule finden sich nur kleine unscharf begrenzte Knorpelherde, welche an den Ansatzstellen der Septa intermuscularia der Chorda dorsolateral anhaften und die ersten Anlagen der Bogen darstellen.

Die Labyrinthregion, welche sich rom Vagus bis zur Trigeminuswurzel erstreckt, zeigt eine mächtige Entfaltung der Ohrkapsel, welche der ganzen Region ihr Gepräge gibt. Die Ohrkapsel bildet die ganze Schädelseitenwand und beteiligt sich auch noch am Aufbau des Schädelbodens.

Die Chorda dorsalis reicht nicht mehr, wie noch im vorigen Stadium, durch die ganze Labyrinthregion hindurch, sondern endet schon etwas caudal ron der Trigeminuswurzel. Da sichere Momente einer Rückbildung der Chorda nicht nachzuweisen sind, so folgt aus dem Verhalten zum mindesten ein erhebliches Zurückbleiben der Chorda dorsalis im Verhältnis zum Knorpelcranium. Bis in dic Höhe der Facialiswurzel bilden die Parachordalia, welche als dicke Platten der Chorda anliegen, mit dieser einen festen Schädelboden. Die Parachordalia sind jeweils so dick wie der entsprechende Chordaabschnitt, sie werden also rostralwärts mit der allmählich sich verjüngenden Chorda dünner. In der Höhe des Glossopharyngeus bis Vagus haben die Parachordalia mit einer dünnen Knorpelschale die Chorda ventral umgriffen (Fig. 14) und sich hier miteinander vereint. Es handelt sich hier nicht um eine Verknorpelung, sondern um ein Umwachsenwerden der Chordascheide. In der Höhe der Facialiswurzel endet der mediale Teil der Parachordalia mit schmalem rostralem Rande. Die Knorpel ziehen in einigem Abstande von der Chorda, und somit den caudalen Teil der Fenestra basicranialis begrenzend, rostralwärts und gehen ror dem Trigeminus in die Orbitotemporalregion über.

In der ganzen Labyrinthregion hängt jetzt die Ohrkapsel mit den Parachordalia zusammen. Die Verbindung ist eine 
massiv knorpelige im rostralen Teile, wo von der ersten Anlage an die Commissura basicapsularis anterior bestand, von welcher die weitere Verknorpelung der Ohrkapsel ausging; in den mittleren Teilen, im Gebiete der gleich zu beschreibender Fossa sacculi, besteht die Verbindung aus zellreichem Jungknorpelgewebe, am caudalen Ende ist noch deutlich eine Nahtfuge zwischen Ohrkapsel und Schädelboden in der Struktur des Knorpels ausgeprägt. Die Ohrkapsel lässt jetzt schon die wesentlichen Züge des Baues erkennen, wie er früher beim jungen Tiere beschricben wurde (V e it [1907]); ich werde mich deswegen auch, zum Teil die damalige Beschreibung rekapitulierend, etwas kürżer fassen dürfen. Die Ohrkapsel lässt einen Boden, Seitenteil und Dach unterscheiden; die drei Teile gehen fliessend ineinander über. Das Dach ist noch nicht vom Seitenteil scharf abgegrenzt wie im späteren Stadium, es ist noch keine Crista parotica an der Grenze von Dach und Seitenteil entwickelt. Rostral und caudal endet die Ohrkapsel mit je einer Kuppel; nur im Bereiche dieser Kuppeln ist eine mediale Wand der Ohrkapsel gebildet, im übrigen besteht kein Abschluss der Ohrkapsel gegen das Cavum cerebrale cranii. Für das Verständnis des Baues der Ohrkapsel ist die Kenntnis der Form des Labyrinthorganes notwendig, wie es oben genauer beschrieben wurde. Es sei noch einmal auf Fig. 15 (Taf. A) hingewiesen.

Der Boden der Ohrkapsel setzt sich gegen den Schädelboden scharf ab. Hier wölbt der Sacculus den Boden stark ventralwärt: vor, sodass bei Betrachtung von innen eine Fossa sacculi, von aussen eine Bulla acustica saccularis entsteht. Die Bulla saccularis erstreckt sich rom hinteren Rande der Fenestra basicapsularis bis caudal hinter den Austritt des Glossopharyngeus; sie geht auf den Schädelboden medial und rostral flach ausstrahlend über, während ihr caudaler Rand etwas stärker gegen den Schädelboden abgesetzt ist; lateral 
geht sie in die Seitenwand der Ohrkapsel über. Vergleichen wir mit dem vorigen Stadium, so crgibt sich folgendes: Die Bulla acustica saccularis ist dadurch entstanden, dass der Sacculus sich in den Schlitz hinein entwickelt hat, welcher zwischen Commissura basicapsularis anterior, Parachordale und Ohrkapsel sich fand und caudal durch Vorknorpelgewebe geschlossen war; es wurde erwähnt, dass der Schlitz der Fenestra basicapsularis der Teleostier entspricht. Die Fossa saccularis ist innen ziemlich scharf vom Schädelboden abgesetzt, von caudal schiebt sich selbst ein kulissenartiger Vorsprung zwischen Schädel und Fossa saccularis vor.

Die Seitenwand der Ohrkapsel wird durch den Canalis semicircularis lateralis nach aussen stark vorgebuchtet. Die Knorpelwand läuft zunächst von der Bulla saccularis fast horizontal lateralwärts, biegt dann um den Canalis semicircularis lateralis um und geht auf dessen Dorsalfläche über, bildet dann also hier ein Dach der Ohrkapsel. Caudalwärts verstreicht diese lateral vorgebuchtete Ohrkapselwand gegen die caudale Ohrkapselkuppel, rostral fällt sie in der Höhe des Foramen hyomandibulare fast plötzlich ab. So entsteht hier das Bild einer Prominentia ampullae lateralis. Ventral an der Prominentia ampullae lateralis ist die Knorpelwand zu einer flachen kleinen Gelenkpfanne für die Hyomandibel vertieft. Das Dach der Ohrkapsel deckt nur den Canalis semicircularis lateralis, der Sinus superior utricularis bleibt zwischen den beiden Ohrkapselkuppeln noch frei. Bei der Betrachtung von innen tritt entsprechend der Ausbuchtung der Ohrkapselwand das Cavum semicirculare laterale in Erscheinung. Die Bildung eines knorpeligen Septum semicirculare laterale ist in den ersten Anfüngen zu erkennen; es erhebt sich in der Fortsetzung der lateralen Wand der Fossa sacculi eine Knorpelleiste dorsalwärts als Anlage des Septum laterale.

Es bleibt nun noch die vordere und hintere Ohrkapsel- 
kuppel zu besprechen. Die hintere Kuppel umhüllt den Canalis semicircularis posterior; sie erscheint als direkte Fortsetzung von Boden, Seitenwand und Dach des bisher beschriebenen Teiles der Ohrkapsel. Ihr frei rorspringendes caudales Ende, welches durch die Ampulla canalis semicircularis posterioris ausgebuchtet wird, schicbt sich noch etwas lateral über den Vagusstamm und begrenzt von vorn her den Austrittsschlitz des Vagus. Die Ohrkapsel besitzt hier cine mediale Wand, welche einen Abschluss gegen das Cavum cerebrale cranii gewährt. Mit dem Schädelboden ist die Ohrkapselkuppel verwachsen, doch ist an Querschnitten zu erkennen aus der Anordnung der Knorpelzellen, dass diese Vereinigung erst kürzlich sekundär erfolgt sein kann. In der Ohrkapselkuppel liegt das Cavum semicirculare posterius, welches an allen übrigen Seiten knorpelig abgeschlossen rostral gegen das Cavum cranii geöftnet ist. Als erste Anlage des Septum semicirculare posterius springen von medial und von dorsolateral kleine Knorpelleisten in das Cavum posterius vor.

Die vordere Ohrkapselkuppel umhüllt den Canalis semicircularis anterior; sie erscheint als direkte Fortsetzung von Seitenwand und Dach des mittleren Teiles der Ohrkapsel, steigt rom Boden dorsalwärts an. Vor der Fossa sacculi geht der Schädelboden ein wenig ansteigend breit in den Boden der vorderen Ohrkapselkuppel über; diese Verbindungsstelle von Ohrkapsel und Schädelboden entspricht der Commissura basicapsularis anterior. Die Ohrkapsel endet rostral in der Höhe der Trigeminuswurzel; an sie schliesst sich die später zu erwähnende Cartilago supraorbitalis an. Der rostrale Teil der Ohrkapselkuppel besitzt eine mediale Wand. Das Cavum semicirculare anterius ist an allen übrigen Seiten von Knorpelwänden umgeben, nur caudal öffnet es sich gegen den Schädelraum. Als Anlage des Septum semicirculare anterius springen Knorpelleisten von dorsolateral und ron medial vor. Ausser 
der oben erwähnten Verbindung vor der Fossa sacculi ist die Ohrkapselkuppel noch rostral davor durch eine breite Knorpelplatte mit dem Schädelboden verbunden. Die Knorpelplatte zieht als Verbreiterung des Schädelbodens lateralwärts und setzt dorsalwïrts umbiegend ventrolateral an der rostralen Ohrkapselkuppel an. Durch diese charakteristisch nach ventrolateral konvex gebogene Platte wird ein Raum abgegrenzt, der ventromedial unter dem vorderen Teil der Ohrkapsel liegt. Hier befinden sich die Hauptmassen der Ganglien des Facialis, Ophthalmicus lateralis und Trigeminus; der Raum ist die Trigeminofacialiskammer (Veit [1907]). Die Kammer ist noch nicht so charakteristisch wie später gegen das Cavum cerebrale cranii abgegrenzt, da zwischen den Ganglien und dem Hirn die Dura mater noch nicht als geschlossene Membran entwickelt ist. Rostral offnet sich die Kammer weit gegen die Orbita; ventral lässt eine kleine öffnung den Ramus palatinus facialis austreten, ventrocaudal verlïsst der Truncus hyoideomandibularis facialis unter der Ohrkapselkuppel entlang die Trigeminofacialiskammer, lateral durchbohrt der Ramus oticus ophthalmici lateralis die Knorpelwand und geht um die Ohrkapsel herum dorsalwärts; seine Austrittsstelle am Schädel ist von ventral abgegrenzt durch eine kleine Knorpelleiste, welche die erste Anlage der Crista parotica darstellt. Ausser diesen Nerven, welche in der Trigeminofacialiskammer den Schädel verlassen, ist in der Labyrinthregion nur noch der Glossopharyngeus zu erwähnen, welcher am caudalen Ende der Fossa sacculi durch deren Seitenwand austritt. Das Ganglion glossopharyngei, welches in den jüngeren Stadien fast direkt ventrolateral am Sacculus lag, liegt jetzt ventrolateral der Bulla acustica saccularis an. Hier ist die Wand der Bulla verdünnt, der Knorpel noch sehr zellreich und arm an hyaliner Grundsubstanz; man gewinnt sofort den Eindruck, dass hier die Knorpelbildung erst seit kurzer Zeit eingesetzt hat. Der Vagus- 
stamm verlässt zwischen Ohrkapsel und occipitaler Seitenwand den Schädelraum durch einen dorsal noch nicht geschlossenen Schlitz.

Das Knorpelskelet der Orbitotemporalregion ist noch sehr einfach gestaltet. Es ziehen die Trabekel von der Labyrinthregion als Knorpelspangen rostralwärts, lateral längs des Vorderhimbodens, medioventral längs des Auges. Die beiderseitigen Knorpel nähern sich einander und vereinigen sich in der Mittellinie vor dem Recessus praeopticus. Die Fenestra basicranialis crstreckt sich demnach wiederum von dem vorderen Teil der Liabyrinthregion bis vor den Recessus praeopticus. Es springen vor der Chordaspitze in der Höhe des Foramen nervi palatini die Knorpel gegen die Mediane etwas vor und grenzen so all der Fenestra basicranialis einen caudalen Labyrinthteil von einem rostralen Orbitotemporalteil ab. Es entspringt an der Schädelbasis gerade an der Grenze von Labyrinth- und Orbitotemporalteil der Fenestra basicranialis wiederum der Rectus lateralis bulbi.

Die Commissura trabecularis hat sich durch Verknorpelung des Gewebes, welches im vorigen Stadium sich unter dem Vorderhirn zusammenballte, zu einem Planum orbito$\mathrm{n}$ a s a le entwickelt, welches vom Recessus pracopticus bis vor das Hirnende reicht. Die Knorpelplatte liegt dem Hirnboden fest an, sie ist zur Aufnahme des Hirnes leicht konkav ausgehöhlt. Gegen das Vorderhirnende verdickt sich die Platte and steigt entsprechend dem verjüngten Hirnende dorsal etwas an. Die Orbitonasalplatte endet ein wenig rostral ror dem Hirnende. Caudal vom Olfactorius steigt jederseits cine schmale kurze Leiste von der Schädelbodenplatte dorsalwärts an und liegt hier ventrolateral neben dem Hirn; an dieser Leiste, welche die erste Anlage der Schädclseitenwand dieses Gebietes darstellt, inserieren die beiden Musculi obliqui bulbi. Rostral vor dieser Leiste springt ron der Orbitonasalplatte jederseits 
eine plumpe Platte lateral vor; diese ist nach ventrolateral gekrümmt, sie liegt ventral vom Olfactorius, rentromedial vom caudalen Teile des Nasensackes; diese Knorpelplatte wurde von W. K. Parker (1882) als Corn u trabecula re bezeichnet. An der zum Plattenmodell verwendeten Serie ist noch eine kleine Besonderheit zu erwähnen, die bei anderen Serien dieser Entwickelungsperiode sich nicht fand. Es springt, nur auf der rechten Seite, am caudalen Ende des Planum orbitonasale ejne kleine Leiste lateralwärts vor; Beziehungen zu einem Muskel oder anderen besonderen Weichteilen hat diese Leiste nicht.

Als neuer Skeletteil ist die Cartilag o supra orbital is aufgetreten. Sie stellt einen Knorpelstab dar, welcher von der rostralen Kuppe der Ohrkapsel, mit der for fest verwachscin. ist, ausgeht; der Knorpel läuft dorsomedial über den Bulbus, lateral am Mittelhirn entlang und nähert sich dorsalwärts etwas ansteigend der Medianen. Thr Ende findet die Cartilago supraorbitalis in der Furche zwischen Saccus dorsalis und Mittelhirn nahe der Mittellinie, erreicht aber den Knorpelstab der anderen Seite nicht ganz.

Splanchnocranium. (Fig. 13, 14, Taf. B.) Das Skelet von Kiefer- und Kiemenbogen hat sich sehr weitgehend vervollständigt. Das Pa la to quadratum lässt eine Pars quadrata und palatina unterscheiden. Die Pars quadrata ist eine Knorpelplatte, welche in der Seitenwand der Mundhöhle gelegen ist; ihr dorsaler Rand läuft in einigem $\mathrm{Ab}$ stande parallel und ventrolateral von der Trabekel; caudalwärts endet die Pars quadrata mit einem Fortsatz, der die Verbindung zur Hyomandibel vermittelt. Ausserdem verbindet dichtes Vorknorpelgewebe den caudalen Teil der Pars quadrata ventral vom Ganglion trigemini mit der Trabekel; dies ist die erste Andeutung der später sich hier ausbildenden Anlagerung des Palatoquadratum an den Hirnschädel. Rostral etwa in der Höhe des Opticus hört die Pars 
quadrata auf; ventral verbindet sie sich mit der Mandibula, dorsal setzt sie sich in die Pars palatina palatoquadrati fort. Letztere zicht als allmählich sich verjüngender Knorpelstab parallel der Trabekel ventromedial längs des Bulbus rostralwärts und endef etwa in der Höhe des Olfactoriusursprunges.

Die II a ndibel liegt im Boden der Mundhöhle. Sie legt sich mit ihrem verdickten caudalen Ende der Pars quadrata palatoquadrati an; die beiden Knorpel sind durch ein dichtzelliges Gewebe, welches als Vorknorpel bezeichnet werden könnte, verbunden; ein Gelenkspalt ist noch nicht gebildet. Die Mandibel zieht rostralwärts und sogleich medianwärts weiter, nimmt an Umfang immer mehr ab und endet in der Höhe des vorderen Hirnendes; sie stösst hier mit dem Knorpel der anderen Seite zusammen, zellreicher Vorknorpel verbindet die beiden Mandibeln.

Im Hyalbogen sind Hyomandibel, Interhyale, Keratohyale und Hypohyale erkennbar geworden. Die einzelnen Skeletstücke sind zwar gut voneinander abzugrenzen, hängen aber an den Grenzen durch zellreichen Jungknorpel miteinander zusammen, Gelenke sind also noch nicht gebildet. Die Hyomandibel ist eine längliche Knorpelplatte, welche ventral sich den Seitenteilen der Ohrkapsel anlegt, und zwar dem vorderen Teile der Prominentia ampullae lateralis und von hier in schräg ventralwärts abfallender Linie bis über die Austrittsstelle des Truncus hyoideomandibularis facialis. Die Hyomandibel ist durch zellreiches Knorpelgewebe synchondrotisch mit der Ohrkapsel verbunden. Nur an der Prominentia ampullac lateralis ist zwischen Hyomandibel und Ohrkapsel eine schmale Schicht von Bindegewebe gelegen, die Ohrkapselwand zeigt hier, wic oben beschricben wurde, eine seichte Fossa hyomandibularis als ersten Anfang der Gelenkpfanne für die Hyomandibel. Rostral geht von der Hyomandibel ein Fortsatz aus, welcher sich ventral dem caudalen Ende des 
Palatoquadratum anlegt, caudal geht die Hyomandibel bis an die Wurzel des Kiemendeckels heran. Die Platte der Hyomandibel wird vom Truncus hyoideomandibularis facialis durchbohrt.

Das Interhyale ist ein sehr kurzer Knorpelstab, welcher den ventralen Rand der Hyomandibel mit dem caudalen Ende des Keratohyale verbindet. Letzteres zieht als dicker Knorpelstab rostralwärts und zugleich medianwärts. An seinem rostralen Ende liegt das kleine Hypohyale, welches mit dem gleichnamigen Knorpel der anderen Seite median zusammenstösst.

Die Kiemenskeletbögen sind einfache Knorpelspangen, die in rostrocaudaler Reihe an Länge abnehmen. Sie beginnen median am Mundhöhlenboden und reichen im ersten und zweiten Kiemenbogen bis an das Dach der Mundhöhle, in den caudalen Bögen enden sie schon nach kürzerem Verlaufe. Ein langes Basibranchiale liegt median im Mundhöhlenboden. Es beginnt caudal hinter den Hypohyalia, mit denen es durch rerdichtetes Mesenchymgewebe verbunden ist, und reicht bis an das ventrale Ende des dritten Kiemenbogens. Der erste und zweite Kiemenskeletbogen legen sich seitlich dem Basibranchiale an, der dritte stösst an sein caudales Ende.

Stadium V. Gesamtlänge des Tieres $20 \mathrm{~mm}$. (Fig. 16, 'Tafel E, Fig, 17-_20, Tafel C.)

Die Entwickelung des Primordialcranium vollzieht sich jetzt weiterhin in Bahnen, die in den Hauptzügen durch Untersuchungen an anderen Formen bekannt sind, besonders zeigen sich mannigfache Anklänge an die Bcfunde bei Selachiern sowohl wie bei Teleostiern. Es soll deswegen genauer nur noch ein schon sehr viel weiter ausgebildeter Zustand des Primordialcranium von Lepidosteus osseus beschrieben werden. Wo es zum Verständnis der Entwickelung nötig ist, werde ich aus 
zwischenliegenden Stadien ergänzende Mitteilungen einfügen können. Zur Ausfüllung der grossen Lücke, die noch zwischen dem jetzt zu beschreibenden Stadium und dem früher Mitgeteilten bleibt, fohlt mir zurzeit das Material. Es werden sich aber immerhin schon eine Reihe interessanter Vergleiche mit den damals beschriebenen Befunden anstellen lassen.

Ä usserer Entwickelungsgrad. Durch völligen Schwund des Dottersackes und weiteres Auswachsen and Strecken des Kopfes hat das junge Tier jetzt typische Fischform angenommen. Der Kopf hat im Verhältnis zum äbrigen Körper wieder stark an Grösse zugenommen; am Kopfe selbst ist besonders die Verlïngerung des vor den Augen gelegenen rostralen Abschnittes auffallend (Fig. 16). Ein Mittelhirnhöcker ist nicht mehr erkennbar. Die vordere Fläche des stumpfen rostralen Kopfendes trägt nur noch die Reste einiger Saugnäpfe. Der Mund hat sich durch Vorwachsen der Kiefer zu einer langen Fischschnauze entwickelt. Die Nase liegt seitlich am rostralen Ende der Schnauze im grossen Abstande vor den Augen. Die äussere Nasenöffnung hat sich in ein rostrales und caudales Nasenloch geteilt, welcher Vorgang im vorigen Stadium schon in den Anfängen zu erkennen gewesen war. Der Kiemendeckel ist erheblich caudal und ventral ausgewachsen, die ventralen Ränder beider Kiemendeckel überdecken sich gegenseitig. Die Brustflossen, deren rostraler Rand wieder vom Kiemendeckel verdeckt wird, haben sich zu typisch gebauten Flossen entwickelt; sie springen als freie Platten weit vor, ihre Ansatzlinie am Rumpf verläuft fast transversal. Die Bauchflossenanlagen heben sich erst als kleine Falten vom Rumpfe ab.

Kopfdarm. Der Kiefer-Kiemenapparat ist jetzt in fast allen Teilen so entwickelt, wie er beim erwachsenen Tiere beobachtet und beschrieben ist und wie er bei allen Ganoiden und Teleostiern in prinzipiell gleicher Weise sich findet. Eine genauere Beschreibung kann deshalb unterbleiben. Am Kiemen- 
deckel ist die Hyoidkieme in erster Anlage zu erkennen, von der Psendobranchie findet sich noch nichts. Das Kiemenbogengebiet erstreckt sich caudalwärts bis in die Höhe des Nervus VII ; es hat sich demnach noch weiter verschoben und reicht über das Niveau der caudalen Vaguswurzel rückwärts hinaus. Die Spritzlochanlage (Fig. 16, Spr.) hat ihre volle Ausbildung erreicht, sie nimmt nach den Lntersuchungen von F r. W. M üller (1897) später nur noch an Grösse zu, lüsst aber keine neuen Bildungen mehr entstehen. Direkt vor dem Zungenbeinbogen senkt sich beiderseits das Dach der Mundhöhle zu einer breiten trichterförmig verjüngten Tasche ein. Daran schliesst sich ein kleiner Kanal an, der vor der Hyomandibel dorsolateralwärts ansteigt und bald sich an den Boden der vorderen Ohrkapselkuppel anlegend endet. Aus der dorsalen Wand dieses Kanales steigt ein zweiter an - Recessus dorsalis spiracularis -, welcher lateral um die Ohrkapsel herumläuft und dorsal auf dem Dach der Ohrkapsel endet. Der Recessus dorsalis ist zum Teil vom Knorpel der Ohrkapsel umwachsen, liegt also in cinem Canalis spiracularis des Cranium; sein Ende liegt dorsolateral auf dem Schïdel kurz hinter der Stelle, an welcher der Ramus oticus ophthalmici lateralis austritt. Die allgemeine Anordnung ist demnach die gleiche wie im vorigen Stadium; nur hat sich in der ganzen Spritzlochanlage ein feines Lumen gebildet. Das Epithel, welches, bisher sich wie das Epithel des Rachens verhielt, hat sich an der medialen Wand des Recessus dorsalis spiracularis spezifisch differenziert; es ist hier ein typisches Sinnesepithel. An diese mediale Wand des Recessus dorsalis treten feine Zweige des Ramus oticus heran.

Im Ge hirn (Fig. 16) sind cinige weitere Differenzierungen aufgetreten. Das Gehirn hat sich im ganzen verlängert und gestreckt, vorwiegend im Vorderhirngebicte. Die Bodenplatte des Hinterhirnes ist verhältnismässig stark verdickt, besonders in 
den vorderen Teilen, welche zum Mitfelhimboden ansteigen. Ebenso haben die Kleinhirnanlagen sich vergrössert; zwischen den beiden Anlagen sind Commissurenfasern aufgetreten, sodass in dem Gebiete zwischen den zwei Kleinhirnhälften das Hinterhirndach nicht mehr rein ependymatös ist. Vom Mittelhirn ist nur zu erwähnen, dass es sich wieder weiter über das Hinterhirn herüber geschoben hat. Die Epiphyse beginnt unregelmässige Ausbuchtungen zu entwickeln; ihre Wand besteht aus Cylinderzellen, die etwas niedriger geworden sind als im jüngeren Stadium. Der Saccus dorsalis hängt jederseits lateralcaudalwärts bis neben die Epiphyse und den Anfangsteil des Mittelhirnes über. Die Paraphyse ist länger ausgezogen, die Zellen ihrer Wand haben sich weiter abgeflacht. An der Vorderhirnbodenplatte ist ein weiteres caudalwärts gerichtetes Auswachsen des Infundibulum zu erkennon; zur Absetzung des Saccus-vasculosus-Gebietes ist es noch nicht gekommen. Die Lobi olfactorii haben in erheblichem Masse an Grösse zugenommen und sich rostralwärts vorgeschoben; grösstenteils liegen sic vor der Lamina terminalis nebeneinander. Der Hirnventrikel setzt sich in jeden Lobus olfactorius fort.

Hirnnerven und Sinnesorgane. Bei der Beschreibung des Hirnnervenbefundes sei auf die Rekonstruktionsfiguren dieses und des vorigen Stadiums verwiesen (Fig. 10 und 16, Taf. D, E); die Rekonstruktionen ergïnzen sich gegenseitig, da bei beiden einzelne Teile in verschiedener Weise fortgelassen sind, um das einzelne Bild nicht zu schr zu überladen. Ich werde nur die Ursprungsverhältnisse und Hauptverzweigungen beschreiben, da ich den vorliegenden Beschreibungen der Endramifikation nichts Neues hinzuzufügen habe.

Das Ge ruch s orga hat sich in ganz ausserordentlichem Masse rostralwärts vorgeschoben; es liegt weit vor dem Hirne am Ende des Kopfes. Der Nasensack ist noch einheitlich gestaltet, es zcigen sich nur die ersten Anfänge einer Falten- 
bildung der Wandung. Die im vorigen Stadium schlitzförmige Nasenöffuung hat sich in ein rostrales und caudales Nasenloch geteilt, welche durch eine breite Brücke getrennt werden. Der Olfactorius (Fig. 16, Ol.) ist zu einem langen Nerven ausgewachsen. Lr entspringt ventrolateral und rostral aus dem Lobus olfactorius, verlässt das Cavum cerebrale cranii durch das Foramen olfactorium evehens, läuft längs des wciter unten zu beschreibenden knorpeligen Rostrum, ruhend auf dessen lateral vorspringenden Flügelplatten, rostralwärts und tritt nach langem Verlaufe von caudal her an die mediale Wand des Nasensackes.

Auch das A uge hat sich rostralwärts vorgeschoben, aber nur in sehr geringem Grade. Es liegt neben dem Vorderhirne, reicht nicht mehr caudalwärts in das Hinterhirngebiet. Die Lobi olfactorii springen vor das Auge rostralwärts noch vor. Der 0 p ti c us (Fig. 16, Opt.) verläuft rentral- und etwas rostralwärts, er erreicht schon nach sehr kurzem Verlaufe den Bulbus. Aus der Verlaufsrichtung des Opticus ist deutlich abzulesen, in welchem Grade sich das Auge am Hirn entlang rorgeschoben hat.

Der Oculomotorius (Fig. 16, Ocm.) entspringt mit breiter: Wurzel, die in zwei Bündel zerfällt, ventral aus dem Mittelhirn an der Stelle, wo dieses das Mittelhirnpolster (Ga up p [1905]) überbrückt; er läuft in dem Mittelhirnpolster ventrolateralwärts an den caudalen Pol des Bulbus. Ein kurzer Ramus superior tritt an den Rectus superior bulbi (Fig. 16, R.s.) heran. Um den caudalen Rand dieses Muskels herum geht der Rest des Oculomotorius, als Ramus inferior zu bezeichnen, ventralwärts weiter. Hier zieht der Nerv rostral vor dem Ophthalmicus profundus vorbei, nimmt cinen Ramus anastomoticus dieses Nerven auf und schwillt nun durch Einlagerung von Ganglienzellen sehr erheblich an. Der Ramus inferior oculomotorii liegt jetzt ventromedial am Bulbus. Der Nervenstamm nimmt wieder an Umfang ab, entsendet einen 
kurzen Ramus ciliaris (Fig. 16, Ci.) in den Bulbus herein, versorgt weiterhin mit kurzen Ästen die Musculi recti inferior und medialis bulbi und geht mit langem Endaste ventromedial längs des Bulbus hinzichend zum Obliquus inferior bulbi (Fig. 16, Ob.i.).

Der Nervus trochlearis (Fig. 16, Tro.) entspringt caudal vom Oeulomotorins aus dem Mitteshirn, und zwar ventral aus dem Teil, welcher über das Hinterhirn herübergeschoben ist. Der Nerv läuft zuniichst in der Furche zwischen Mittelhirn und Hinterhirn rostralwïrts, zieht weiterhin im Mittelhirnpolster lateralwärts und tritt hier durch die Dura mater hindurch. Nun ist der Nerv anfangs dorsomedial, dann ventrolateral von den Nervi ophthalmici und supraorbitalis am Bulbus entlang rostralwïts zu verfolgen, um sich nach langem Verlaufe in den Obliquus superior bulbi (Fig. 16, Ob.s.) einzusenken.

Der A b d u cens (Fig. 16, Abd.) entspringt mit zwei Wurzelfäden weit caudal aus dem ventralen Teil des Hinterhimbodens in der Höhe der Glossopharyngeuswurzel. Der Nerr zieht als sehr feiner Stamm längs des Hirnbodens rostralwärts, medial am Ganglion des Facialis und Trigeminus entlang. An der Wurzel des Processus basipterygoideus stösst der Nerv auf den Rectus lateralis und senkt sich sofort in den Muskel ein.

Der Ophthalmicus profundus (Fig. 16, Oph.pr.) entspringt mit rundlicher Wurzel ventrolateral aus den rostralen Teilen des Hinterhirnes. Er liegt hier medial rom Trigeminusganglion, zieht dann nach Durchbohrung der Dura mater auf dieser entlang rostralwärts und schwillt zu einem grossen Ganglion an, welches sich dorsalwärrts in die Höhe zieht. Hier geht ein kurzer Ramus anastomoticus an den Ramus inferior oculomotorii heran. Der Hauptstamm läuft über den Oculomotorius lateral hinweg, steigt dorsalwärts an und zieht nun dorsomedial vom Bulbus rostralwärts, wo er weithin gegen die Schnauze zu verfolgen ist. 
Der Trigeminus (Fig. 16, Tri.) entspringt mit zwei starken, nebeneinander befindlichen Wurzeln caudal vom vorigen Nerven aus dem Seitenteil der Hinterhirnbodenplatte. Der Stamm liegt hier medial ron den Ganglien des Facialis und Ophthalmicus lateralis. Sehr bald schwillt der Trigeminus zu einem mächtigen Ganglion an, welches anfangs auf dem Processus basipterygoideus, dann weiterhin frei hinter dem Bulbus gelegen ist. Dorsalwär,s geht aus dem Ganglion der $0 \mathrm{ph}$ tha $\mathrm{l}$ micus superficialis trigemini hervor, welcher sich dem Ophthalmicus profundus nahe anlegt und den gleichen Weg wie 'dieser dorsomedial am Bulbus entlang nimmt. Der Rest des Ganglion, der Truncus maxillomandibularis trig emini (Fig. '16, Max.mand.) gibt zunächst einen kurzen $\Lambda$ st an Muskeln des Oberkiefers ab, nimmt dann von caudal eine breite Anastomose rom Facialis auf, tritt lateralwärts, zieht auf der dorsalen Kante des Palatoquadratum entlang und zerfällt schliesslich in den Ramus maxillaris und mandibularis.

Der Facialis (Fig. 10, Fac.) entspringt eine Strecke weiter caudal aus den Seitenteilen des Hinterhirns. Sofort geht er in sein grosses Ganglion über, aus welchem die Äste entspringen. Die Äste treten durch einzelne öffnungen aus dem Schädel heraus. Der Truncus hyoideomandibularis tritt unter der rostralen Ohrkapselkuppel in schräg nach ventrolateral und caudal gerichtetem kurzem Kanale aus dem Cavum cranii heraus; er liegt nun medial ron der Hyomandibel und entsendet hier kurze Äste an die Muskulatur des dorsalen Hyalbogenendes, sowic einen längeren $\mathrm{R}$ a mus opercularis facialis (Fig. 10, Op.f.) in den Kiemendeckel. Der Stamm durchbohrt weiterhin die Hyomandibel und zerfällt dann sehr bald in den Ramus hy oideus (Fig. 10, Hy.f.) und Ramus mandibularis facialis (Fig. 10, Mand.f.). Letzterer Nervenast rersorgt die Sinnesorgane des Mandibularkanales. 
Der Nervus palatinus (Fig. 10, Pa.f.) löst sich ventral aus den rostralen Teilen des Ganglion faciale, durchbohrt den Schädelboden an der Wurzel des Processus basipterygoideus und ist nun weithin am Mundhöhlendach zu verfolgen. Das rostrale Ende des Facialis senkt sich in den Truncus maxillomandibularis trigemini ein.

Der Ophthalmicus lateralis (Fig. 10, Oph. l.) entspringt dorsal von dem Facialis aus den Seitenteilen des Hinterhirns; auch er geht sofort in sein Ganglion über. Zunächst löst sich der Ramus oticus (Fig. 10, Ot.) vom Ganglion; dieser Nerv tritt ventral vor der Ohrkapselkuppel in dic Schädelwand ein und läuft in ihr dorsolateralwärts. Der Nerv kommt aus dem Schädelknorpel heraus direkt ror dem Ende des Recessus dorsalis spiracularis. Sinnesorgane der Seitenlinie dieser Region und die neuroepithelial verdickte Partie des Recessus dorsalis spiracularis sind die Teile, welche vom Ramus oticus versorgt werden. Das Gan. glion ophthalmici lateralis tritt vor der Ohrkapsel aus dem Cavum cranii heraus und zerfällt in seine beiden Endäste. Der Ramus supraorbitalis ophthalmicilateralis (Fig. 10, Su. orb.) steigt dorsalwärts an und versorgt die Sinnesorgane des Supraorbitalkanales; der Nerv geht den gleichen Weg wie der Ophthalmicus profundus und Ophthalmicus superficialis trigemini, denen er direkt anliegt, über den Bulbus dorsomedial hinwegziehend. Der $\mathrm{R}$ amus infraorbitalis ophthalmici lateralis (Fig. 10, In. orb.) tritt ventralwärts und zieht ventromedial am Bulbus entlang, die Sinnesorgane des Infraorbitalkanales versorgend.

Die Ganglien des Trigeminus, Facialis und Ophthalmicus lateralis liegen eng aneinander ventromedial unter der vorderen Ohrkapselkuppel in der Trigeminofacialiskammer. Der Trigeminus liegt medial, der Facialis ventrolateral, der Ophthalmicus lateralis dorsolateral in diesem Raume. Bei Beschreibung der 
jüngeren Stadien wurde erwähnt, dass es nicht möglich war, die Beziehungen des Ophthalmicus lateralis und Facialis zueinander genau festzustellen. Es gelang nun das Bild zu klären. Es wurden lückenlose Querschnittserien von $6 \mu$ Schnittdicke angefertigt und die Achsencylinder mit Hïmatoxylin-Eisenalaun nach $H$ eidenhain gefärbt. So liess sich mit Sicherheit feststellen, dass tatsïchlich der Ophthalmicus lateralis rom Facialis völlig abzutrennen ist. Nur an einer Stelle findet ein Faseraustausch statt. Es treten Fasern aus dem Ophthalmicus lateralis in das Facialisganglion üher und von dort sofort weiter in den Truncus hyoideomandibularis. Der übrige Facialis erhält keine Fasern aus dem Ophthalmicus lateralis. Die Trennung in Facialis und Ophthalmicus lateralis scheint mir für den ganzen Nervenkomplex dadurch berechtigt zu scin. Es schein! mir zudem wahrscheinlich, wenn auch durch den mikroskopischen Befund nicht sicher nachweisbar, dass die Elemente des Ophthalmicus lateralis in den Ramus mandibularis facialis eirtreten. Es würden dann sämtliche Seitenorgane des Vorderkopfes vom Ophthalmicus lateralis versorgt werden.

Der A custicus (Fig. 16, Ac.) entspringt aus dem Hinterhirn zwischen dem Facialis und Ophthalmicus lateralis. Er läuft auch zwischen den Ganglien des Facialis und Ophthalmicus lateralis hindurch, bildet dann sein eigenes grosses Ganglion und tritt an die einzelnen Teile des Labyrinthorganes heran.

Das Labyrinthorgan hat an Grösse weiter zugenommen; es schiebt sich caudalwärts bis fast in die Höhe des vereinigten Vagusstammes vor. Der Sacculus ist grösser ausgewachsen. Dic Furche zwischen Litriculus and caudalem Sacculuspol hat sich vertieft.

Der Glossopharyngeus (Fig. 16, Gl.) ist mit der vorderen Vaguswurzel so innig zu einem Stamm vereint, dass er geradezu als ein Ast dieses Stammes erscheint. Er entspringt 
aus den Seitenteilen des Hinterhirns in einigem Abstande caudal von dem letzten oben beschriebenen Hirnnerven. Zunächst läuft der Nerr mit der vorderen Vaguswurzel zwischen Hirn und Iabyrinthorgan candalwärts, biegt dann scharf ventral um und tritt lateralwärts in den Spaltraum ein, welcher zwischen caudalem Sacculuspol und Itriculus sich befindet. Das Cavum cranii verliisst der Glossopharyngeus ventrolateral durch die Seitenwand der Fossa sacculi. Jetzt schwillt der Nerv zu einem grossen Ganglion an, welches der Ohrkapsel ventrolateral direkt anliegt: ans dem Ganglion gehen die einzelnen Äste dorsal-, rostral und ventralwïrts hervor. Der $\mathrm{Ramus} d$ orsalis glos s oph a rynge i (Fig. 16, D. gl.) läuft dem Perichondrium der Ohrkapsel anliegend dorsalwärts zu den Sinnesorganen der Seitenlinic dieses Gebietes. Der Ramus posttrematicus glossopharyngei (Fig. 16, Po.gl.) tritt ventral- und anfangs auch caudalwärts gerichtet in den ersten Kiemenbogen heral. Rostral vor ihm geht ein kurzer Nervenast aus dem Ganglion hervor, welcher an Muskeln des dorsalen Endes des ersten Kiemenbogens herantritt und die Schleimhaut zwischen dem ersten Kiemenbogen und Hyalbogen versorgt. Rostral verlässt der Ramus pharyngeus glossopharyngei (Fig. 16, Ph.gl.) das Ganglion. Er ist am Dache des Kiemendarmes bis gegen die Spritzlochtasche zu verfolgen.

Ler Vagusurs prung dehnt sich über eine lange Strecke der Hinterhirnseitenwand aus rom Glossopharyngeus an bis gegen die Hirn-Rückenmarksgrenze. Es lassen sich wieder eine grosse vordere und eine in zahlreiche Füden zerfallende hintere Wurzel unterscheiden. Die vordere Vaguswurzel entspringt als ein Stamm gemeinsam mit dem Glossopharyngeus. Sie lïuft lïngs der Hirnseitenwand caudaliwärts und stösst in der Höhe des caudalen Poles der Ohrkapsel auf die hintere Vaguswurzel. Diese entspringt mit einer grossen Reihe ron Wurzelfäden, welche vorn rostral und caudal zusammentreten zur Bildung 
des Wurzelstammes, welcher reichlich Ganglienzellen enthält. Der caudale Wurzelstamm liuft rentral- und lateralwärts und vereinigt sich beim Austritt aus dem Schädel mit der vorderen Wurzel. Der vereinigte Vagusstamm verlässt den Schädel in schräg ventrolateral und caudal gerichtetem Verlaufe hinter der caudalen Ohrkapselkuppel. Der Nerv bildet sogleich ein grosses Ganglion, welches lateral dem Schïdelboden anliegt; dieses zerfällt sehr bald in die Pars branchialis rag i, welche abwärts zu den Kiemenbögen tritt und die L'ars lateralis vagi (Fig. 16, Lat.va.), welche an die Sinnesorgane der Seitenlinie lateralwärts herantritt. Lis lïsst sich feststellen, dass die vordere Vaguswurzel im wesentlichen in die Pars lateralis vagi übergeht, die hintere Wurzel $n$ u $\mathrm{r}$ in clie Pars branchialis. Von der Pars lateralis vagi ist nur ein Schädelast zu erwähnen, der Ramus dorsalis vagj (Fig. 16, D. va.). Dieser entspringt rom Vagus direkt nach dem Austritt aus dem Schädel; er läuft an der Seitenwand des Schädels in die Höhe und versorgt die Simesorgane der Schleimkanalquercommissur, welche hier die beiden Seitenlinien verbindet. Die Pars branchialis vagi versorgt den zweiten bis fünften Kiemenbogen und den entsprechenden Abschnitt der dorsalen Darmwand. Der rostrale Teil des Ganglion vagi schicbt sich über das dorsale Ende des ersten Kiemenbogens; er ist rom Hauptganglion als besonderer Teil abgesetzt - Ganglion branchiale II vagi. Aus diesem Ganglionabschnitt geht ein Ramus posttrematicus in caudal stark konvexem Bogen in den zweiten Kiemenbogen herab: Ramus posttrema. ticus Ii vagi (Fig. 16, Po.va.II.). Rostralwärts tritt ein feiner Nerv aus dem Ganglion branchiale ragi, welcher an dem Dach der Darmhöhle median ron dem Kiemenbogenende eine Strecke weit entlang zu verfolgen ist: Ra mus phary $n$ geus vagi (Fig. 16, Ph. va.). Die übrige Pars branchialis vagi erstreckt sich über die dorsalen Kiemenbögenenden caudal- 
Wïts und senkt sich entsprechend mit ihnen etwas ventralwïrts. Aus ihr gehen Äste herab in die Kiemenbögen, welche lïngs der caudalen Wand der einzehnen Spalten herablaufen: Rami posttrematici III-V vagi. Ausser diesen grossen Rami posttrematici gehen nun noch aus der Pars branchialis vagi eine Reihe kürzerer Äste hervor, welche das Dach der Mundhöhle und die Muskeln zwischen den dorsalen Kiemenbogenenden versorgen. Einzelne Nervenstränge sind an der vorderen Wand der Kiemenspalten herab zu verfolgen. Stärkere fami praetrematici vagi konnte ich aber nicht auffinden. Caudalwärts setzt sich die Pars branchialis ragi als Ramus intestinalis fort. In der Rekonstruktion ist die Pars branchialis wieder so weit eingetragen, als die Kiemenbogenregion caudalwärts reicht. Es ist so die Gesamtausdehnung des Kiemenbogenapparates caudalwärts zu ersehen, in gleicher Weise wie die Lage der Rami posttrematici benutzt werden kann, um die dorsalen Kiemenbogenenden in ihrer Projektion auf die Medianebene zu bestimmen.

My otome und Spinalnervendes Hinterkopfes (Fig. 16, Taf. E). Die Spinalnerven und Myotome des Hinterkopfes verhalten sich fast genau wie in dem vorigen Stadium, es sind nur kleine, aber in prinzipieller Hinsicht nicht unwichtige Veränderungen eingetreten. Beiderseits liegen ventral tom Vagus wieder die ventralen Nervenwurzeln IV ${ }^{v}$ und $V^{v}$, welche lateralwärts durch den Knorpel der occipitalen Seitenwand hindurch zu ihrem Muskelgebiete ziehen. Dann folgt die Reihe der typisch zweiwurzeligen Spinalnerven. Nervus IV ${ }^{\mathrm{v}}$ ist ein dünner, aber gut verfolgbarer Nerv; die folgenden sind alle sehr kräftig entwickelt. Nervus VI sendet einen sehr feinen, die folgenden Nerven kräftige Äste in die Brustflosse. Die caudale Wurzel des Vagus reicht mit ihren letzten Ursprungsfäden wiederum bis in dic Höhe des Nervus $V^{v}$. Während nun im vorigen Stalinm die Nerven sämtlich in ihrem Anfangsteil von dorso- 
caudal nach ventrorostral gerichtet waren, sind jetzt darin gewisse Änderungen eingetreten. Nervus IV läuft von dorsorostral nach ventrocaudal, Nervus $\mathrm{V}^{\mathrm{v}}$ fast rein von dorsomedial nach ventrolateral; am Nervus VI entspringt die ventrale Wurzel erheblich weiter caudal wie die dorsale, sodass letztere von rostral an die ventrale Wurzel herantritt. Als individuelle Variation will ich erwähnen, dass in einem Falle der Nervus VI ${ }^{d}$ der einen Seite sich nicht mehr mit dem zugehörigen Nervus VIV vereinigte, sondern vorher frei endete, ohne durch die Rückenmarkshäute herauszutreten. Die erwähnte, allgemein rorkommende Inkongruenz im Lrsprung des Nervus VI und VIV kann nur auf einer caudalwärts erfolgten Verschiebung des Ursprunges des Nerrus $V^{\mathrm{V}}$ beruhen; denn Nervus $V^{d}$ entspringt wie in früheren Stadien an der Grenze von Rückenmark und erweitertem Hirn. Wir müssen demnach im Verhalten der Nerven IVv, $V^{r}$ und VI eine gewisse Verschiebung des Ursprungsgebietes der ventralen Wurzeln caudalwärts erkennen.

Die Reihe der Myotome zeigt ebenfalls Zeichen dieser Verschiebung caudalwärts. Ihr rostraler Rand hat sich auch etwas weiter caudalwärts zurückgezogen, sodass das erste Myotom, besonders in den mittleren Teilen, auf einen schmalen Streifen beschränkt ist. Auch das zweite Myotom ist noch schmäler als die folgenden. Die Septa intermuscularia selbst, deren Anheftungslinien an der Chorda in der Rekonstruktion angegeben sind, sind sehr stark schräg gestellt, ihre Anheftung an der Chorda ist der am meisten rostral gelegene Teil; die einzelnen Myotome decken sich dachziegelartig.

Gegenüber dem vorigen Stadium sind demnach die wichtigsten Veränderungen: Der Glossopharyngeus und Vagus verlaufen noch schärfer caudalwärts, um in das Kiemenbogengebict zu gelangen, welches jetzt bis in die Höhe des Nervus VII reicht. Dadurch sind die Myotome und Spinalnerven noch weiter 
zurückgedrüngt, ohne dass es zum Schwunde einzelner Teile gekommen wäre.

Skelet (Fig. 17-20, Taf. C). Die Chorda dorsalis reicht rostral noch eben soweit vor wie im vorigen Stadium. Ihr rostrales Ende ist stark zugespitzt, die Chordahüllen sind aber noch völlig ron Chordagewebe, welches keine Reduktionserscheinungen zeigt, ausgefüllt. Es ist also wohl zu einem relativen Zurückbleiben der Chorda gekommen, indem sie nicht mehr in einem dem Entwickelungsstadium entsprechendem Masse an Volumen zugenommen hat, eine eigentliche Chordarückbildung ist aber noch nicht eingeleitet. Durch das Auswachsen des Infundibulum caudalwärts ist der Abstand von Chordaspitze und Infundibulum sehr klein geworden (drei Schnitte à $10 \mu)$.

Neurocranium. Die Schädelanlage hat sich weiter vervollständigt, es ist besonders der vordere Teil des Schädels in der Ausbildung stark fortgeschritten, während in der Labyrinth- und Occipitalregion die weitere Differenzierung im wesentlichen sich in den schon im vorigen Stadium angewiesenen Bahnen abspielt. An einigen Stellen stossen die Knorpelhälften des Schädels dorsal über dem Gehirn aneinander und bilden so einen dorsalen Abschluss des Cavum cranii.

Occipitalregion. Die occipitale Seitenwand ist kräftig ausgewachsen, während der Boden der Occipitalregion wic bisher im wesentlichen nur von der Chorda und ihren schmalen parachordalen Knorpelbelägen gebildet wird. Caudal geht die occipitale Seitenwand in die Wirbelsäule kontinuierlich über, rostral ist sie in Verbindung getreten mit der Ohrkapsel. Als Grenze gegen die Labyrinthregion betrachte ich wieder die Austrittsstelle des Vagus. Der parachordale Knorpelbelag liegt als einheitliche Masse seitlich der Chorda an bis hinter den Nervus $V^{\mathbf{v}}$, dann zieht er sich wieder in eine dorsolaterale und ventrolaterale Parachordalspange aus. Bis caudal hinter 
den Nervus IV ${ }^{\mathrm{r}}$ haben die Parachordalia die Chorda ventral umwachsen im Anschluss an den entsprechenden Knorpelbelag in der Labyrinthregion. Von den Parachordalia steigt nun bogenförmig die occipitale Seitenwand dorsolateral an; oberhalb der Austrittsstelle des Vagus, Tervus $I^{\mathrm{V}}$ und $\mathrm{V}^{\mathrm{v}}$, biegt dann die Seitenwand dorsomedialwärts um. Die ventrale Hälfte der Seitenwand sieht demnach ventrolateralwirts, die dorsale Hälfte dorsolateralwärts. In allgemeinen ist das Lmbiegen des ventralen in den dorsalen Teil ein allmähliches, nur direkt caudal hinter dem Vagusaustritt ist der C̈bergang ein schrofferer, sodass hier die Andeutung einer Crista occipitalis lateralis von aussen zu erkennen ist. Ventral rom Vagus geht die occipitale Seitenwand in den Schädelboden der Labyrinthregion über, dorsal über dem Vagus verschmilzt sie mit der caudalen Ohrkapselkuppel. In diesem rostralen Teile stossen die beiden occipitalen Seitenwände dorsal rom Hirne fast aneinander, zur Bildung eines geschlossenen Daches ist es aber noch nicht gekommen. Dic Seitenwand nimmt caudalwärts rasch an Höhe ab und läuft schon vor dem Nervus VII in die dorsolaterale Parachordalspange aus. Durch den ventralen Teil der Seitenwand geht der Nervus $I V^{v}$ und $V^{v}$ hindurch, dorsal äber den letzten Teil läuft der Nervus VI hinweg auf dem Wege zu seinem Myotom. Dieser letzte Teil der Seitenwand hängt etwas mehr lateralwärts über und biegt nicht mehr nach dorsomedial um. Es wird später ausgeführt werden, dass dieser letzte Teil, über welchen der Nervus VI hinwegläuft, als ein Wirbelbogenrudiment anzusehen ist. Caudalwärts rom Nervus VI besteht die Skeletanlage, wic oben erwähnt jederseits aus einer dorsolateralen und ventrolateralen Parachordalspange. Es tritt hicr zunächst der Nervus VII lateralwärts zu seinem Myotom herüber. Caudal von dem Nerven springen flache niedrige Buckel von der Parachordalspange lateralwärts ror, welche als kurze dorsale Begenstümpfe anzusprechen sind. Hinter diesen Stümpfen tritt 
der Nervus VilI heraus. Nun erhebt sich ein breiter Knorpelbogen, welcher den ventrolateralen IImfang des Rückenmarkes umgreift. Damn folgt wieder der Austritt des Nerrus IX, ein neuer Knorpelbogen schliesst sich an; dies Bild wiederholt sich weiterhin, wir sind jetzt also im Bereich der echten Wirbelsäule angelangt. Kurz zusammengefasst ergibt sich also folgender Befund: Der parachordale Knorpelbelag geht caudal hinter dem Nervus VI in eine dorsolaterale und ventrolaterale Knorpelspange über, welche sich in die gleichen Teile der Wirbelsäulenanlage fortsetzten. Die echten Wirbelbogen beginnen zwischen Nervas VIII und IX. Daror findet sich zwischen Nervus VIII und Vil ein kurzer Bogenstumpf, rostral davor erhebt sich langsam die cimheitliche occipitale Seitenwand, welche mit der Labyrinthregion des Schïdels verschmilzt. Will man dic Occipitalregion gegen die Wirbelsäule abgrenzen, so ist die Grenze vor dem crsten vollentwickelten Bogen an der Stelle des Austritts des Nervus VIII anzusetzen. Es sei gleich hier rorweg bemerkt, dass die definitive Schädelgrenze sich später am Nervus IX ausbildet.

Laby rinthregion. In der Labyrinthregion sind gegen das vorige Stadium nur relativ geringfügige Veränderungen aufgetreten. Die Chorda dorsalis reicht noch ebenso weit rostralwärts wic im rorigen Stadium; ihr vorderer Teil ist nur nicht mehr dicker geworden, also im Verhältnis zum Knorpelschädel verdünnt. Die Parachordalia bilden mit der Chorda bis in die Höhe der Facialiswurzel den Schädelboden, sie enden hier in ihrem medialen Teile mit schmaler rostraler Kante, ihr lateraler Teil zieht in cinigem Abstande von der Chorda weiter und geht in die Trabekel der Orbitotemporalregion über. In die Fenestra basicranialis, deren caudaler Teil ron den Parachordalia umgrenzt wird, springt die Chordaspitze cine Strecke weit vor. Von der Höhe des Glossopharyngeus ab ist die Chorda ventral von Knorpel unwachsen, wie schon im jüngeren Sta- 
dium; dieser ventrale Knorpelbelag der Chorda hat sich auch in den Anfang der Occipitalregion fortgesetzt, wie oben erwähnt wurde.

Die Ohrkapsel hängt jetzt in ganzer Länge massiv knorpelig mit dem Schädelboden zusammen. Andeutungen von Nahtfugen finden sich nirgends mehr. Dic einzelnen 'Teile der Ohrkapsel sollen nicht wieder genau beschrieben werden, da dies in den meisten Punkten eine Wiederholung der Beschreibung des vorigen Stadiums wäre; ich werde nur die Veränderungen hervorheben. Im Boden der Ohrkapsel hat sich die Fossa sacculi mehr vertieft, die Bulla acustica saccularis hebt sich entsprechend aussen schärfer ab. Die Seitenwand der Ohrkapsel wird durch den Canalis semicircularis stärker vorgewölbt; der seitliche Bogengang hat sich im Vergleiche zum Sacculus etwas stärker ventralwärts gesenkt und wölbt somil die Seitenwand um so mchr ior. Dic rorgebuchtete Seitenwand verstreicht gegen die caudale Ohrkapselkuppel, rostral springt in ihrer Fortsetzung cine scharfe Leiste lateralwärts vor, welche an der vorderen Ohrkapselkuppel mit einem stumpfen Knorpelvorsprung endet. Die Leiste ist die $\mathrm{Cr}$ ista parotica, der stumpfe Fortsatz die Anlage des Processus postorbitalis. Die Prominentia ampullae lateralis wird durch die Crista parotica fast völlig verdeckt. Die nur wenig vergrösserte Gelenkpfanne für die IIyomandibel wird von der Crista parotica überdacht. Vor der Hyomandibularpfanne wird die Crista parotica von einem Kanale durchbohrt, in welchem der Recessus dorsalis spiracularis gelegen ist. Das Dach der Ohrkapsel ist weiter ausgewachsen, sodass jetzt das Labyrinthorgan völlig von oben gedeckt ist. Die Canales semicirculares posterior und anterior machen sich als leichte Prominenzen am Ohrkapseldach bemerkbar. Zwischen den beiderseitigen caudalen. Ohrkapselkuppeln hat das Dach sich über das Hinterhirn hinweg mit dem der anderen Seite vereint - Tectum synoticum. 
Bei Betrachtung von innen her ergibt sich ein Bild, welches fast völlig an das erinnert, wic es früher beim jungen Tiere beschrieben wurde. Von der Seitenwand der Fossa sacculi erheht sich das Septum semicirculare laterale, welches das entsprechende Cavum semicirculare von dem übrigen Schädelraume trennt. lnter dem Dach münden dorsorostral und dorsocaudal über dem Septum semicirculare laterale die Cava semicircularia anterius und posterius. Entsprechend dem Körperwinkel, welchen die drei Bogengänge einschliessen, ist das Dach erheblich verdickt und bildet hier einen den Körperwinkel ausfüllenden Wulst: M a s a angularis (Ga u p p [1908]); an dieser Massa angularis setzt sich von ventral her das Septum semicirculare laterale an.

Dic caudale Ohrkapselkuppel, von der schon erwähnt wurde, dass in ihrem Bereiche ein Tectum synoticum gebildet ist, ist dorsal über dem Vagus breit mit der occipitalen Seitenwand verwachsen. Ventral vor dem Vagus ist die Knorpelwand als Prominentia ampullae posterioris vorgewölbt. Die Betrachtung von innen lehrt, dass das Septum semicirculare posterius vollständig geworden ist, es geht von caudal her in die Massa angularis uber.

Die vordere Ohrkapselkuppel zeigt keine neu aufgetretenen Besonderheiten. Von aussen sitzen ihr der Processus postorbitalis und die Crista parotica an, welche schon oben besprochen wurden. Die Ohrkiapselkuppel steigt im ganzen etwas weniger stark dorsalwärts an. Die Trigeminofacialiskammer unter der vorderen Ohrkapselkuppel ist jetzt gegen das Carum cerebrale cranii durch eine gut entwickelte Dura mater abgeschlossen. Die Nervenwurzeh treten durch die Dura mater in die Kammer ein und verlassen sic durch die im vorigen Stadium erwähnten Ausgangspforten. Die austretenden Nervenstämme gehen in der Hauptmasse in die Orbitotemporalregion. über, der Nervus palatinus durch das gleichnamige Loch des 
Schädelbodens zum Ilundhöhlendach, der Truncas hyoideomandibularis facialis in schrägem Kanal unter der vorderen Ohrkapselkuppel hindurch, der Ranus oticus ophthalmici lateralis durch seinen Kanal, welcher caudal hinter dem Processus postorbitalis direkt ror der dorsalen öffnung des Canalis spiracularis mündet.

Im Zusammenhang mit der Bodenplatte der Trigeminofacialiskammer und mit der Trabekel springt eine kleine Knorpelplatte lateral- und rostralwärts vor; an diese Platle legt sich das Palatoquadratum an. Es handelt sich um den ersten lufang des Processus basipterygoideus. Der Glossopharyngens tritl an der gleichen Stelle wie im jüngeren Stadium in der caudalen Hälfte der Fossa sacculi durch deren Seitenwand aus. Der Vagus tritt in schräg caudalwärts gerichteten Kanale unter der candalen Ohrkapselkupel hindureh; der Austriusschlitz des vorigen Stadiums ist jetzt zum foramen vagi geschlossen dadurch, dass die Ohrkapsel über den Vagus sich mit der occipitalen Seitenwand rereinigt hat.

Das Knorpelskelet der Orbitotemporalregion zeigt recht erhebliche Verändermngen. Es hat die Bildung des Daches begonnen und ist besonders das Carum cerebrale cranii rostral abgeschlossen. Die beiden Trabckeln, welche in der Fortsetzung der Parachordalia die Fenestra basicranialis ungrenzen, nähern sich rasch cinander and verschmelzen schliesslich ror dem Recessus pracopticus zum Planum orbitonasale. In der Höhe der Chordaspitze ist die Fenestra basicranialis wieder etwas verengt, sodass ein Labyrinthteil ron einem Orbitotemporalteil unterschieden werden kann. Von dem Planum orbitonasale steigen Knorpelwände empor, welche das Vorderhirnende umhüllen. Bei der Beschreibung des jüngeren Stadiums wurde erwähnt, dass rom Planum orbitonasale caudal hinter dem Olfactorius Leisten aufstiegen, dass ausserdem rostral ror dem Hirnende die Knorpelplatte sich verdickte und ein wenig in die 
Höhe schob. Hier sind nun Knorpelwände ausgewachsen, welche lateral und rostral das Hirn umhüllen; über dem Olfactorius sind die Knorpelplatten miteinander verwachsen unter Iussparung einer öfnung für den Olfactoriusaustritt: For a men olfactorium evehens. Die seitlichen Platten schieben sich über dem Hirn herauf und vereinigen sich hart ror ler laraphyse miteinander. Eine Ta en ia tecti media anterior verbindet diesen Dachbezirk mit der Knorpelplatte, welche das Hirn rostral deckt; dieser Knorpelstreifen liegt über der Furche, welche die beiden Lobi olfactorii trennt. Es wird so durch die unpaare rostrale und die paarigen lateralen Platten, durch das Dach vor der Paraphyse und die Taenia tecti media anterior eine relativ rollständige Limhüllung des Forderhirnendes erreicht. Nur zwei kleine Fontancllen bleiben. ausgespart; diese sind durch derbes Bindegewebe verschlossen.

Die Ca rtilag o sup ra o r bital is liaft ron der rostralen Ohrkapselkuppel an Mittelhirn seitlich entlang rostral- and dorsalwärts. Die beiderseitigen Knorpel, welche sich im vorigen Stadium hinter der Epiphyse einander näherten, sind jetzt hier miteinander rerwachsen. Eine Taenia tecti media posterior zicht ron hier eine Strecke weit über das Mittelhirn caudalwärts. Yon ihrer Vereinigungsstelle hinter der Epiphyse ziehen dic Supraorbitalknorpel wieder getrennt weiter, liegen lateral auf den Seitenteilen des Saccus dorsalis und gehen rostral schliesslich in das Dach über, welches das Vorderhirn deckt. So ergibt sich folgendes Bild des Schüdeldaches: $Z u$ einem geschlossenen Schädeldach ist es noch nirgends in grösserer Ausdehung gekommen. Vorn deckt die Platte, welche sich vom Planum orbitonasale erhebt, das äusserste Vorderhirnende, vor der Paraphyse ist ein Dachplattenstreifen gebildet, ein gleicher hinter der Epiphyse, am meisten caudal das Tectum synoticum. Line grosse Fontanelle lässt so das Mittelhirn und den grössten Teil des Hinterhirnes unbedeckt; die Taenia tecti 
media posterior beginnt die Fontanelle in zwei symmetrische Hälften zu zerlegen. Epiphyse, Saccus dorsalis und Paraphyse liegen in einer grossen Vorderhirnfontanelle frei zutage. Am rostralen Ende sind die Lobi olfactorii in zwoi schmalen Streifen noch nicht von Knorpeln bedeckt; diese zwei schmalen Lücken des Schädeldaches sind durch straffes Bindegewebe verschlossen, die beiden grossen Fontanellen nur durch ein weniger derbes Gewebe gedeckt. Die Seitenwand der Orbitotemporalregion ist noch fast in ganzer Ausdehnung offen; nur rostral ist durch die Seitenplatten, die von der Orbitonasalplatte zum Dach ansteigen, neben dem Vorderhirnende eine Seitenwand gebildet. Von dem Rande dieser Seitenwand entspringen die Musculi obliqui superior et inferior bulbi.

Der letzte Teil des Neurocranium, welcher ror dem bisher beschriebenen cerebralen Abschnitte sich anschliesst, soll als Rostrum bezeichnet werden. Dic Orbitonasalplatte ist zu einer massiven, sagittal gestellten langen Knorpelplatte ausgewachsen; diese Platte nimmt gegen das Kopfende an Dickenund Höhendurchmesser ab, sie endet in der Höhe des vorderen Nasensackendes und damit zugleich des vorderen Endes der Mundspalte. Der vor dem Knorpel noch verblcibende Teil des Kopfendes ist der von den letzten Resten der Saugnäpfe bedeckte Abschnitt. Von der sagittalen Rostrumplatte, dem Septum rostri, springt jederseits eine breite horizontale Knorpelplatte flügelförmig vor; sie sitzt der ventralen Hälfte des Septum rostri seitlich an. Gegen das Kopfende zu wird die Platte immer schmäler und endet schliesslich kurz vor dem Ende des Septum rostri. Caudalwärts springt die Flatte jederseits mit einem plumpen verdickten Fortsatz neben das Vorderende der Schädelseitenwand vor. An der rechten Seite des Modelles ist die Spitze dieses Fortsatzes mit der Schädelseitenwand verwachsen, auf der linken Seite ist eine Verwachsung nicht eingetreten. Die ganze horizontale flügelförmige Platte wird von 
W. K. Parker (1882) als Cornu trabeculare bezeichnet. Auf diesem „Cornu trabeculare" liegt der Nervus olfactorius auf seinem Wege vom Foramen olfactorium evehens zum Nasensack; mit ihm verlaufen einige Blutgefässe.

Splanchnocranium. Der Kieferbogen ist sehr stark rostral ausgewachsen, entsprechend der Verlängerung des ganzen Vorderkopfgebietes. Das P a la to qu a d r a t u m tritt caudal mit dem Zungenbeinbogen in Verbindung in ähnlicher Weise wie im vorigen Stadium, ausserdem hat es aber am Neurocranium für sein rostrales und caudales Ende feste Stützpunkte gewonnen. Die Pars quadrata und palatina, welche sich wieder unterscheiden lassen, zeigen in den allgemeinen Beziehungen das gleiche Verhalten wie im jüngeren Stadium. Nur ist insofern eine gewisse Veränderung eingetreten, als der vordere Rand der Pars quadrata sich jetzt am Neurocranium rostralwïrts weiter vorgeschoben hat bis in die Höhe des vorderen Bulbusrandes. Es ist demnach die Pars quadrata relativ stärker in die Länge gewachsen als der entsprechende Teil des Neurocranium. Caudal endet die Pars quadrata mit einem kurzen Fortsatz, der ventral vom Processus basipterygoideus sich an die Pars symplectica der Hyomandibel anlegt. Kurz davor legt sich der dorsale etwas verdickte Rand der Pars quadrata an die ventrale Fläche und den rostralen Rand des Processus basipterygoideus. Diese feste Anlagerung ist erst ganz kürzlich entstanden. I $m$ Stadium IV bestand hier nur eine aus verdichtetem Zellgewebe gebildete Verbindung der Pars quadrata palatoquadrati mit dem Schädelboden. Serien, welche zwischen den Stadien IV und $V$ stehen, zeigen, dass später hier Jungknorpel die Pars quadrata mit dem auswachsenden Processus basipterygoideus verbindet. Jetzt ist schon ein schmaler Gelenkspalt zwischen den beiden Skeletteilen in Bildung begriffen.

Die Pars palatina palatoquadrati ist $\mathrm{zu}$ einem langen Knorpelstab ausgewachsen, welcher den Rand der Orbitonasal- 
platte und weiterhin dem Cornu trabeculare dicht anliegt; er endet zugespitzt etwa an der Cirenze von hinterer und rorderer Rostrumbälfte. Die Pars palatina ist am knde durch festes Bindegewebe mit dem Cornu trabeculare verbunden.

Das Hinterende der M a n d i bel, wolches zu einem Cielenkkopf verdickt der Pars quadrata palatoquadrati sich anlegt, ist mil dieser rostralwärts vorgeschohen, sodass das Kiefergelenk jetzt rentral ror dem Bulbus liegt. Die Bildung des Kiefergelenkspaltes ist cingeleitet, vielfach geht aber noch das Perichondrium der Mandibel direkt in das des Palatoquadratum über. Vom Gelenkende der Mandibel springt ein kurzer Fortsatz dorsorostral vor, welcher Lnterkiefermuskeln zum Ansatz dient. Die beiden Mandibeln stossen in der Höhe der Rostrumspitze aufeinander und sind hier miteinander verwachsen.

Dic H y om a n d b e l hat nur an Grösse zugenommen, ihro Form und Lage aber beibehalten. Mit der Ohrkapsel ist die Hyomandibel noch zum grössten Teile verwachsen; die spïteren Grenzen der beiden aneinander stossenden Skeletteile sind zwar schon zu erkennen, es rerbindet sie aber noch ein zellreicher hyaliner Knorpel. Eine Fossa hyomandibularis der Ohrkapselseitenwand, wie sie oben beschrieben wurde, ist nur so zu verstehen, dass der hyaline Knorpel der Ohrkapselwand hier in den zellreichen Verbindungsknorpel äbẹrgeht in der Weise, dass er eine Gelenkpfanne erkennen lässt, wenn man den Verbindungsknorpel sich fortgenommen denkt. Es' beginnt von rostral und caudal her sich Bindegewebe an den Verbindungs. knorpel cinzuschieben, und damit die Absetzung der Hyomandibel von der Labyrinthwand einzuleiten. Der rostrale Fortsatz der Hyomandibel, welcher die Verbindung zum Kieferbogen vermittelt, schiebt sich als schmaler Knorpelstab am ventralen Rande der Pars quadrata palatoquadrati weit entlang. Trotz der schweren Bedenken, die G a up p (1905) gegen die bisher gebräuchliche Nomenklatur cingewendet hat, will 
ich den Fortsatz doch als Processus symplecticus bezeichnen, da eine neue Benennung der hyomandibularen Knorpelabschnitte und Verknöcherungen mit Erfolg erst eingeführt werden kann, wenn ein grösseres Material vergleichend-embryologisch untersucht ist.

Der ventrale Teil des Hyalbogens gliedert sich in Interhyale, Koratohyale und Hy phy ale, die sich ingleicher Weise wio in jüngeren Stadium verhalten. Die einzehen Knorpelstücke sind gut roneinander abzugrenzen, hängen aber noch synchondrotisch zusammen.

Die vier ersten Kiemenskelethogen lassen jetzt eine Gliederung in Hypo-, Kerato- und Epibranchiale erkennen. Die Hypo- und Keratobrauchialia bilden den ventralen Teil der Kiemenskeletbogen, der ron dem Mundhöhlenboden dorsocaudal. und lateralwïrts ansteigt. Die Epibranchialia hiegen nach dorsorostral zurück; ihre Enden liegen im Dach der Mundhöhle und sind zum Teil zu grösseren Platten verbreitert. Dieser letzte Abschnitt muss als das noch nicht abgegliederte Pharyngobranchiale angesprochen werden. Nur am vierten Bogen sind Epi- und Pharyngobranchiale schon gegeneinander abzugrenzen. Die dorsalen Enden der Kiemenskeletbögen endigen frei im Mundhöhlendache; sie werden durch die hier gelegene Muskulatur fixiert. Der fünfte Kiemenskeletbogen ist zu einem ungegliederten Knorpelstab ausgewachsen, der dem ventralen Teil der rorderen Bögen homodynam ist (van Wijhe [1882]). Das lange Basibranchiale zieht von den Hypohyalia, denen es ventral anliegt, bis an das ventrale Ende des Branchiale V. Eine Gliederung in mehrere Abschnitte ist nicht zu erkennen. Die einzelnen Elemente eines jeden Kiemenskeletbogens sind zwar in der eben beschriebenen Weise gegeneinander abzugrenzen, sie sind aber noch durch zellreiches hyalines Knorpelgewebe synchondrotisch verbunden. Ebenso sind die Hypobranchialia mit dem Basibranchiale, dieses 
wiederum mit den Hypohyalia verbunden. Es ist noch nirgends zur bindegewebigen Tremung, geschweige denn zur Gelenkbildung gekommen.

Die Bildung der Deckknochen ist in den ersten Anfängen deutlich zu crkennen; irgendwelche Bedentung für das Kopfskelet als solches haben die feinen Knochenstückchen noch nicht gewomen. Von ihrer Beschreibung sehe ich deshalb hier ab. Von Ersatzrerknöcherung sind noch nicht di: geringsten Andeutungen erkennbar.

II. Abschnitt.

\section{Zusammenfassung und Diskussion der Befunde.}

\section{Theoretische Vorbemerkungen.}

Eho ich in eine Besprechung der Einzelbefunde eingehe, möchte ich in den Hauptzügen kurz darlegen, wie sich meines Erachtens auf Grund der vorliegenden neueren Cintersuchungen die Lehre vom Kopfe der Wirbeltiere darstellt. Dann erst werde ich die Resultate meiner Untersuchungen anschliessen können.

In den berühmten Arbeiten über den Kopf der Selachier $(1871,1872)$, sowie erneut in der Abhandlung über die Metamerie des Kopfes (1887) hat C. Gegen baur seine Lehre von der Segmentation des Kopfes der Wirbeltiere dargelegt, rorwiegend fussend auf Befunden bei erwachsenen Tieren. Van Wijhe (1882) gab die erste Darstellung der Entwickelung des Kopfes der Selachier, welche auf den Anschauungen Gegen baur's aufgebaut war und für sie eine der wichtigsten Stützen wurde. Seither sind zahllose Arbeiten erschienen, welche die Theorie 
von Gegenbaur weiter stützten und ergänzten. Die ausführlichste Darstellung über den Weg, welchen diese theoretischen Anschauungen genommen haben, findet sich in der Arbeit von M. F ü r b r in ger über die spinooccipitalen Nerven der Selachier (1897) ${ }^{1}$ ) und den zusammenfassenden Arbeiten ron E. G a up p $\left.(1898,1905)^{1}\right)$. F ür b r inger's Ausführungen gipfeln in folgendem: Frühzeitig in der Ascendentenreihe der Wirbeltiere kam es unter dem Einfluss der Entwickelung der Kopfsinnesorgane (Nase, Auge, Ohr) und der Kopfdarmorgane (Mund, Kiemen) zur Bildung eines Urkopfes am Vorderende des Körpers aus den vordersten primitiven Metameren. Dieser Kopt war demnach prinzipiell segmentiert gebaut. Unter Rückbildung caudaler Metamere konzentriert sich dieser Urkopf zum einheitlichen Paläocranium, welches mit der Ohrkapsel abschliesst. Niun wuchern Rumpfmetamere in das caudale Gebiet des Kopfes ein und erobern sich durch Verdrängung paläo. cranialer Muskeln paläocraniale Skeletteile (Kiemenbogen); so wird ein neuer Teil dem Paläocranium angegliedert: protometameres Neocranium. Schliesslich werden ganze Rumpfmetamerc mit Muskein und Skelet dem Kopf assimiliert: auximetameres Neocranium.

Seither ist durch zahlreiche embryologische and vergleichend-anatomische Intersuchungen eine grosse Reihe von Tatsacher zu unserer Kenntnis gebracht worden. Es erscheint mir nunmehr möglich, fussend auf den neu aufgedeckten Tatsachen der Ontogenie und vergleichenden Anatomie die Kopftheorie, wie sie auf der Basis der Gegenbaur'schen Auffassungen weiter ausgebildet ist, zu erweitern und in einigen prinzipiellen Punkten zu modifizieren. Ich werde an diesem Orte die Literatur, welche hierüber handelt, nicht im einzelnen referieren, sondern die mir wichtig erscheinenden prinzipiellen

1) Dort befindet sich auch ein ausführliches Literaturverzeichnis über die hier behandelten Fragen. 
Punkte hervorheben. Bahnbrechend sind in erster Linie die Arbeiten ron 1. Froxiep (1882-.. 1902). Auf Grund seiner Untersuchungen über die Entwickelung des Hinterkopfes der Wirbeltiere hat Froriep schon seit längerer Zeit versucht, die Lehre vom Kopf der.Wirbeltiere zu vertiefen. Vornehmlich seine Abhandlung über die Entwickelung des Kopfes von Torpedo ocellata (1902) dient mir zum Ausgangspunkt für die folgenden Betrachtungen. Die Hauptbefunde dieser Arbeit müssen daher hier kurz angeführt werden. Bei einem Torpedo von $1,8 \mathrm{~mm}$ Gesamtlänge ist in der ganzen Länge des Tieres jederseits meben der am vorderen Ende verjüngten, spezifisch differenzierten Chorda dorsalis die Reihe der Somite gelegen. Die Somite nehmen rostralwärts sukzessive an Grösse ab. Die Darmhöhle endet ebenfalls in der Höhe der Spitze der spezifisch differenzierten Chorda. Vor dem Ende des Darmes biegt als Verlüngerung der spezifisch differenzierten Chorda ein Zellstrang aus lockeren Zellklumpen ventralwärts um. Dort liegt neben und vor diesem Zellstrang ein unsegmentierter Mesoblastbezirk, welchen ich kurz als Endmesoblast bezeichnen möchte. F r o r i e p nennt den kurzen Bezirk, welcher Endmesoblast und den als hinfällige Chorda gedeuteten Zellstrang enthält, den präspinalen (branchialen, caduci-chordaten) Bezirk und stellt ihn scharf dem übrigen spinalen Bezirk gegenüber. Der präspinale Bezirk wächst nun mächtig aus, in seinem Bèreich entwickelt die Medullarplatte Mittelhirn und Vorderhirn, in seinem Bereich treten die Kiemenspalten auf, in seinem Bereich entstehen die Kopfsinnesorgane, Auge und Nase. Dieser präspinale Bezirk dehnt sich nicht nur rostralwärts aus, sondern auch in erheblichem Masse caudalwärts; dabei verdrängt der Endmesoblast die spinalen Somite, welche in parachordales Mesenchym. gewebe aufgelöst werden, während die Spinalnerven durch die Kopfganglienleiste zerstört werden. Besonders schiebt sich ventral durch sukzessive rostrocaudale Neubildung ron Kiemen- 
spalten mit diesen der ventrale Teil des Endmesoblastes candalwärts weit vor, die spinalen Seitenplatten verdrängend, während der dorsale Teil des Endmesoblastes durch die spinalen Somite relativ etwas zurückgehalten wird und hier zunächst nur die Kopfganglienleiste entsprechend den Kiemenspalten sich gegen die spinale Ganglienleiste rordrängt. Es werden so ventral die spinalen Seitenplatten bis auf kleine Reste auf weite Strecken hin zerstört, es werden die spinalen Nerven in entsprechendem Gebiet: fast völlig vernichtet, sodass nur einige wenige Nervenstränge übrig bleiben, die zu den Resten der Seitenplatten herabtreten, es werden die rostralen spinalen Somite direkt zersprengt, die folgenden erst von Nerven entblösst, um später in Mesenchym zu zerfallen. Von diesem ganzen betroffenen spinalen Bezirk des rostralen Körperendes bleibt nur die Chorda unveründert erhalten; ihrer bemächtigen sich die eingedrungenen präspinalen Massen und erhalten so erst eine feste Stütze zur Anlagerung. So entsteht bei Torpedo ocellata der Kopf, und hierin glaubt Froriep wohl mit Recht ein Abbild der phylogenetischen Entstehung des Kopfes der Wirbeltiere zu erkennen. Die Quintessenz seiner Anschauung ist folgende: In dem primär ausserordentlich kleinen präspinalen Bezirk ${ }^{1}$ ) entwickeln sich Kiemenspalten und Kopfsinnesorgane und als deren Folge vergrösserł sich hier das Centralnervensystem zum Gehirn. Dieser präspinale Bezirk wächst dabei rostral- und caudalwärts aus, er vernichtet den Mesoblast und die Nerven des rostralen spinalen Bezirkes und vereinigt sich mit Resten dieser und mit der erhalten gebliebenen Chorda zum Paläocranium.

Diese Anschauungen führen zu wichtigen Konsequenzen in der Lehre des Baues des Wirbeltierkopfes. Die so zahlreich unternommenen Versuche, eine Metamerie des bis dahin meist prächordal benannten Kopfbezirkes zu erweisen, haben sämt-

1) Über die ancestrale Bedeutung des Endmesablastes s. Froriep, Anatom. Anz. Bd. 21. 1902. 
lich kein völlig befriedigendes Resultat ergeben. So wie die spinale Neuromerie allgemein als eine Folge aufgefasst wird der Myomerie der mesodermalen Leibeswandung, so ist nunmehr die Anordnung der branchialen Kopfnerven als eine Folge der Branchiomerie zu deuten, welche mit der spinalen Metamerie nichts zu tun hat, vielmehr eine Bildung sui generis ist. Es ist bei der Frage der Branchiomerie vollkommen abzusehen von den Befunden bei Amphioxus; es bricht sich auch sonst. ganz allgemein die Überzeugung immer mehr Bahn, dass Amphioxus als Nicht-Vertebrat in nur sehr beschränktem Masse und nur bei ganz allgemeinen Problemen in der vergleichenden Morphologie der Wirbeltiere zu verwerten ist. Offen bleibt hier die Frage der Phylogenese der Augenmuskulatur, ein Problem, das auch bisher nicht in befriedigender Woise gelöst werden konnte.

Nur bei einer Klasse der Vertebraten, den Cyclostomen, befindet sich der Kopf zur Jetztzeit im wesentlichen auf dem hier beschriebenen Stadium des Paläocranium. Die Erklärung der Erscheinungen des Neocranium hat bisher der vergleichenden Forschung erhebliche Schwierigkeiten bereitet. Es musste eine Assimilation ron Wirbeln angenommen werden mit folgender oder rorangegangener Rückbildung spinaler Muskeln. Fs wurde die Ausdehnung eines Deckknochens, des Parabasale, benutzt, um eine Immobilisierung von Wirbeln zu erklären. Alle dies: Hilfshypothesen scheinen mir nun nicht mehr die ausschlaggebende Bedeutung zu besitzen.

Ich halte es jetzt für möglich, durch logischen Ausbau der Anschauungen von Froriep dic Erscheinungen des sogenannten Neocranium zu erklären, wie sie in Ontogenie und ausgebiidetem Zustande uns entgegentreten. Der Prozess des Auswachsens des präspinalen Bezirkes und seiner Vereinigung mit den Resten des zerstörten rostralen Endes des spinalen Bezirkes, welcher bei Cyclostomen zum bisher als Paläocranium 
bezeichneten Kopf geführt hat, ist bei den übrigen Formen fortgeschritten. Als Ersache für dieses fortgesetzte rostralwärts gerichtete Auswachsen kormt in Betracht die weitergehende Differenzierung der Kopfsinnesorgane und Kopfdarmorgane, die Ausbildung der rostralen Spitze als Wellenbrecher bei wasserlebenden Formen, sowic besonders die in stetem Fortgang begriffene Differenzicrung des Hirnes. Denn während die Kopfsinnesorgane bald eineı sehr vollkommenen Grad der Ausbildung crreicht haben, zeigt das Hirn eine stets fortschreitende Differenzicrung, um die ihm ron den hochpotenzierten Sinnesorganen zukommenden Reize der Aussenwelt in stets vollkommener Weise verwerten zu können. Je weiter nun der präspinale Bezirk caudalwärts gelangt, desto mehr Reste der unter Zerstörung einverleibten spinalen Segmente werden erhalten bleiben, da diese, bis der präspinale Bezirk an sie gelangt, schon weitergehend differenziert sind und nicht mehr einfach in Mesenchymgewebe ruckgebildet werdon können. So erklärt sich die Erscheinung, dass im Hinterkopf dann deutlichere Reste dieser einbezogenen, teilweise zersprengten spinalen Elemente erkennbar sind. In der gleichen Weise glaube ich auch erklären zu kömnen, dass schliesslich ganze spinale Skeletwirbel, noch anfangs ontogenetisch als solche nachweisbar, dem Cranium vollkommen zugefügt werden. Für diesen letzteren Prozess kommt besonders eine Erscheinung in Frage, die vorher schon bei Torpedo erwähnt wurde, das besonders weitgehende Vorrücken des ventralen, Kiemenspalten enthaltenden Gebietes, das wohl auf eine spezielle Entfaltung des MundKieferapparates zurückgeführt werden kann. Hierdurch wird ventrale spinale Muskulatur zersprengt und eine partielle Immobilisierung des dorsalen Gebietes eingeleitet, die dann leichter in volle Assimilation übergehen kann.

Es kommt aber für die fortschreitende Assimilation spinaler Gebiete an das Cranium noch ein anderes sehr wichtiges Moment 
hinzu. Es ist eine allgemein verbreitete Erscheinung, ein sogenanntes Entwickelungsgesetz, dass wichtige Organe die Tendenz zeigen, in der Ontogenese möglichst frühzeitig aufzutreten. Das gleiche sehen wir auch am Kopf; wir sehen, dass, je höher in der Vertebraten-Reihe wir gelangen, um so früher Hirn- und Kopfsinnesorgane sich anlegen. Dadurch wird dem präspinalen Bezirke die Zersprengung und Assimilation spinaler Teile noch mehr erleichtert. Han pflegt nun meisthin solche Verschiebungen des zeitlichen Iuftretens von Organen in der Ontogenese als cänogenetische Vorgänge zu deuten, denen weitere prinzipielle Bedeutung nicht zukommt. Es wird sich aber bei weiterem Ausbau der hier erörterten Anschaungen als notwendig herausstellen, den Begriff Cänogenese sehr einzuschränken, hier ist er jedenfalls durchaus nicht anwendbar. So wahr es ist, dass eine grosse Reihe ontogenetischer Erscheinungen nur im Lichte der Phylogenie zu verstehen sind, was den Hauptinhalt des biogenetischen Cirundgesetzes ausmacht, so wahr scheint es mir auch, dass eine grosse Reihe sogenannter cänogenetischer Verschiebungen neue phylogenetische Veränderungen einleiten. Man war bisher gewohnt, die Ontogenie in der vergleichenden Anatomie nur zu verwerten, um postulierte phylogenetische Veründerungen zu demonstrieren. Ich möchte jetzt einen schritt weiter gehen: Die phylogenetischen Veränderungen beginnen in der Ontogenese des Individuums, zum Teil unter dem Bilde zeitlicher Verschiebungen im Auftreten der Organe. Die Ontogenie ist also nicht nut eine kurz rekapitulierte Phylogenie, sondern selbst in weitem Masse geradezı die Urrsache der Veränderungen der Art. Es liegen schon jetzt Tatsachen in der Literatur festgelegt vor, die diese Anschanung erläutern und festigen. Lm ein Beispiel aus der Lehre des Kopfskelets herauszugreifen: Sewertzoff (1899) hat nachgewiesen, dass die für den Schädel des erwachsenen 
Acanthias charakteristische Sattellehne und Basalecke einfach eine Folge daron ist, dass die Parachordalia und Trabeculae auftreten zu einer Zeit, wo dic Mittelhirnbeuge voll ausgeprägt ist, dass daher die Knorpel in der ersten Anlage senkrecht zueinander stehen und so sich rereinigen. Diesem Beispiele liessen sich weitere anfügen und besonders wird dies in reichem Masse möglich werden, wenn erst eimmal genauer auf solche Erscheinungen geachtet wird. Zur Demonstration des Prinzips genügt mir dies eine Beispiel.

In der bisherigen Kopftheorie wird nun seit $\$$ agemehl (1884-1891) untersehieden zwischen protometamerem und auximetamerem Neocranium. Diese Unterscheidung ist auch nach F ürbring e r (1897), welcher in erster Linic in neuerer Zeit sie vertritt, nicht prinzipieller Natur; ich halte sie für nicht mehr möglich. Wenn Fürbringer selbst sagt, dass er als Cirenze des protometameren gegen das auximetamere Neocranium bei Ganoiden nur findet, dass die Austrittsstelle der dorsalen Wurzel des crsten zweiwurzeligen spinooccipitalen Nerven bei Polyodon am Schädel durch ein partielles Ligament markiert ist, dass er deshalb diesen Nerven als a bezeichnet, so geht schon daraus hervor, dass die Grenze nur sehr unsicher bestimmbar ist. Diese Trennung wird meines Erachtens unmöglich, seit R os e n be r g's (1886) Befund, dass bei Mustelus und Carcharias ein als frcicr Wirbel nachweisbares Segment dem Cranium assimiliert wird, erweitert ist durch C. K. H off mann, Sewertzoff und van Wijhe. C. K. Hoffmann (1894) zeigte, dass bei Acanthias ein Rumpfsomit mehr als bei Scyllium dem Cranium angefügt wird. Van Wijhe (1905) bestätigt diesen Befund und glaubt ausserdem nachweisen zu können, dass bei Heptanchus zwei Wirbel dem Schädel assimiliert werden. Sewertz off (1898) findet selbst, dass bei Torpedo vier Somite mehr als bei Pristiurus in den Kopf einbezogen werden. Aus diesen und ähnlichen Befunden bei 
Ganoiden und Teleostiern scheint mir zu folgen, dass die Grenze von Schädel und Wirbèlsäule noch jetzt eine fliessende ist bei Selachiern, Ganoiden und Teleostiern. IIier ist es noch nicht zu einer scharfen definitiven Absetzung von Schädel und Wirbelsäule oder Kopf und Rumpf gekommen. Es ist dies ein primitives Merkmal der kiemenatmenden Wirbeltiere. Besonders wichtig ist mir der Befund van $\mathrm{W}$ ijho's bei den Notidaniden. Gewöhnlich werden diese Selachier als die primitivsten Formen hingestellt, auf die stets bei phylogenetischen Fragen zurückzugreifen ist. Ihre vermehrte Kiemenzahl kann aber nach den oben gegebenen allgemeinen Betrachtungen der Craniogenese, welche eine Anlage der Kiemen in rostrocaudaler Reihe zeigt, nicht mehr ohne weiteres in diesem sime gedeutet werden. Zwar hat van Bemmelen (1886) zu beweisen versucht, dass die Suprapericardialkörper pentancher Haie als Reste zu Cirunde gegangener Kiemenspalten aufzulassen sind und damit die pentanchen Haie ron Formen mit einer grösseren Zahl von Kiemenspalten alyzuleiten seien, er gibt aber selbst zu, dass seine Deutung der Suprapericardialkörper sehr unsicher ist. Andere Befunde, welche darauf hinweisen, dass die Kiemenspaltenzahl der pentanchen Haie früher grösser war, sind, soweit mir bekannt, nirgends erhoben worden. Das Fehlen einer scharfen Abgrenzung der Wirbelsäule gegen den Schädel ist ebenfalls kein den Notidaniden eigentümlicher Charakter; dass gegen die Auffassung der Autostylie des Kieferbogens in der Weise der Notidaniden als primitiv manches einzuwenden ist, werde ich bei der Besprechung meiner speziellen Befunde zu zeigen versuchen.

Wenn man sich zu der Auffassung bekennt, dass dic Grenze von Schädel and Wirbelsäule bei den kiemenatmenden Wirbeltieren noch eine fliessende ist, dann sind auch die so ausserordentlich zahlreichen Tariationen im Auftreten der spinooccipitalen Nerven zu erklären. Die Ausbildung des Kopfes 
hat sich nicht in grauer Torzeit vollzogen, sondern ist noch jetzt vor unseren Augen im Crange. Anders ist es bei den terrestrischen Wirbeltieren. Hier sind im Dienst der Kopfbewegung die ersten freien Wirbel in ganz spezieller Weise differenziert; diese differenzierten Wirbel treten als neue wichtige Teile auch in der Ontogenese früh auf. Hier jst damit der Kopf vom freien Rumpfe scharf getrennt, die Grenze wird nicht mehr so leicht überschritten. Als weiteres Homent, welches in diesem sinne wirkt, konmt die Rückbildung dor Kiemenbogen hinzu, deren starkes Vordringen ein wesentlicher Faktor der Craniogenese war. Vergrösserungen des Schädels erfolgen bei terrestrischen Wirbeltieren durch eigenes Schïdelwachstum, nicht durch Wirbelassimilation. Dass aber prinzipiell die gleichen Vorgänge bei der Craniogenese noch eine Rolle spielen, zeigen die Entersuchungen über die Entwickelung der Occipitalregion der Amnioten (Froriep [1882-1886], van Wijhe [1886], Goron ow itsch $[\mathbf{1 8 8 6}]$ ), sowie das gelegentliche, wem auch seltene Vorkommen gan\%er oder teilweiser Assimilation des ersten freien Wirbels an den Hinterkopf.

Diese hier auseinandergesetzten Anschanumgen beruhen in allen wesentlichen Punkten auf in der Literatur festgelegten, tatsächlichen Befunden, in erster Linie der Ontogenese. Es ist mir aber auch keine Erscheinung der vergleichenden Inatomie des erwachsenen Tieres bekannt, die ihr prinzipiell entgegenstände.

Ich habe diese Erörterungen der Einzeldiskussion meiner Befunde rorangestellt, weil eine Deutung meiner eigenen Befunde auf einer anderen Basis mir unmöglich war. Es war mein Bestreben, unter Vermeidung ron einem weitgehenden Eingehen auf Einzelheiten die prinzipiellen Gesichtspunkte scharl hervorzuheben. In einer besonderen Abhandlung, die ich innerhalb nicht zu langer Frist abzuschliessen hoffe, will ich dann genauer darzulegen versuchen, in welcher Weise die 
bisherige Lehre der Metamerie des Kopfes der Vertebraten bei den einzelnen Klassen modifizieri werden muss. Sollte der Grundsatz, dass ontogenetische Prozesse die Lrsache von Veränderungen der Art, also phylogenetischer Prozesse, sein können, sich Geltung verschaffen, so scheint er mir von gewissem Wert zu sein für kommende Untersuchungen. Es gewinnen damn die Befunde der experimentellen embryologischen Forschung, sowie C̈berlegungen, in welcher Weise funktionelle Einflüsse aluf Organe, die in der Ontogenese frühzeitig auftreten, einwirken können, für die allgemeine Morphologie sehr erheblich an Bedeutung. In späteren Intersuchungen wird es meine Aufgabe sein müssen, die hier niedergelegten Inschauungen zu stützen und zu erweitern.

\section{Die Eutwickelung des Primordialcraniun.}

Erste Schädelanlage. Die Anlage des Kopfskelets eilt den skeletbildungen des übrigen Körpers zeitlich voraus. Im Kopfe selbst legt sich wiederum das Neurocranium frïher an als das Splanchnocranium. Diese zeitliche Reihenfolge der Skeletanlagen ist charakteristisch für die Vertebraten im allgemeinen. Denn bej den Formen, welche das Visceralskelet zeitlich vor dem Neurocranium anlegen (Amphibien), ist dies als eine Anpassung an das Jarvenleben erkannt worden. Die erste Schädelanlage ron Lepidosteus osseus schliesst sich eng an die der Selachier an, wie sich aus den Untersuchungen von Sewertzoff (1899) und ran Wijhe (1905) ergibt. Zwischen den Trabekch und Parachordalia, die als erste Grundlage des Neurocranium bei allen Wirbeltieren erkannt sind, tritt in der Höbe der Chordaspitze ein kleiner Knorpel auf, welchen ich nach van Wijhe als Polknorpel bezeichnen möchte. V an Wijhe (1905) fand, dass die erste Anlage des Schädels bei Acanthias in gleicher Weise sich vollzicht. Die Ohrkapsel ist 
schon bei ibrem ersten Auftreten an der Stelle der Commissura basicapsularis anterior in kontinuierlichem Zusammenhange mit den Parachordalia in sehr ähnlicher Weise wie bei Icanthias (Sewertzoff [1899]). Ich möchte aber kein entscheidendes Gewicht legen auf diese Unterschiede gegenüber dem Verhalten bei Teleostiern und terrestrischen Formen. Bei diesen ist ein Polknorpel bisher nicht beobachtet worden, die Ohrkapsel entsteht als isolierte Knorpelschale am lateralen Lmfang des Labyrinthorganes. Es erscheint mir durchaus nicht ummöglich, dass auch bei manchen Teleostiern sich an der Grenze von Trabekel und Parachordale ein isolierter Polknorpel zunächst anlegt. Es ist klar, dass eine Knorpelspange von der immerhin beträichtlichen Länge der Trabekel nicht auf eimmal in ganzer Ausdehnung verknorpelt; welche Teile nun bei der Verknorpelung zunächst bevorzugt werden, has scheint mir ron manchen mehr zufälligen Momenten abhängen zu können. So möchte ich darauf hinweisen, dass bei Lepidosteus am Polknorpel die Anlage des Rectus lateralis bulbi sich findet. Es ist durchaus möglich, wenn auch natürlich nicht lirekt zu erweisen, dass diese Organanlage bei ihrem Wachstume dje Veranlassung wird, dass die Stelle des Schädelbasisknorpels, dem sie anliegt, ein wenig frühzeitiger wie ihre nächste ITgebung der Verknorpelung anheimfällt. Ob die vorderen Parachordalia von Petromyzon (Sewertzoff [1897, 1899]) mit den Polknorpeln homologisiert werden können, jst mir aus den vorliegenden Beschreibungen nicht völlig klar geworden. Es ist vielleicht auch möglich, in ähnlicher Weise die frühzeitige Verknorpelung der Commissura basicapsularis anterior verständlich erscheinen zu lassen. Denn hier liegen die grossen Ganglien des Ophthalmicus lateralis, Facialis und Acusticus der Commissur auf. Es ist immerhin denkbar, dass der Druck dieser Ganglienmassen bei ihrer Vergrösserung cinen gewissen Einfluss im Simne der Beschleunigung auf den bei allen Formen 
hier später erfolgenden Verknorpehngsprozess ausübt. Ich möchte zwar nicht sagen, dass auf die hier erwähnten Momente die Abweichungen der crsten Skeletanlage gegenüber den Teleostiern und Amphibien allein und ohne weiteres zurückzuführen sind, sondern mehr nur dimit ausdrücken, dass ich nicht die Uberzeugung gewomen habe, dass der Erscheinung des Polknorpels und des primïren Zusammenhanges ron Ohrkipsel mit Parachordale eine sehr grosse prinzipielle Bedeutung in morphologischer Hinsicht zukommt. Ich glaube nicht, dass der Polknorpel als besonderes primordiales Skeletelement anzusehen ist, ebensowenig wic in der Frage, ob die Ohrkapsel von Haus aus eine selbständige Sinneskapsel ist, rorläufig etwas geändert wird durch den Nachweis des primären Zusammenhanges mit der Schädelbasis bei cinigen Formen. Weiterhin vollzieht sich die Entwickelung des Primordialeraniums in Bahnen, welche vielfache Anklïnge an Teleostier und Selachier zeigen, wio dies bei der Stellung des Lepidosteus im System auch nicht weiter auffallen kann.

Der Besprechung lege ich die Regioneneinteilung zugrunde.

Labyrinthregion. Die weitere Differenzierma der Labyrinthregion wird vollkommen beherrseht von der dusbildung der Ohrkapsel. Dic Bodenplatte bleibt in wesentlichen auf dem Anfangszustand bestehen. Sic wird gebildet von Chorda und Parachordalia. Eine geschlossene Bodenplatte entsteht nur in dem caudalen Teile der Labyrinthregion; denn die Parachordalia ziehen als gerade Knorpelspangen rostralwärts weiter und entfernen sich dadurch von der Chorda, welche sich allmählich verjüngt und den Raum zwischen den beiden Parachordalia nicht mehr völlig ausfüllt. So entsteht der hintere Abschnitt der grossen Fenestra basicranialis, welche hier zunächst durch die Chordaspitze in zwei symmetrische Hälften zerlegt wird. Dic geschlossene Bodenplatte bleibt bei der weiteren Entwickelung im Wachstum etwas zurück, sodass 
ihr rostraler Rand, weleher anfangs noch in gleicher Höhe mit der Commissura basicapsularis anterior sich findet, relatir etwas caudalwärts verlagert erscheint, $d . h$. mit anderen Worten, die Seitenwand der Labyrinthregion schiebt sich an der Bodenplatte rostralwärts vor. Interessant ist das Verhalten der Chorda dorsalis: sie bleibt im Wachstum fast stehen, sodass im Stadium $V$ das Stück, welches in die Fenestra basicranialis vorragt, fast ebenso lang ist wie im Stadium III. Eine alssolute Rückbildung liess sich nicht nachweisen. Die Chorda wird im caudalen Teile der Labyrinthregion von den Parachordalia ventral umwachsen, sodass sie hier auf einem Knorpelhoden aufruht. Diese Knorpelunterwachsung der Chorda breitet sich nach ihrem ersten Auftreten wohl caudalwiirts auf die Occipitilregion, aber nicht rostralwärts weiter aus. Auf diesem so entstandenen Zustande bleibt dio Bodenplatte der Labyrinthregion sehr lange Zeit bestehen. Selbst bei dem früher beschriebenen jungen Tiere von $15 \mathrm{~cm}$ Gesamtlänge fanden sich noch im wesentlichen die gleichen Verh:̈ltnisse. Es lag die Chorda im caudalen Teil der Labyrinthregion in einer Rinne auf den vereinigten Parachordalia frei auf, wurde dann etwa in derselben Höhe wie bei dem jetzt beschriebenen Tiere ron $20 \mathrm{~mm}$ (Stadium $\mathrm{V}$ ) auch ventral frei, endete aber sehr bald und erreichte nicht mehr die Fenestra basicranialis, da inzwischen ihr rostrales Ende rückgebildet war. Als einzige Erscheinung, die in der langen Entwickelungszeit neu aufgetreten war, ist die Bildung einer Knorpelplatte dorsal auf dem Saccus vasculosus zu erwähnen.

Komplizierter sind die Entwickelungsvorgänge der Ohrkapsel, welche sehr rasch sich vervollstindigt und im ganzen sich vergrössert. Zunächst wird das Labyrinthorgan lateral, sowie am dorsalen und caudalen Pole von Knorpel umwachsen; von dieser lateralen Ohrkapselwand und der rostralen und caudalen Kapselkuppel schreitet die Differenzierung rasch vor- 
wärts. Auffallen muss bei dem so frühzeitigen Auftreten der Commissura basicapsularis anterior, dass relativ spät erst dee caudale Teil der Ohrkapsel sich mit dem Schädelboden verbindet, dass es dabei nicht zur Entwickelung einer isolierten Commissura basicapsularis posterior und zur Bildung einer Fenestra basicapsularis kommt, wie es sonst so verbreitet in der Reihe der Wirbeltiere ist. Eine Erklärung für dieses eigentümliche Verhalten scheint mir der Glossopharyngeus zu geben. Dieser Nerv liegt ron Anfang an dem caudalen Pol des Sacculus und mit seinem Ganglion ventral dem Sacculus an. Eine Commissura basicapsularis posterior müsste so entstehen, dass die Ohrkapselanlage sich dorsal über den Nerr wegschiebt und caudal ron ihm sich mit dem Parachordale verbindet. Nun dehnt sich das Labyrinth rasch caudalwärts aus, aber auch der Glossopharyngeus wird infolge der Verschiebung des Kiemenbogengebietes zu einem stark caudalwärts gerichteten Verlaufe seines Stammes gezwungen. In der Ausdehnung und Verschiebung des Labyrinthes caudalwärts kann eine Lrsache für das Lnterbleiben der Bildung einer Commissura basicapsularis posterior nicht wohl gesehen werden: das Labyrinthorgan wird sehr frühzeitig ron der caudalen Ohrkapselkuppel umgriffen. Der Glossopharyngeus wird aber dadurch, dass er sich jeweils über die Stellen wegschiebt, an welchen die Commissura basicapsularis posterior hätte entstehen müssen, die Bildung dieser Knorpelverbindung verzögern. So tritt eine Vereinigung der Ohrkapsel mit der Schädelbasis in diesem Gebiete fast gleichzeitig ventral um den Sacculus herum und an der hinteren Ohrkapselkuppel ein, sodass eine Fenestra basicapsularis gar nicht in Erscheinung tritt. Dic Bildung des Tectum synoticum, das Überwachsen des Vagusaustrittes durch Vorschieben des caudalen Ohrkapselpoles bis zur Vereinigung mit der occipitalen Seitenwand erfolgt in einer Weise, wie sie durch Lntersuchungen an Teleostiern bekannt ist. 
Die rostrale Ohrkapselkuppel verbindet sich im Bogen $\mathrm{mm}$ die Ganglien des Trigeminofacialiskomplexes herum mit der Schädelbasis, sodass ein extracerebraler Schädelraum lür die Ganglien geschaffen wird. Auf die Bedeutung dieser so entstehenden Trigeminofacialiskammer als $Z$ wischenstufe zwischen den Befunden bei Selachiern, bei denen die grossen Ganglien in der Hauptmasse im Orbitawinkel auf dem Orbitalboden liegen, und den Befunden bei manchen Teleostiern (Scomber, All is |1903]) habe ich früher schon hingewiesen (V e it [1907]). Der Boden der Trigminofacialiskammer tritt num schon sehr frühzeitig bei Tieren von $11-12 \mathrm{~mm}$ Gesamtlänge auf, während die Anlage des Processus basipterygoideus, welcher in der Fortsetzung des Schädelbodens liegt, erst später erfolgt. Dadurch wird schon daranf hingewiesen, dass die Ursache für die Entstehung dieser beiden Knorpelplatten nicht die gleiche sein. kann. Der Boden der Trigeminofacialiskammer ist als Verbindung der Ohrkapsel mit dem Schädelboden aufzufassen, wie solche zwischen allen Teilen der Ohrkapsel und dem Schädelboden entsteht. Nur verhindern die grossen Ganglien des Trigeminofacialiskomplexes, dass hier eine direkte Verbindungsplatte entsteht, wie z. B. zwischen caudaler Ohrkapselkuppal und dem entsprechenden Schädelboden.

Bei den Teleostiern und Ganoiden sind die topographischen Beziehungen etwas andere als bei Selachiern. Bei letzteren liegen dic Ganglien des Trigeminofacialiskomplexes ror der rostralen Ohrkapselkuppel, während bei Teleostiern und Ganoiden Ganglien und Ohrkapselkuppel in gleichem Querniveau liegen. Es bleibt dabei hier zunächst unerörtert, ob die Ganglien caudalwärts oder die Ohrkapsel sich rostralwärts verschoben hat; es ist mir wahrscheinlich, dass beide Prozesse nebeneinander hergehen. Jedenfalls beruht auf dieser Veränderung der Topographie die Ausbuchtung des Schädelbodens und der Schädelseitenwand zur Trigeminofacialiskammer. Bei manchen Tele- 
ostiern kommt es nach den Intersuchungen ron $\mathrm{All}$ is (1903) an Scomber scomber noch zur Verknöcherung der Dura mater, welche den Raum der Trigeminofacialiskammer vom (arum cerelorale cranii abschliesst.

Anders liegen die Verhältnisse für den Processus basipterygoideus. Es wurde früher von mir schon dargelegt, dass diese Knorpelplatte auf den Orbitalboden der Selachicr zurückgefühıt werden kann. Für die krältige Entwickelung der Knorpelplatte bei Lepidosteus scheint mir das Palatoquadratum die Trsache abzugeben. Es soll deswegen der Processus basipterygoideus erst bei dem splanchnocranium mithesprochen werden.

Als caudale Cirenze der Labyrinthregion wird entsprechend dem allgemein geübten (iebrauche der Lustritt des Vagus angesehen. Es ist klar, dass die Bestimmung der Grenzen nur einen relativen Wert zur Vergleichung besitzt, da die Labyrinthregion keine morphologische Crösse an sich ist, sondern nur ein zur Erleichterung der Beschreibung und rascheren Verständigung eingeführter konventioneller Begriff. Setzt man als caudale Grenze der Labyrinthregion das hintere Ende des Labyrinthorganes und der Ohrkapsel an, so crgeben die Befunde, dass die Grenze zu verschiedenen Zeiten der Entwicke. lung in rerschiedenem Niveau liegt. Denn das Labyrinthorgan und später auch die Ohrkapsel dehnt sich caudalwärts stärker aus als der entsprechende Teil von Hirn und Schädelbasis, sodass schliesslich der Vagus zum Teil schon ventral unter der caudalen Ohrkapselkuppel liegt. Richtet man sich nur nach den Nerven, so spricht man in solchen Fällen ron einer Ausdehnung der Ohrkapsel in die Occipitalregion. Später wird diese Verschiebung der Ohrkapsel caudalwärts noch deutlicher, indem der Vagus beim jungen Tiere nach den früheren Befunden fast ganz ventral unter der caudalen Ohrkapselkuppel austritt. Als rostrale Grenze der Lahyrinthregion wird die Grenze 
von chordalem und prïchordalem Schädel angesehen. Die Chordaspitze reicht in den jüngsten Stadien bis an die Grenze von Mittel- und Hinterhirn. Nach den Untersuchungen von A. Froriep (1902), der die Entwickelung des Kopfes bei Torpedo von den ersten Anfängen an verfolgt hat, ist es wahrscheinlich, dass bei keinem Vertebrat die echte Chorda in der ersten Anlage vor das Hinterhirn rostralwärts vorragt.

Zur Bestimmung der Grenze von chordalem und prächordalem Schädel kann bis zu einem gewissen Grade neben der Chorda das Hirn und das Labyrinthorgan benutzt werden; denn auch letzteres liegt für. gewöhnlich mit seiner rostralen Kuppe im Niveau der Chordaspitze. Es ist nun von einer gewissen Bedeutung noch andere Momente neben der Chorda zur Grenzbestimmung heranzuziehen, da die Chorda bei vielen Formen ontogenetisch sehr frühzeitig zurückgebildet wird, zum Teil selbst nicht mehr bis an ihr phylogenetisches Ende angelegt zu werden scheint, und deshalb häufig die Grenze von Labyrinth- und Orbitotemporalregion erst sekundär erschlossen werden muss. Lepidosteus osseus zeigt nun in sehr markanter Weise, welche erheblichen Verschiebungen zwischen Seitenwand und Boden und auch noch zwischen lateralen und medianen Bodenabschnitten erfolgen können. Es wurde vorher schon darauf hingewiesen, dass nicht nur die Chorda, sondern auch der ihr anliegende mediale Teil des Schädelbodens im Wachstum zurückbleibt. Es ist durch Vergleiche der einzelnen Entwickelungsstadien sehr leicht, sich davon zu überzeugen, dass die Seitenteile des Bodens und die Schädelseitenwand, die Ohrkapsel, sich im Verhältnis zum mittleren Bodenteil rostralwärts verschieben. Bei der ersten Schädelanlage reicht die Chorda weit vor das rostrale Ende des Labyrinthorganes (Figg. 1, 2, 5) und findet sich am Schädelboden der Austritt des Ramus palatinus facialis rom Hirn zum Mundhöhlendach neben den vorderen Teilen der Parachordalia 
(Figg. 2, 7) noch etwas caudal hinter der Chordaspitze. Nun bleibt die Chorda und der ihr anliegende Teil des Schädelbodens in der Entwickelung ungefähr stehen. Die lateralen Teile des Schädelbodens entwickeln sich mit dem übrigen Kopfskelet weiter und schicben sich damit rostralwärts ror, sodass schon im Stadium IV (Figg. 10, 14) das Foramen palatinum vor der Chordaspitze liegt. In noch stärkerem Grade rückt die Ohrkapsel rostralwärts vor, sodass sie noch vor das Niveau des Foramen palatinum vorstösst. So gestaltet sich die Grenze von Labyrinth- und Orbitotemporalregion etwas kompliziert, indem die Orbitotemporalregion von den lateralen Teilen der Labyrinthregion umgriffen wird, median keiliörmig caudalwärts vorspringt. Dieses keilförmige Vorspringen in den Boden der Labyrinthregion ist nun wohl als Folge des caudalwärts gerichteten Auswachsens des Infundibulum aufufassen, das ein Vorrücken des labyrinthären Schädelbodens hier hemmt. Eine gewisse Verschiebung tritt später insofern noch ein, als, wie aus den früher mitgeteilten Befunden sich ergibt, das Vorrücken der Ohrkapsel bald zum Stillstand kommt, während der laterale Teil des Schädelbodens noch weiter rostralwärts sich vorschiebt; so liegt späterhin das Foramen palatinum wieder vor dem Niveau der rostralen Ohrkapselkuppel. Es ist somit die vordere Grenze der Labyrinthregion in den lateralen Teilen weiter rostral anzusetzen als in den mittleren. Es wurde bei der Einzelbeschreibung schon darauf hingewiesen, dass die grosse Fenestra basicranialis in einen caudalen und rostralen Abschnitt zerfällt; die Grenze beider Abschnitte der Basislücke ist durch einen leichten Vorsprung der umsäumenden Knorpelspangen zu erkennen. Spüter kommt es hier zu einer Einschnürung der grossen Fenestra basicranialis, welche dadurch Sanduhrform erhält. Es wurde schon 1907 von mir darauf hingewiesen, dass diese Form der grossen Basislücke sehr an die gleichen Erscheinungen am Lachsschädel erinnert $(G$ a u p p 
[1905]). Dort findet sich die Einschnürung der Fenestra basicranialis noch ungefähr in gleicher Höhe mit dem Foramen palatinum und der vorderen Ohrkapselkuppel. Es ist also beim Lachs nicht zu so erheblichen Verschiebungen der Ohrkapseln und der Seitenteile des Schädelbodens gegen die mediane Schädelbodenpartie gekommen.

Orbitotemporalregion. Die Entwickelung der Knorpelwïnde des Schädels in der Orbitotemporalregion, welche zunächst nur Schutz und Stütze für Hirnteile abgeben sollen, erfolgt in der Weise, dass in den Hauptzügen ein Gerüst angelegt wird, welches die definitive Form vorzeichnet. In dieser Art vollzieht sich die Schädelentwickelung bei den meisten daraufhin untersuchten Formen, wie die Untersuchungen von Ga up p (1893, 1898, 1905), P eter (1898), Sew ertzoff (1899) u. a., welche Formen verschiedener Wirbeltierklassen betrafen, gelehrt haben. Es wird durch die Trabekeln und die aus der Trabecularcommissur sich entwickelnde Orbitonasalplatte der Grundplan der Schädelbasis festgelegt; auch später kommt es hier nicht zu einer weiteren Vervollständigung, da das Infundibulum und der Recessus praeopticus, zwischen die Trabekeln sich einschiebend, die Verknorpelung an der Hirnbasis hemmen; die grosse Fenestra basicranialis des Primordialcranium wird aber sehr bald durch das Parabasale verschlosesn.

Am Hirn werden nun zunächst die Teile von Knorpel umgriffen und bedeckt, welche am wenigsten stark hervorspringen. Rostral werden die Lobi olfactorii fast völlig knorpelig umschlossen, im Anschluss an die Ohrkapsel wachsen die Cartilagines supraorbitales aus, welche über die Seitenteile des Hirnes entlang ziehen und sich vereinigen mit der Knorpelkappe, welche das Hirnende einhüllt. Hinter der Epiphyse und vor der Paraphyse legen die ersten Teile des Schädeldaches im Anschluss an die Cartilago supraorbitalis und die rostrale 
Knorpelkappe des Hirns sich an, welche als Epiphysearleiste (Gaup [1905]) und Paraphysearleiste bezeichnei werden können. Von diesen Teilen aus erfolgt später der weitere Abschluss des Schädeldaches. Nur die caudale grosse Fontanelle bleibt erhalten, sie wird aber durch Auswachsent der Taenia tecti media posterior bis zum Tectum synoticum später in zwei symmetrische Hälften zerlegt. Die Fontanellen werden dann gedeckt von den Parietalia, welche die ganze Labyrinth- und Orbitotemporalregion bedecken. Bei Lepidosteus osseus entsteht demnach schliesslich ein sehr vollständiges Schädeldach, welches den direkten Vergleich mit dem rollständig geschlossenen Dache von Amia calva und den Knorpelganoiden ermöglicht. Für die seitlichen Leisten, welche von der rostralen Ohrkapselkuppel ausgehen und den zuerst entstehenden Teil des Schädeldaches resp. den Rand der Schädelseitenwand darstellen, habe ich den Namen Cartilago supraorbitalis (auch Taenia marginalis, Ga upp) beibehalten. Diese Knorpel finden sich an den Primordialcranien der meisten Vertebraten wieder (S ew ertz off [1899]). Ich halte aber die Namen Alisphenoidknorpel (Sewertz of f [1899]) und Sphenolateralknorpel (Ga upp [1905]) für nicht sehr günstig, da die Komponente Sphen wohl besser für die Ersatzverknöcherungen der Orbitotemporalregion reserviert bleibt. Die Form, in welcher die Cartilago supraorbitalis („Sphenolateralis“) bei Acanthias zuerst auftritt, ist zudem vielleicht als spezielle Anpassung an den Ausbildungsgrad der übrigen Kopforgane aufzufassen. Eine Schädelseitenwand ist in der Orbitotemporalregion bisher nur am rostralen Ende lateral von den Lobi olfactorii entwickelt. An dem caudalen Rande dieser Seitenwand entspringen die Musculi obliqui superior et inferior bulbi. Die Stelle des Ansatzes dieser Muskeln war auch der erste Teil der Seitenwand, welcher angelegt wurde, sodass wohl eine gewisse Abhängigkeit der frühzeitigen Entstehung dieser Seitenwand 
von den Muskeiansätzen angenommen werden muss. Späterhin entsteht noch im hinteren Teile der Orbitotemporalregion eine breite Knorpelplatte, welche die Cartilago supraorbitalis mit der Trabekel verbindet, sodass zwischen vorderer Ohrkapselkuppel und Seitenwand ein Foramen prooticum für den Austritt der orbitalen Äste des Trigeminofacialiskomplexes aus ihrer Trigeminofacialiskammer ausgespart bleibt. Durch diese Seitenwand treten dann noch der Oculomotorius, Trochlearis und Ophthalmicus profundus in der früher beschriebenen Weise aus. Es bieibt dann inmer noch der grösste Teil der orbitotemporalen Seitenwand offen zwischen dieser caudalen und der kleinen rostralen Knorpelwand; die grosse Öffnung, welche späterhin grösstenteils membranös verschlossen wird, wurde früher als Fenestra optica bezeichnet (V e it [1907]).

Ethmojdalregion. Ene Finnoidatregion des Primordialcranium kommt erst sehr spät zur Entwickelung (Staldium V). Die Momente, welche die ontogenetisch späte, gewaltige Verlängerung des präcerebralen Kopfgebietes bei Lepidosteus osseus bedingen, sind uns unbekannt. Es muss diese Erscheinung als Tatsache hingenommen werden. Mit dem Vorderkopf wächst nun die Orbitonasalplatte zum Septum rostri aus, ihre anfangs sehr kleinen seitlichen Fortsätze zu den Cornua trabecularia. Beziehungen zum Nasensack hat das Knorpelskelet des Vorderkopfes nicht, weshalb ich auch den indifferenten Namen Rostrum vorgezogen habe. Ebenfalls lassen sich die eigentümlichen Cornua trabecularia nicht ohne weiteres mit ker Anlagerung der Pars palatina palatoquadrati in direkte Beziehung bringen. Es finden bei der weiteren Entwickelung noch sehr eingreifende Verinderungen in der Pars praecerebralis cranii statt. Das Septum interorbitale ist eine später erst auftretende Bildung, welche aus dem jetzt noch gar nicht besonders erkennbaren Rostrumteil zwischen Hirnschädel und Cornu trabeculare entsteht. Vor den Cornua trabecularia wächst 
später das Rostrum zum langen Septum nasi aus, ohne dass die Cornua trabecularia diesem Auswachsen folgen. Besonders erscheint der Befund, dass bei einem Schädel, welcher spüter geradezu als Typus des tropibasischen erscheint, ein Interorbitalseptum erst so ausserordentlich spät auftritt. Noch im letzten hier behandelten Stadium (Fischehen von $20 \mathrm{~mm}$ Gesamtlänge) liegt das Auge seitlich neben dem Vorderhirn; es. schiebt sich erst viel später vor die Pars cerebralis cranii. Wir sehen hier eine prinzipiell gleiche Erscheinung wie bei der Labyrinthregion, dass nämlich die Grenze der Orbitotemporalgegen die Fthmoidalregion ontogenetisch sehr starke Verschiebungen aufweist. Die späte Entstehung des Septum interorbitale ist deswegen auch von besonderem Interesse, weil G a up aus vergleichend-anatomischen Giründen eine primäre Tropibasie in gewissen Grenzen für wahrscheinlich hält. Eine Ableitung und Vergleichung der eigentümlichen Bildungen der Pars praecerebralis cranii von Lepidosteus mit den Rostrumbildungen bei den Selachiern scheint mir nicht ohne weiteres möglich zu sein.

Occipitalregion. Die Entwickelung der Occipitalregion des Primordialcranium vollzieht sich in der gleichen Weise, wie prinzipicll bei allen niederen Wirbelticren (S ewertz off [1896]). Die Entwickelungsvorgänge, welche bei der Anlage der Occipitalregion bei Lepidosteus osseus eine Rolle spielen, hat K. E. Schreiner (1902) beschrieben; in den meisten Punkten kann ich seiner Beschreibung zustimmen. Die Verknorpelung der Occipitalregion beginnt etwas später als die der übrigen Craniumabschnitte. Die Parachordalia strahlen von der Labyrinthregion caudalwärts aus in eine dorsolaterale und ventrolaterale parachordale Längsleiste. Zwischen den einzelnen Spinalnerven an den Ansatzstellen der Septa intermuscularia bilden sich an der dorsolateralen Längsleiste kleine Knorpelbuckel aus, welche die einzigen rasch vorübergehenden An- 
klänge an Wirbelbogen in dem Anfangsteil der Occipitalregion darstellen (Fig. 8). Solche Knorpelbuckel treten auf zwischen dem Stamm des Vagus und dem Nervus IVv, zwischen dem Nervus IV ${ }^{v}$ und $V^{v}$, sowie zwischen den Nerven $V^{v}$ und VI Wir können demnach im Stadium III noch drei kleine Wirbelbogenrudimente erkennen. Nun verschmelzen aber die Knorpelvorsprünge sehr rasch dorsal von den Nerven miteinander, wachsen als geschlossene occipitale Seitenwand aus und legen sich der caudalen Ohrkapselkuppel über dem Vagusstamme hinweg an. So entsteht eine occipitale Seitenwand, durch welche der Nervus IV ${ }^{\mathbf{v}}$ und Vv. hindurchtreten, während der Nervus VI zunächst noch über ihren caudalen Teil hinwegtritt (Fig. 17). Dieser caudale Rand hängt stärker lateralwärts über und setzt sich von der übrigen Seitenwand noch etwas ab; nach Schreiner wird er als isolierter, dorsaler Bogen angelegt, der sehr rasch mit der occipitalen Seitenwand vor ihm verschmilzt; dieses rasch vorübergehende Zwischenstadium konnte ich nicht beobachten.

Der dorsale Bogen, der mir demnach nur noch nach seiner Verschmelzung mit der occipitalen Seitenwand als deren caudaler Rand erschien, ist der Bogen zwischen dem Nervus VI und VII. Ein rudimentärer kurzer Bogen bildet sich noch zwischen Nervus VII und VIII, dann folgt zwischen Nervus VIII und IX der erste echte Wirbelbogen. Dieser erste vollentwickelte Wirbelbogen wird später noch dem Occipitalbogen des Schädels angefügt. Der Chorda haften in dem ganzen hier in Betracht kommenden Gebiete - es wurde von den älteren Entwickelungsstadien nur die vordere Körperhälfte in fortlaufende Serien zerlegt, sodass ich nicht aussagen kann, wie weit die Wirbelsäulenanlagen caudalwärts fortgeschritten sind - jederseits eine dorsolaterale und ventrolaterale knorpelige Längsleiste an, sodass die Wirbelbogen durch die dorsolaterale parachordale Längsleiste an ihren Basen miteinander verbunden 
sind. Welche Momente nun die Absetzung des Kopfes rom Rumpfe zwischen dem ersten und zweiten vollentwickelten Wirbel bedingen, soll erst bei der Gesamtentwickelung des Kopfes am Schluss besprochen werden. Die Frage der Metamerie der Occipitalregion wird weiter unten bei Besprechung der Nerven erfolgen. Jetzt soll nur noch in aller Kürze besprochen werden, wie die definitive Occipitalregion von dem letzten hier beschriebenen Stadium alogeleitet werden muss. Bei dem erwachsenen Tier zerfüllt die occipitale Seitenwand in die Seitenwand im engeren Sinne und den Occipitalbogen. Durch die Seitenwand treten durch die Nerven $V^{v}$, VI und VII (F ür bring er's Nervus $z, a, b$, s c hre in er's 1., 2., 3. Nerr.), durch den Occipitalbogen die Nerven VIII und IX (Fürbringer's c, d, Schreiner's 4., 5. Nerr.). Aus diesem Verhalten der Nerven lässt sich sofort die Mbleitung der occipitalen Seitenwand des erwachsenen Tieres von dem embryonalen Zustande ablesen. Der Occipitalbogen des erwachsenen Tieres muss aus der Verschmelzung des Bogenstumpfes zwischen Nervus VII und VIII mit dem ersten rollentwickelten Wirbelbogen zwischen Nervus VIII und IX entstanden sein. Die occipitale Seitenwand ist eine weitere Fortbildung der Seitenwand, wie sie schon beim Tiere von $20 \mathrm{~mm}$ (Stadium V) sich findet. Die Verschmelzung des ersten Wirbelbogens mit dem Bogenstumpf zwischen Nervus VII und VIII erfolgt sehr spät; denn bei dem früher beschriebenen Tiere von $15 \mathrm{~cm}$ Gesamtlänge (Veit [1907]) waren die beiden Komponenten des Occipitalbogens noch getrennt ${ }^{1}$ ). Der Occipitalbogen des erwachsenen Tieres ist also zwei Skeletmelameren des Rumpfes gleichzusetzen, die noch in der Entwickelung als freier Wirbelbogen und Bogenrudiment nachweisbar sind. Die occipitale Seiten-

1) In der damaligen Beschreibung ist ein Fehler unterlaufen. Es wurde das Bogenrudiment zwischen Nervus VII und VIII (damals naeh Fürbringer bezeichnet b, c) nicht dem Occipitalbogen, sondern der occipitalen Seitenwand zugerechnet. 
wand ist vier Skeletmetameren gleichzusetzen, ron denen aber in der Entwickelung nur eines noch als Bogenrudiment auftritt zwischen Nervus VI und VII. (Schreiner), während divor nur in der allertrühesten Anlage kleine Knorpelhöcker zwischen den Nerven an den Ansatzstellen der Septa intermuscularia auf eine ehemalige skeletsegmentierung hinweisen.

Splanchnocran i um. Die Entwickelung des Splanchnocranium vollzieht sich im allgemeinen in Bahnen, die aus den Untersuchungen bei anderen Fischen schon bekannt sind. Xur einen Punkt möchte ich herausgreifen. In der ersten Anlage, dem Vorknorpelstadium, bilden die rerdichteten Mesenchymmassen einen kontinuierlichen Stab in jeder Kiemenbogenhälfte, dic Zellmassen stossen ventral im Gebiete des spüteren Basibranchiale unter den Hypohyalia atufeinander und konfluieren hier; dorsal lösen sich die Vorknorpelstäbe der einzelnen Kiemenbögen allmählich in lockeres Mesenchymgewebe auf, ohne an der Schädelbasis als dichte Zellmassen zu erscheinen. Nur der Vorknorpelstab des Hyalbogens setzt sich bis gegen. die Ohrkapselanlage heran fort und verschmilzt jetzt schon untrennbar mit ihr. In den vorknorpeligen Kiemenskelelanlagen treten nun einzehe Knorpelherde auf, entsprechend den späteren Teilen eines jeden Kiemenbogens. Diese Knorpelherde, welche von Anfang an durch die verdichteten Zellmassen miteinander zusammenhängen, stossen bei ihrem Iuswachsen aufeinander und verschmelzen nun synchondrotisch. Es bilden so die einzelnen Elemente eines jeden Kiemenskeletbogens unter sich einen Stab, dieser wieder verschmilzt mit dem Basibranchiale, sodass zum Schluss die einzelnen Teile des ganzen Hyobranchialskelets miteinander zusammenhängen. Es ist aber trotzdem möglich, die Grenzen der einzelnen Skeletstücke festzustellen, zumal der Knorpel, welcher die Stücke verbindet, sehr bald sich färberisch ein wenig anders verhält wie der sonstige hyaline Knorpel; später wird dieser Verbindungsknorpel 
durch Bindegewebe ersetzt, in welchem es dann schliesslich zur Bildung eines Gelenkspaltes kommt. Von besonderem Interesse ist es nun, dass die Hyomandibel, deren Vorknorpelanlage schon bis an die Ohrkapsclanlage heranreichte, knorpelig mit der Ohrkipsel verwächst; und zwar ist der Knorpel an der (irenze ron Hyomandibel und Ohrkapsel stellenweise echter hyaliner Knorpel, der sich genau so färbt wie anderer hyaliner Knorpel. Es erscheint mir dieser Befund für die Gehörknöchelfrage bei den terrestrischen Wirbeltieren von einigem Interesse zu sein, weil neuerdings ron verschiedenen Seiten (Fuch s [1905, 1906], D r üner [1904]) grosses Gewicht darauf gelegt wird, dass die Gehörknöchelchen oft in der ersten Vorknorpelanlage mit der Ohrkapsel zusammenhängen. Doch will ich mich mit diesem Hinweis vorläufig begnügen, da das Thema mir jetzt fern liegt.

Die Zerlegung der Kiemenskeletbögen in ihre einzelnen Elemente und die Ausbildung der Gelenke erfolgt so spät, dass dies von mir nicht mehr beobachtet werden konnte. Auf die allgemeine Bedeutung, die diesem Befunde zukommt, soll weiter unten noch hingewiesen werden.

Prinzipiell ganz gleich spielen sich dic Entwickelungsvorgänge am Kieferbogen ab. Die Mandibel ist durch hyalinen Knorpel mit dem Palatoquadratum verwachsen, dieses mit dem Processus basipterygoideus. Nur ist hier die synchondrotische Verwachsung rasch vorübergehender Natur, da schon bei einem Fischchen ron $20 \mathrm{~mm}$ Gesamtlänge (Stadium V) die Bildung des Gelenkes zwischen Palatoquadratum und Processus basipterygoideus und zwischen Mandibel und Palatoquadratum eingeleitet ist.

\section{Hirnnerven und Spinooccipitalnerven.}

Zur Frage der peripheren Ausbreitung der Hirnnerven habe ich den bekannten Tatsachen nichts Neues hinzufügen können. 
In den Arbeiten von Allis (1897) und van Wijhe (1882) sind die Verhältnisse der Kopfnerven der Ganoiden ganz besonders eingehend untersucht worden. Soweit meine Lntersuchungen des Ursprunges und der ersten Verzweigung der Hirnnerven zu Resultaten geführt haben, die von den bisher bei anderen Fischen gewonnenen abweichen, will ich mich in dieser Abhandlung auf eine kurze Aufzählung der abweichenden Daten beschränken. Es sind noch so manche Punkte in der Anatomie der Hirnnerven der niederen Wirbeltiere ungeklärt, dass es mir noch nicht möglich erscheint zu übersehen, welche Erscheinungen im Himnervenverlauf bei Lepidosteus als ursprünglich, welche als abgeändert aufgefasst werden müssen. Eine jede Verallgemeinerung und vergleichend-anatomische Verwertung der Befunde will ich deshalb vorläufig unterlassen.

Von allen Autoren, die sich in letzter Zeit mit der Anatomie der Kopfnerven der Fische beschäftigt haben, ist immer wieder betont worden, dass die gebräuchliche Nomenklatur völlig unzureichend ist; B. A. Panschin (1910) hat dieser Ansicht letzthin wieder ganz besonders Ausdruck verliehen. Ich habe, ohne damit in theoretischer Hinsicht irgend eine Deutung geben zu wollen, rein nach dem sich bietenden systematischen Bilde eine von der üblichen etwas abweichende Bezeichnung angewandt. Dass der Nervus ophthalmicus profundus, welcher bisher zumeist als Trigeminus I bezeichnet wurde, als selbständiger Hirnnerv aufzufassen ist, dürfte wohl keinem Widerspruch begegnen. Nicht nur muss der Nerv in seinem anatomischen Verhalten völlig vom Trigeminus abgesondert werden, er hat auch eine abweichende Entstehungsgeschichte, wie aus den Lintersuchungen von A. Brauer (1904) und H. Marcus (1910) hervorgeht, welche zeigten, dass bei Gymnophionen der Nerv nur aus einer ectodermalen Placode, nicht aus der Kopfganglienleiste entsteht. Ich habe deshalb einen neuen Namen 
gewählt und dafür den des einzigen Hauptastes zur Benennung des ganzen Nerven benutzt. Lis fand sich, dass der Ophthalmicus profundus eine kurze, aber breite Anastomose zum Ramus inferior oculomotorii sendet. Dic Nervenfasern des Ramus anastomoticus gehen zu einem Ganglienzellhaufen, welcher in der Bahn des Ramus inferior oculomotorii sich findel; weiterhin entsendet der Oculomotorius einen Ramus ciliaris in den Bulbus. Nach dem Verhalten der anderen Formen ist es wahrscheinlich, dass der Hauptteil der Fasem des Ramus ciliaris oculomotorii aus dem Ganglienzellhaufen des Ramus inferior stammt (G. Schwalbe [1879]). Schneider (1882) deutete den Ophthalmicus profundus als ventrale Wurzel des Oculonotorius; dem kann nicht mehr zugestimmt werden, da der Ophthalmicus profundus als völlig selbständiger Nerv entsteht und erst sekundär die Verbindung mit dem Oculomotorius eingeht; Schneider beschreibt auch selbst, dass der Hauptstamm des Ophthalmicus profundus über den Bulbus hinweg rostralwärts zieht.

Es wurde schon oben bei der Beschreibung ausgeführt (\$. 160), dass der Ophthahnicus lateralis rom Facialis rölig abgetrennt werden muss. Der Nerv versorgt die Simnesorgane der Seitenlinie der vorderen Labyrinthregion mit einem allgemein als Ramus oticus bezeichneten Nerven, sowie weiterhin die Sinnesorgane des Supraorbital- und Infraorbitalkanales; die beiden letzteren Äste wurden als Nervi infraorbitalis und supraorbitalis bezcichnet, sodass in ihren Namen schon ihre Bedeutung erkembar ausgedrückt ist, und die Nerven nicht mehr als Facialisiaste in der Nomenklatur erscheinen. Es wurde ebenfalls schon bemerkt, dass die ainzige Inastomose, welche rom Ophthalmicus lateralis in den Facialis geht, sicher nur in den Truncus hyoideomandibularis eintritt, und hier wahrscheinlich nur Fasern in den Ramus mandibularis entsendet. Säntliche Seitenorgane des Vorderkopfes würden dann rom Nervus ophthalmicus lateralis allein innerviert werden. 
Der Trigeminus und Facialis liessen sich vollständig voneinander trennen. Es ging nur eine mächtige Anastomose aus dern Facialisganglion in den Truncus maxillomandibularis trigemini. Der Trigeminus versorgte weiterhin den Kieferbogen und den Vorderkopf (Truncus maxillomandibularis, Ramus ophthalmicus superficialis, Rami musculares), der Facialis den Hyalbogen und die Sinnesorgane des Mandibularkanals (Truncus hyoideomandibularis), sowie das Dach der Mundhöhle (Ramus palatinus). Erwiihnen möchte ich nur, dass ich keinen Ramus internus des Nervus mandibnlaris facialis fand. Dor Nervus glossopharyngeus und vigus zeigen im Verhalten ihres Ursprunges und ihrer Ramifikation keine Erscheinungen, die einen prinzipiellen L'nterschied gegenüber den Befunden bei anderen Fischen darstellen.

Einen Nervus praeopticus konnte ich nicht finden. Dieser Nerv scheint eine Eigentümlichkeit der Dipnoer zu sein (P in kus [1894, 1895], Sewertzoff [1902]). Das etwas abgesetzte Bündel des Olfactorius, welches Allis (1897) bei Amia als Nervus praeopticus deutet, scheint mir doch diese Deutung nicht zuzulassen, zumal C. L. A riëns Ka p pers (1909) ausdrücklich hervorhebt, dass er bei der Untersuchung des Hirnes von Lepidosteus und Amia keine Andeutung eines Nervus praeopticus findet.

Mit wenigen Worten möchte ich noch das Verhalten der spinooccipitalen Nerven besprechen. Im ein ausführliches Wiederholen der Einzelbefunde zu vermeiden, habe ich ein Diagramm in der von $\mathrm{S}$ e w e r t z of f (1896) zuerst angewandten Weise angefertigt, aus welchem die Befunde direkt abzulesen sind. Im Stadium I fand sich ein Bild der Myotome und Spinooccipitalnerven, welches völlig dem entsprach, welches K. E. Schrein er (1902) von gleich alten Stadien beschreibt. Nur war die rostrale Myotomplatte nicht mehr in einzelne Myotome zerlegbar; das erste Myotom Schreiner's war schon 
rückgebildet, wie nicht anders erwartet werden durfte. Weiterhin finden sich aber gewisse Differenzen zwischen den Befunden von Schreiner und meinen eigenen. Ich finde, dass so-

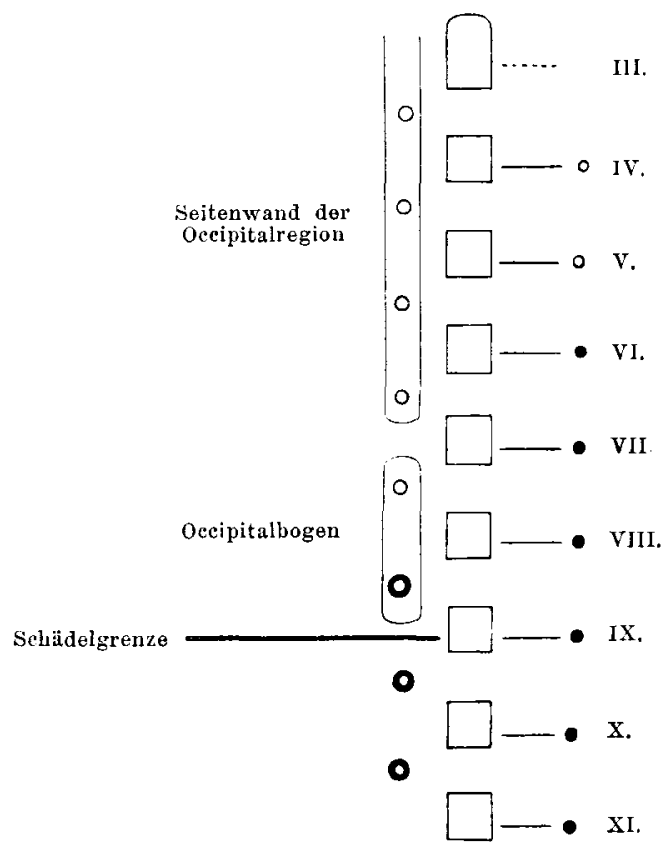

Textfigur 1.

Schematisches Diagramm zur Darstellung der Eutwickelungşorgänge der Occipitalregion von Lepidosteus osseus, nach der von Sewertz of f (1896) zuerst angewandten Methode. Die Rechtecke stellen die Myotome dar. Rechts ind durch horizontale Striche die ventralen Nervenwurzeln, durch punktierte Linie die zu Grunde gehende ventrale Wurzel angegeben; die ausgefüllten Kreise stellen die dorsalen Nervenwurzeln dar, leere Kreise deuten zu Grunde gehende dorsale Wurzeln an. Links sind durch dick umrandete Kreise die als echte vollständige Wirbelbogen angelegten dorsalen Bogen angegeben, durch dünn umrandete Kreise die Bogenrudimente.

wohl der Nervus IV als auch der Nervus V ihre dorsalen Wurzeln verlieren und lange Zeit als isolierte ventrale Wurzeln erhalten bleiben. Es ist mir selbst nicht möglich gewesen, mich von der Rückbildung des Nervus $I^{\mathrm{v}}$ zu überzeugen, sodass ich 
es offen lassen muss, ob nicht der Nervus IV überhaupt persistiert und bisher nur seiner Feinheit wegen übersehen. wurde.

Ich kann mir die Divergenz gegenüber den Befunden von K. E. Schreiner nur so erklären, dass ihm in Horizontalserien die feine Wurzel IV ${ }^{\mathrm{v}}$ entgangen ist, und in den Transversalserien zufällig individuelle Variationen vorgelegen habon, bei denen die dorsale Wurzel des Nervus $V$ noch erhalten war. Dass sehr erhebliche Variationen im Bilde der spinooccipitalen Nerven vorkommen, habe ich selbst an vielen meiner Serien erfahren, wie bei der Einzelbeschreibung auch angeführt wurde. Da mir aber eine recht beträchtliche Anzahl von Serien zur Verfügung steht, glaube ich für meine Befunde und deren Dentung einstehen zu können.

Nach meinen Befunden werden die ersten drei Myotome in Mesenchymgewebe aufgelöst, das vierte Myotom stark reduzicrt, erst vom fünften ab bleiben die Myotome völlig rrhalten. Es werden eine ventrale und zwei dorsale Winzeln rückgebildet $\left(\mathrm{III}^{\mathrm{v}}, \mathrm{IV}^{\mathrm{d}}\right.$ und $\mathrm{V}^{\mathrm{d}}$ ); ob der Nervus $\mathrm{IV}^{\mathrm{v}}$ später noch schwindet, kann ich nicht aussagen. Bei Besprechung der Entwickelung der Occipitalregion des Schädels wurde schon erwähnt, dass in die occipitale Seitenwand die Reste von rier dorsalen Bögen aufgenommen werden, dass der Occipitalbogen sich aus zwei dorsalen Bögen aufbaut. Die Verhältnisse sind in das Diagramm ebenfalls eingetragen. Es liess sich feststellen, dass vom Nervus VI an Äste in die Brustfloss: eintreten; dies korrespondiert mit den Untersuchungen von $\mathrm{F}$ ü $\mathrm{r}$. bringer (1897), welcher zeigte, dass rom Nervus a $(=\mathrm{VI})$ an Äste in die Brustflosse des erwachsenen Lepidosteus eintreten. 


\section{Zusammenfassung der Resultate. Der Kopf in seiner Entwickelung als Ganzes betrachtet.}

Es wurden bisher stets nur die Inderungen besprochen, welche ein einzelnes Organ oder eine Region des Schädels bei der Entwickelung erkemnen liess. Fis soll jetzt versucht werden, das Bild zusammenfassend, eine kntwickelung des Kopfes als Canzes zu entwerfen, soweit dies bisher untersucht werden konnte.

Bei der Entwickelung kommt es zu einer Vergrösserung, einem Auswachsen des Kopfes. Die Entwickelung der einzelnen Organe und Abschnitte des Kopfes erfolgt sehr verschieden rasch. Sie führt bei dem einen Teile in erster Linie zu einer Differenzierung und Spezialisierung der $A b$ schnitte, bei einem anderen Teile zu einer Gesamtvergrösserung. Hieraus resultiert ein starkes Verschieben der einzelnen Organe gegeneinander. Demnach muss bei der Entwickelung des Kopfes stets unterschieden werden zwischen dem Wachstum und der Vergrösserung des Kopfes im ganzen und deren Folgen für den übrigen Körper, sowie dem Wachstum und der Vergrösserung der einzelnen Bestandteile des Kopfes und ihrer gegenseitigen Beeinflussung.

Das erste Organ des Kopfes, welches sehr frühzeitig einen Höhepunkt der Entwickelung erreicht, ist das Gehirn. Dieses erstreckt sich anfangs durch die ganze Länge des Kopfes; seine einzelnen Hauptabschnitte sind im Stadium I im wesentlichen entwickelt. Später differenzieren sich nur noch die 
einzelnen Teile des Gehirnes woiter, das Organ streckt sich im ganzen durch Verringerung der Mittelhirnbeuge, die Lobi olfactorii wachsen aus den Seitenteilen des Vorderhirnendes aus und legen sich schliesslich vor das ursprüngliche Hirnende; im ganzen bleibt aber das Gehirn im Verhältnis zum übrigen Kopfgebiete relativ stark im Wachstum zurück.

Vor dem Hirne entfaltet sich der Vorderkopf; dieser wächst in ganz ungewöhnlichem Masse aus, sodass schliesslich das cerebrale Kopfgebiet nur wie ein kleiner Anhang des Vorderkopfes zwischen diesem und dem Rumpfe eingeschaltet erscheint. Starke Verschicbungen der Nerven und Sinnesorgane begleiten diesen Vorgang. Das Geruchsorgan, welches anfangs neben dem Vorderhim liegt, entfernt sich weit von ihm, da das Organ infolge des Auswachsens des präcerebralen Kopfgebictes weit rostralwärts vorgeschoben wird. Der Nervus olfactorius wird dadurch zu einem langen Nervenstrang ausgezogen.

Ebenso schiebt das Auge sich am Hirn entlang rostralwärts, wenn auch bei den beobachteten Stadien die Verlagerung sich noch in mässigen Grenzen hält. Erst späterhin treten auch hier sehr weitgehende Verschiebungen ein, sodass schliesslich das Auge ror der Pars cerebralis cranii liegt. Dann wächst auch der Nervus opticus zu einem relativ langem Stamme aus, welcher von caudomedial nach rostrolateral zum Bulbus zieht.

Auch dic übrigen Hirnnerven des Vorderkopfes zeigen in deutlicher Weise die Folgeerscheinungen der Verlängerung des Vorderkopfes. Fs kommt hierbei selbst zu gewissen Verschiebungen der Nervenursprünge gegeneinander. Da das Gehirn im Wachstum relativ stehen bleibt, wird bei der Vergrösserung der Nervenwurzeln und ihrer Ganglien der Abstand zwischen den einzelnen Wurzeln relativ geringer, sodass schliesslich 
die Nerven des Trigeminofacialiskomplexes zu einem fast unentwirrbaren Ganzen verschmelzen. Die Wurzel des Ophthalmicus profundus wird vom Ganglion trigemini gedeckt. Die beiden Wurzelfäden des Trigeminus, welche anfangs ventralwärts zogen, um ihr Ganglion ventrolateral neben der Hinterhirnbasis zu bilden, vereinigen sich später zu einem Strang, der von dorsocaudal nach ventrorostral läuft und ein lang ausgezogenes Ganglion ventrolateral vor dem Hinterhirn bildet. Die Wurzeln und das Ganglion des Trigeminus werden ausserdem noch ron den Ganglien des Ophthalmicus lateralis und Facialis bedeckt. Es wurde schon oben (S. 197) darauf hingewiesen, dass diese Verschiebungen der Organe des Vorderkopfes - Nase, Auge, Hirnnerven - in dem zuletzt beschriebenen Stadium $V$ noch lange nicht zum Stillstand gekommen sind. Es interessieren diese Erscheinungen, denen in späteren Lntersuchungen noch weiter nachgegangen werden muss, zunächst nur deshalb ganz besonders, weil sie die Verschiebungen erklärlich machen, welche zwischen den einzelnen Abschnitten das Cranium sich nachweisen liessen. Es wurde oben (S. 193) ausführlich besprochen, wie weitgehende Verschiebungen besonders im Grenzgebiet der Labyrinth- und Orbitotemporalregion stattfinden. Es kommt hier zu Verschiebungen der seitlichen Schädelwand gegen die Bodenplatte, der lateralen Teile der Bodenplatte gegen deren medianes Gebiet. Der Ausdruck Verschiebung ist hier natürlich so zu verstehen, dass ein ungleiches Wachstum der Schädelgebiete statthat. Das Zurückbleiben der medianen Teile des Schädelbodens der Labyrinthregion konnte in Verbindung gebracht werden mit dem Auswachsen des Infundibulum aus der Vorderhirnbodenplatte. So ändert sich das Bild der Grenzen der einzelnen Schädelregionen gegeneinander in nicht unbeträchtlichem Masse während einer langen Entwickelungszeit. Es ist überhaupt eine generelle Eigentümlichkeit „primitiver" Formen, dass ihre Entwickelung 
erst sehr spüt zum Abschluss kommt. Das tritt bei Lepidosteus osseus ganz besonders deutlich hervor. Denn bei einem $20 \mathrm{~mm}$ langen Ticre sind einige der auffallendesten Charaktere des Schädels des erwachsenen Tieres noch gar nicht angedeutet. Es besteht noch kein Interorbitalseptum, welches später als mediane Platte zwischen der Pars cerebralis cranii und dem Gebiet der "Cornua trabecularia" sich einschiebt, es besteht noch kein langes Septum nasi, beides Bildungen, welche in ihrer besonders mächtigen Entfaltung dem Kopfskelet von Lepidosteus osseus geradezu das Gepräge verleihen.

Wichtiger noch als die eben besprochenen Erscheinungen, welche sich im Gebiete des Kopfes selbst abspielen, sind ähnliche Vorgänge an der Kopf-Rumpfgrenze. Hier dehnen sich die Kiemenbögen allmählich vom Kopf in den Rumpf hinein aus, hier wird der Vagus und Glossopharyngeus caudalwärts ausgezogen. Es werden dabei unter Mitwirkung des sich ausdehnenden Labyrinthorganes und der knorpeligen Ohrkapsel die ersten Rumpfmyotome und die ersten spinalen Nerven zum Teil zerstört. Es ist dies prinzipiell der gleiche Vorgang, wie ihn besonders F r o ri e p in seinen zahlreichen Untersuchungen klar gestellt hat. Es erhebt sich nun die Frage, wo kommt es schliesslich zur Bildung der Kopf-Rumpfgrenze, resp. welche Momente sind hierbei Ausschlag gebend? Es ist leicht verständlich, dass in dem Gebiete, in welchem die Myotome und Septa intermuscularia fehlen oder stark reduziert sind, eine Anlage isolierter Wirbel nicht mehr erfolgt. Denn das darf wohl als sicher gestellt gelten, dass bei niederen Formen, welche noch eine sehr primitive Wirbelsäule aufweisen, die Bildung der Wirbel in hohem Masse ron der Muskulatur abhängig, bis zu einem gewissen Grade eine Funktion derselben ist. Da nun an der Kopf-Rumpfgrenze Spinalnerven und Myotome als solche zu Grunde gehen und zum Teil nachweislich in Mesenchym zerfallen, so kann es nicht wundernehmen, dass die Knorpel- 
anlagen der Wirbelsäule nicht mehr in typischer Weise erscheinen, sondern bei im allgemeinen weniger kräftiger Gesamtanlage und Verringerung der sie trennenden Abstände infolge der Verschmälerung der Myotome verschmelzen. Welche Momente bedingen es aber, dass freie Wirbel dem schädel assimiliert werden? Man hat hier eine Immobilisierung der Wirbel angenommen durch die Kiemenbögen, durch das Parabasale, durch Zugrundegehen der Muskulatur. So sollte es zu einer sekundären Assimilation der ersten freien Wirbel gekommen sein. Man ist bisher in der Fragestellung ausgegangen rom Verhalten bei erwachsenen Tieren. Dort finden sich freie Wirbel, die dem Schädel folgen, und es handelte sich demnach um das Problem, wie solche freien Wirbel sekundär dem Schädel angegliedert werden können. Die Lösung scheint mir durch die Befunde der Ontogenese sehr erleichtert zu sein. Es handelt sich ga: nicht um eine Assimilation freier Wirbel, sondern um das Ausbleiben einer Zerlegung der zusammenhängenden Wirbelreihe in einzelne Elemente. Hier scheint mir nun dis Funktion eine ausschlaggebende Rolle zu spielen. Bei den meisten Fischen sind die Wirbel zu einer gewissen Zeit der Entwickelung durch Knorpel oder Vorknorpel untereinander verbunden; eine Absetzung der einzelnen Wirbel voneinander erfolgt erst sehr spät (Schauinsland [1905]). Dic experimentellen Forschungen der letzten Jahre haben uns gezeigt, in welch hohem Grade die Entwickelung der Regenerate bei niederen Wirbeltieren in früher Entwickelungszeit durch die Funktion beeinflussbar ist (Harms [1910]). So erscheint es mir berechtigt anzunchmen, dass in gewissen Grenzen funktionelle Einflüsse auch bei der normalen Entwickelung niederer Wirbeltiere eine Rolle spielen können; denn wir dürfen doch wohl nicht annehmen, dass die Eigenschaft, funktionell beeinflussbar zu sein, erst durch Regenerationsprozesse neu hervorgerufen 
wird. Solchen funktionellen Einflüssen müssen nun meines Erachtens auch bei der Ausbildung der Kopf-Rumpfgrenze von Lepidosteus osseus eine Rolle zukommen. Nach den Beobachtungen von Fülle born (1894) u. a. schwimmt ein Fischchen von $20 \mathrm{~mm}$ Gesamtlänge (Stadium V) schon längst frei herum. Seine Muskulatur wird demnach funktionell das Skelet beeinflussen können. Die ersten Wirbelbogen werden durch den Kiemenapparat, welcher sich unter den Anfangsteil der Wirbelsäule unterschiebt, fast unbeweglich fixiert werden; diese Wirbelbogen sind auch ausserordentlich rudimentär, da hier schon die Myotome teilweise verdrängt sind. Aber auch noch der erste vollentwickelte Wirbelbogen wird nicht frei, sondern bleibt an Cranium fixiert. Hier scheint mir nun eine Immobilisierung durch den Kiemenbogenapparat nicht mehr allein bewirkt zu werden; es erstreckt sich nur das Ende des Kiemenbogenapparates soweit caudalwärts. Hier legt sich aber der Schultergürtel, welcher in Stadium $V$ schon in allen seinen Knorpelteilen angelegt ist, dem Schädel an und ist später selbst durch das Suprascapulare fest dem Schädelskelet (Squamosum) verbunden. Diese knöcherne Verbindung ist jetzt erst in der Anlage erkennbar.

Für eine Immobilisierung des ersten vollentwickelten Wirbelbogens kommt demnach bisher als ursächliches Moment nur der primordiale Schultergürtel in Frage. Es ist klar, dass noch manche andere Punkte für die Bestimmung der Lage der Kopf-Rumpfgrenze in Frage kommen können. Wichtig erscheint mir nur, dass funktionelle Einflüsse auf das sich entwickelnde Tier hier eine Rolle spielen können. Vorläufig ist in diesem Punkte kein sicheres Urteil zu gewinnen, da funktionelle Einflüsse durch Lntersuchung der normalen Entwickelung wohl wahrscheinlich gemacht, aber noch nicht erwiesen werden können.

Froriep (1905) hat neuerdings die Frage aufgeworfen, 
ob überhaupt eine Verschiebung der Craniovertebralgrenze bei den Wirbeltieren vorkommt, oder ob nicht vielmehr mit der erstmaligen Ausbildung des Kopfes die Craniovertebralgrenze definitiv festgelegt ist. Es ist ohne weiteres zuzugeben, dass eine Vergleichung sehr erschwert ist, da wir keine festen Punkte haben, von denen ausgehend wir die Zählung der Somite vornehmen können. F ro riep (1902) selbst hat darauf hingewiesen, dass dic Ohrblase nicht als Marke benutzt werden kann, da sie in erheblichem Masse ihre Stellung in der Entwickelung ändert. Dass das craniale Ende der Uniere als fixer Ausgangspunkt dienen kann, wie F r ori e p (1905) neuerdings will, erscheint aber noch viel weniger möglich, da gerade das craniale Ende der Urniere in seinem Auftreten ausserordentlichen Schwankungen unterliegt. Es ist also nur möglich unter Abwägung aller in Betracht kommenden Momente unter Vermeidung einer schematischen Beurteilung von einem Gesichtspunkte aus eine vergleichende Betrachtung verschiedener Wirbeltiercranien anzustellen. Hier muss die Untersuchung und Vergleichung der Zustände erwachsener Tiere, das Untersuchungsgebiet der vergleichenden Anatomie in engerem Sinne, im Zusammenhang mit den Befunden entwickeiungsgeschichtlicher Forschung verwertet werden. Denn so wenig wie die vergleichende Anatomie allein eine Lösung des Problems geben kann, ebensowenig kann die entwickelungsgeschichtliche Forschung für sich eine erschöpfende Beantwortung der hier zu stellenden Fragen geben. Durch die Befunde der entwickelungsgeschichtlichen und vergleichend-anatomischen Forschung scheint mir nun, wie aus den zusammenfassenden Darstellungen von Fü r bring er (1897) und Ga u p p (1898, 1905) hervorgeht, ziemlich sicher erwiesen zu sein, dass die Craniovertebralgrenze der Amnioten um drei Metamere caudalwärts verschoben ist 'gegenüber der Grenze bei Amphibien. Dass die Craniovertebralgrenze bei den Amphibien nicht ohne weiteres 
gleich zu setzen ist der Craniovertebralgrenze bei Selachiern, ist mir schon deswegen wahrscheinlich, weil, wie oben auseinandergesetzt (S. 183), das Selachiercranium überhaupt kein einheitlicher morphologischer Begriff ist. Vielleicht spielen auch bei der Absetzung des Schädels von der Wirbelsäule bei Selachiern funktionelle Einflüsse eine Rolle. Es würde dann besonders darauf $\mathrm{zu}$ achten sein, ob es sich um ovipare oder vivipare Formen handelt, da bei ersteren natürlich funktionelle Einflüsse von geringerer Bedeutung sein müssen. So wäre es auch 'verständlich, dass relativ nah verwandte Formen nicht unerhebliche Verschiedenheiten zeigen können. Ich muss mich mit diesem Hinweise begnügen. Wir kennen einstweilen nur von sehr wenigen Selachiern die einzelnen Phasen der Entwickelung des Kopfes; auf die Bedeutung funktioneller Einflüsse in der Ontogenese und die Möglichkeit, dass auf solche Einflüsse manche Charaktere des erwachsenen Tieres zurückzuführen sind, wurde dabei wohl bisher kaum geachtet. Eigene Erfahrungen über die Entwickelung des Selachicrschädels stehen mir bislang nicht zur Verfügung. Dass überhaupt eine Verschiebung der Craniovertebralgrenze bei den Wirbeltieren vorkommt, scheint mir durch die ontogenetischen Befunde bei verschiedenen Selachiern und besonders bei den Ganoiden sicher erwiesen zu sein.

Es ist nun eine vielleicht zunächst auffallende Erscheinung, dass bei terrestrischen Formen die oft sehr erhebliche Vergrösserung des Schädels nicht zu ausgedehnten Wirbelassimilationen führt wie bei wasserlebenden Tieren. Dies weist schon darauf hin, dass die Ursache der Schädelvergrösserung bei terrestrischen Formen eine andere sein wird wie bei kiemenatmenden Tieren. Bei letzteren spielt, wie zur Genüge hervorgehoben wurde, die Verlagerung des Kiemenbogenapparates unter die Wirbelsäule, welche wohl zum Teil eine Folge der mächtigen Entfaltung der Kiefer ist, und die Befestigung des 
Schultergürtels am Schädel eine Hauptrolle. Es wird so der Schädel durch Anlageriung von Wirbeln verlängert, das Cavum cerebrale cranii und das Gehirn selbst werden davon kaum tangiert. Anders bei terrestrischen Formen; hier vergrössert sich das Gehirn in allererster Linie. Der Hirnschädel nimmt durch eigenes Wachstum an Grösse zu, zum Teil werden ursprünglich extracerebrale Räume dem Cavum cerebrale cranii angefügt, wie aus den Lntersuchungen von G a up p (1905) und neuerdings Voit (1909) hervorgeht. Da der Kiemenbogenapparat zum grossen Teile zurückgebildet wird, nur Reste von ihm neue Verwendung finden, spielt er bei der Schädelbildung keine ausschlaggebende Rolle mehr.

Funktionelle Einflüsse spielen wahrscheinlich auch bei der Zerlegung der Kiemenskeletbögen in ihre einzelnen Segmente eine Rolle. Die Zerlegung der Kiemcnskeletbögen erfolgt ausserordentlich spät zu einer Zeit, in welcher das junge Fischchen schon frei herumschwimmt und auch schon auf Raub ausgeht. Beweglich müssen also die Kiemenskeletbögen schon sein, wenn auch die einzelnen Stücke noch knorpelig zusammenhängen. Die Konsistenz des Knorpels ist wohl als viel weicher anzunehmen als in späteren Stadien. Es ist klar, dass bei einer ontogenetisch so späten Zerlegung der Kiemenskeletbögen in ihre einzelnen Teile zu einer Zeit, in welcher die Teile längst funktionell in Anspruch genommen werden, die Funktion auch einen gewissen Einfluss auf die Gliederung der Skeletbögen wird ausüben können. Dohrn (1884) hat zuerst die Ansicht ausgesprochen, dass die Gliederung der Kiemenskeletbögen als Anpassung an die Muskulatur aufzufassen ist. Cra p p (1905) schliesst sich ihm an und betont besonders, dass das , chamäleonartige Aussehen" des Kiemenbogenapparates bei den Wirbeltieren dadurch am leichtesten erklärbar ist. Nach meinen Befunden bei Lepidosteus muss ich dieser Auffassung rückhaltlos zustimmen und möchte nur betonen, dass die funktionellen 
Einflüsse in der Entwickelung des cinzelnen Individuums noch immer eine Rolle spielen. Somit muss auch zugegeben werden, dass funktionclle Einflüsse in der Ontogenie modifizierend wirken können, dass also schliesslich Veränderungen im Bau des Tieres ontogenetisch beginnen können. Wir wissen nun, dass solche bestimmten, zunächst rein individuellen, ontogenetisch stets neu hervorgerufenen Veränderungen im Bau des Tieres, wenn sich dieselben in mehreren Generationen wiederholen, schliesslich vererbt werden können. So erscheint mir auch hier wieder deutlich erkennbar, dass phylogenetische Veränderungen in der Ontogenie verursacht und eingeleitet werden können.

Zum Schluss sei noch auf einen Punkt hingewiesen. Die Entwickelung des Processus basipterygoideus und die Anlagerung des Palatoquadratum an diesen Fortsatz der Schädelbasis sind ebenfalls ontogenetisch späte krscheinungen. Auch ihre weitere Ausbildung wird demnach durch die Funktion von der ersten Anlage an beeinflusst werden können. Im allgemeinen ist das Palatoquadratum mit seinem Processus palatinus an den Schädel fixiert und verbindet sich dann ventrocaudal verlaufend mit der Mandibula. Hier bildet sich dann gewöhnlich noch eine Verbindung mit der Hyomandibel aus. Nur Heptanchus und Hexanchus zeigen ein abweichendes Verhalten. Bei ihnen verbindet sich die Pars quadrata palatoquadrati noch mit der Labyrinthregion des Schädels. Schon Sewertzoff (1899) hat darauf hingewiesen, dass die Verbindung der Pars palatina palatoquadrati bei Acanthias sehr frühzeitig erscheint; er sprach die Ansicht aus, dass das Palatobasalgelenk als die primitive Anheftungsstelle des Kieferbogens am Schädel aufzufassen ist. Ehe nicht dio ontogenetische Entstehung der Verbindung des Palatoquadratum mit dem Processus postorbitalis bei Heptanchus und Hexanchus bekannt geworden ist, scheint es mir nicht berechtigt, diese Verbindung 
218 OTTO VEIT, Beiträge zur Kenntnis des Kopfes der Wirbeltiere.

für primär zu halten. Es ist durchaus möglich, wie schon $\mathrm{S}$ e w e r $\mathrm{z}$ of f betonte, dass hier sekundäre Vorgänge vorliegen, welche das ursprüngliche Bild verdecken. Nach den Befunden bei Lepidosteus osseus ist solch ein Vorgang sehr wohl möglich. Denn auch bei ihm verbindet sich die Pars quadrata palatoquadrati sekundär mit dem Schädel; diese Verbindung entwickelt sich so kräftig weiter, dass sie schliesslich als Hauptverbindung des Kieferbogens am Neurocranium erscheint. 


\section{Tafelerklärung.}

Sämtliche graphischen and plastischen Rekonstruktionen wurden vach exakten Transversalserien von $10 "$ Schnittdicke bei einer Vergrösserung 100:1 ausgeführt. Die Figuren 1-15 sind auf die Hälfte verkleinert, geben also eine Vergrösserung $50: 1$; die Figuren $16-20$ sind auf ein Drittel verkleinert, geben also eine Vergrösserung $33 \frac{1}{3}: 1$.

Die graphischen Rekonstruktionen geben Medianschnitte des Kopfes wieder mit den eingezeichneten Medianschnitten des Gehirns und der Skelettteile. In den dazu gehörigen Pausen sind dann die Kopfnerven, Sinnesorgane etc. in ihrer Projektion auf die Medianebene wiedergegeben. Soweit die Bezeichnungen nicht ohne weiteres verständlich sind, ist ihre Bedeutung im Folgenden angegeben.

Für alle Figurengültige Abkürzungen und Farbenerklärung.

Ol. $=$ Olfactorius

Opt. $\quad=$ Opticus

Ocm. = Oculomotorius

Ci. $\quad=$ Ramus ciliaris

Tro. $\quad=$ Trochlearis

Abd. $\quad=$ Abducens

Oph.pr. $=$ Ophthalnicus profundus, gelb

Tri. = Trigeminus

$\left.\begin{array}{ll}\text { Oph.s. } & =\text { Ophthalmicus superficialis trigemini } \\ \text { Max.mand. }=\text { Truncus maxillomandibularis trigemini }\end{array}\right\}$ grün

Oph. l. = Ophthalmicus lateralis

Ot. $\quad=$ Ramus oticus ophthalmici lateralis

Su. orb. $\quad=$ Supraorbitalis ophthalmici lateralis

In. orb. $\quad=$ Infraorbitalis ophthalmici lateralis

Fac. $\quad=$ Facialis

Hy. mand. f. = Truncus hyoideomandibularis facialis

Hy.f. $\quad=$ Hyoideus facialis

Mand. f. = Mandibularis facialis

Pa.f. $\quad=$ Palatinus facialis

Op.f. $\quad=$ Opercularis facialis

Ac. $\quad=$ Acusticus 
Gl. $\quad=$ Glossopharyngeus

D. gl. = Dorsalis glossopharyngei

Ph. gl. $\quad=$ Pharyngeus glossopharyngei

Po.gl. = Posttrematicus glossopharyngei

Va. $=$ Vagus

D.va. = Dorsalis vagi

Lat.va. = Lateralis vagi

Br. va. = Pars branchialis vagi

Ph. va. $=$ Pharyngeus vagi

Po.va. Il.--V. = Posttrematicus vagi zum 2. bis 5. Kiemenbogen

IIl. -XI. = = 3. bis 11. Spinalnerv (der Exponent v bedeutet ventrale Wurz.) grün

Spr. $=$ Spritzlochanlage

R. s. $=$ Rectus superior bulbi

R.m. $=$ Rectus medialis bulbi

R.i. $\quad=$ Rectus inferior bulbi

R. $1 . \quad=$ Rectus lateralis bulbi

Ob.s. = Obliquus superior bulbi

Ob. i. $\quad=$ Obliquus inferior $\cdot$ bulbi

$\int$ rot mit Schraffur

Can.sem.a. $(p)=$ Canalis semicircularis anterior (posterior)

Rec. sup. utr. $=$ Recessus superior utriculi

Durch rote Striche ist die rostrale Grenze der Myotome, sowie das basale Stïck der Septa intermuscularia angegeben.

Die Chorda dorsalis ist in den graphischer Rekonstruktionen schraffiert, in den Plattenmodellrekonstruktionen grün angegeben, der Knorpel ist punktiert, resp. blau angegeben.

In den graphischen Rekonstruktionen ist in den Figuren 1, 6, 10 und 16 am Nervus opticus die Ursprungsfläche des Nerven am Hirn durch besondere Schraffur hervorgeboben.

Stadium I. Lepidostous osseus, Gesamtlänge $9 \frac{1}{2} \mathrm{~mm}$.

Fig. 1, Tafel D. Graphische Rekonstraktion des Kopfes.

Stadium II. Lepidosteus osseus, Gesamtlänge $10 \mathrm{~mm}$.

Für die graphische und plastische Rekonstruktion wurde die gleiche Serie benutzt.

Fig. 2, Tafel D. Graphische Rekonstruktion des Kopfes.

Fig. 3, Tafel A. Plattenmodellrekonstruktion von Gehirn und Primordial. cranium, Ansicht der rechten Seite.

Fig. 4, Tafel A. Dasselbe Modell, Ansicht der Ventralseite; auf der linken Seite sind die Kopfsinnesorgane wiedergegeben.

Fig. 5, Tafel A. Dasselbe Modell, Ansicht der linken Seite. Ausser dem Gehirn und Primordialcranium sind die Kopfsinnesorgane und Ursprünge der Kopfnerven wiedergegeben.

Stadium III. Lepidosteus osseus, Gesamtlänge $11 \mathrm{~mm}$.

Es wurde für die graphische und plastische Rekonstruktion die gleiche Serie benutzt. 
Fig. 6, Tafel D. Graphische Rekonstruktion des Kopfes.

Fig. 7, Tafel A. Plattenmodellrekonstruktion des Primordialcranium, Ansicbt der Dorsalseite.

Fig. 8, Tafel A. Dasselbe Modell, Ansicht der rechten Seite.

Fig. 9, Tafel A. Dasselbe Modell, Ansicht der Ventralseite. Das Splanchnocranium ist nur auf der rechten Seite wiedergegeben.

Stadium IV. Lepidosteus osseus, Gesamtlänge $14 \mathrm{~mm}$.

Für die graphische und plastische Rekonstruktion wurde die gleiche Serie benutzt.

Fig. 10, Tafel D. Graphische Rekonstruktion des Kopfes. Der Nervus acusticus ist in dieser Rekonstruktion fortgelassen.

Fig. 11, Tafel B. Plattenmodellrekonstruktion. Ansicht der linken Seite. Es ist das Gehirn, Sinnesorgane, Anfangsteile der Kopfnerven und das Neurocranium wiedergegeben. Die Konturen des Auges - Bulbus und Linse sind durch punktierte Linien markiert.

Fig. 12, Tafel B. Dasselbe Modell, Ansicht der rechten Seite. Das Gehirn ist median durchschnitten, sodass man die. linke Hirnhälfte von innen sieht; davor liegt die rechte Hälfte des Primordialcranium.

Fig. 13, Tafel B. Dasselbe Modell, rechte Hälfte des Neurocranium von innen gesehen.

Fig. 14, Tafel B. Dasselbe Modell. Das Primordialeranium von der Ventralseite gesehen; das Splanchnocranium ist nur auf der rechten Seite wiedergegeben.

Fig. 15, Tafel A. Plattenmodellrekonstruktion des linken Labyrinthorganes, Ansicht der Lateralseite.

Stadium V. Lepidosteus osseus, Gesamtlänge $20 \% \frac{1}{2} \mathrm{~mm}$.

Es wurde für die graphische und plastische Rekonstruktion die gleiche Serie benutzt.

Fig. 16, Tafel E. Graphische Rekonstruktion des Kopfes. Der Nervus facialis und ophthalmicus lateralis sind in dieser Rekonstruktion weggelassen.

Fig. 17, Tafel C. Plattenmodellrekonstruktion. Das Primordialcranium von der linken Seite.

Fig. 18, Tafel C. Dasselbe Modell, Ansicht von der Dorsalseite.

Fig. 19, Tafel C. Dasselbe Modell, Ansicht von der rechten Seite. Die rechte Ohrkapsel ist fortgenommen, sodass die linke Schädelhälfte von innen zu überseben ist.

Fig. 20, Tafel C. Dasselbe Modell, Ansicht von der Ventralseite. Links ist nur der Kieferbogen wiedergegeben, die anderen Teile des linken Splanchnocranium sind fortgelassen. Rechts ist das Interhyale und der grösste Teil des Keratohyale fortgenommen, ihre Konturen sind punktiert angegeben. In der nebenstehenden Zeichnung sind die dorsalen Enden der Kiemenskelettbögen besonders gezeichnet. 


\section{Citierte Literatur.}

1. Allis, E. Ph. jr., The cranial muscles and cranial and first spinal nerves in Amia calva. Journal of morphology. Vol. 12. 1897.

2. - The skull and the cranial and first spinal muscles and nerves in Scomber scomber. Ebenda. Vol. 18. 1903.

3. Ariëns Kappers, C. U., Untersuchungen über das.Gehirn der Ganoiden Amia calva und Lepidosteus osseus. Abhandlungen der Senckenbergischen naturforschenden Gesellschaft. Band 30. 1909.

4. B arfurth, D., Zur Regeneration der Gewebe. Archiv für mikroskopische Anatomie. Bd. 37. 1891.

5. van $\mathrm{B} \theta \mathrm{mmelen}, \mathrm{I}$. F., Über vermutliche rudimentäre Kiemenspalten bei Elasmobranchiern. Mitteilungen aus der zoologischen Station zu Neapel. Bd. 6. Berlin 1886.

6. Brauer, A., Beiträge zur Kenntnis der Entwickelung und Anatomie der Gymnophionen. IV. Die Entwickelung der beiden Trigeminusganglien. Zoologische Jahrbücher, Supplement VII (Festschrift für A. W e i s ma n). 1904.

7. Dohrn, A., Studien zur Urgeschichte des Wirbeltierkörpers. IV. Die Entwickelung und Differenzierung der Kiemenbogen der Selachier. V. Zur Entstehung und Differenzierung der Visceralbogen bei Petromyzon Planeri. Mitteilungen aus der zoologischen Station zu Neapel. Bd. $\dot{0}$. Berlin $1 \& 84$.

8. Drüner, L., Über die Anatomie und Entwickelungsgeschichte des Mittelobres beim Menschen und bei der Maus. Anatomischor Anzeiger. Bd. 24. 1904.

9. Froriep, A., Über ein Ganglion des Hypoglossus und Wirbelanlagen in der Occipitalregion. Archiv für Anatomie und Physiologie, 1882.

10. - Zur Entwickelungsgeschichte der Wirbelsäule, insbesondere des Atlas und Epistropheus und der Occipitalregion. I. Beobachtungen an Hühnerembryonen. Ebenda 1883.

11. - Über Anlagen von Sinnesorganen am Facialis, Glossopharyngeus und Vagus, über die genetische Stellung des Vagus zum Hypoglossus und über die Herkunft der Zungenmuskulatur. Ebenda 1885. 
12. Froriep, A., Zur Entwickelungsgeschichte der Wirbelsäule, insbesondere des Atlas und Epistropheus und der Occipitalregion. II. Beobachtung an Säugetierembryonen. Ebenda 1886.

13. - Bemerkungen zur Frage nach der Wirbeltheorie des Kopfskelettes. Anatomischer Anzeiger. Bd. 2. 1887.

14. - Über die Ganglienleisten des Kopfes und des Rumpfes und ihre Kreuzang in der Occipitalregion. Beitrag zur Entwickelungsgeschichte des Selachierkopfes. Archiv für Anatomie und Physiologie 1901.

15. - Zur Entwickelungsgeschichte des Wirbeltierkopfes. Verhandlungen der anatomischen Gesellschaft, 1902.

16. - Einige Bemerkungen zur Kopffrage. Anatomischer Anzeiger. Bd. 21. 1902.

17. - Die occipitalen Wirbel der Amnioten im Vergleich mit denen der Selachier. Verhandlungen der anatomischen Gesellschaft. 1905.

18. Fuchs, H., Bemerkungen über die Herkunft und Entwickelung der Gehörknöchelchen bei Kạninchenembryonen. Archiv für Anatomie und Entwickelungsgeschichte. Supplement 1905.

19. - Untersuchungen über die Entwickelung der Gehörknöchelchen, des Squamosums und des Kiefergelenkes der Säugetiere. Ebenda Supplement 1906.

20. Fülleborn, F', Bericht über eine zur Untersuchung der Entwickelung von Amia, Lepidosteus und Necturus unternommenen Reise nach Nordamerika. Sitzungsberichte der $\mathrm{kgl}$. Preuss. Akadomie der Wissenschaften zu Berlin. 1894. II.

21. Fürbringer, M., Über die mit dem Visceralskelett verbundenen spinalen Muskeln bei Selachiern. Jenaische Zeitschrift für Naturwissenschaft Bd. 30. N. F. 23.1896.

22. - Über die spinooccipitalen Nerven der Selachier und Holocephalen und ihre vergleichende Morphologie. Festschrift für C. Gegenbaur. Bd. 3. 1897.

23. Gaupp, E., Die Metamerie des Schädels. Ergebnisse der Anatomie und Entwickelungsgeschichte. Bd. 7. 1898.

24. - Die Entwickelung des Kopfskelettes. Handbuch der Entwickelungslehre, berausgegeben von $\mathrm{O}$. Hertwig. Bd. 3. 1905.

25. - Das Hyobranchialskelett der Wirbeltiere. Ergebnisse der Anatomie und Entwickelungsgeschichte. Bd. 14. 1905.

26. - Zur Entwickelungsgeschichte und vergleichenden Morphologie des Schädels von Echidna aculeata Var. typica. Jenaische Denkschriften. Bd. 6. 1908.

27. Gegenbaur, C., Untersuchungen zur vergleichenden Anatomie der Wirbeltiere, Heft 3. Das Kopfskelett der Selachier. Leipzig 1872.

28. - Die Metamerie des Kopfes und die Wirbeltheorie des Kopfskelettes. Morphologisches Jahrbuch. Bd. 13.1888.

29. - Uber die Occipitalregion und die ihr benachbarten Wirbel der Fische. Festschrift für A. v. Kölliker. Leipzig 1887.

30. Harms, W., Über funktionelle Anpassung bei Regenerationsvorgängen. Pflü ger's Archiv, Bd. 132. 1910.

31. Hof $f m a n n$, C. K., Zur Entwickelungsgeschichte des Selachierkopfes. Anatomischer Auzeiger. Bd. 9. 1894. 
32. Marcus, H., Beiträge zur Kenntnis der Gymnophionen. IV. Zur Entwickelungsgeschichte des Kopfes. II. Festschrift für $k$. Hertwig. Bu. 2. 1910.

33. M üller, Fr. W., Über die Entwickelung und morphologische Bedeutung der "Pseudobranchie" und ihre Umgebung bei Lepidosteus osseus. Archiv für mikroskopische Anatomie und Entwickelungsgeschichte. Bd. 49. 1897.

34. Nusbaum, J., Entwickelungsgeschichte und morphologische Beuiteilung der Occipitalregion des Schädels und der Weber'schen Knöchelchen bei den Knochenfischen. Anatomischer Anzeiger. Bd. 32. 1908.

35. Panschin, B. A., Die peripheren Nerven des Hechtes. Anatomischer Anzeiger. Bd. 35. 1910.

36. Parker, W. K., On the development of the skull in Lepidosteus osseus. Philosophical transactions of the royal society of London. Vol. 173. 1882.

37. Peter, K., Die kntwickelung und funktionelle Gestaltung des Schädels von Icbthyophis glutinosus. Morphologisches Jahrbuch. Bd. 25. 1898.

38. Pinkus, F., Über einen noch nicht beschmiebenen Hirnnerven des Protopterus annectens. Anatomiseber Anzeiger. Bd. 9. 1894.

39. - Die Hirnnerven des Protopterus annectens. Morphologische Arbeiten. Bd. 4. 1895 .

40. Rosenberg, E., Untersuchungen über die Occipitalregion des Cranium und den proximalen Teil der Wirbelsäule einiger Selachier. Dorpat 1884.

41. - Über das Kopfskelett einiger Selachier. Sitzungsberichte der naturforschenden Gesellschaft bei der Universität Dorpat. Bd. 8, 1889; Sitzung vom 17. II. 1886.

42. Sagemehl, M., Beiträge zur vergleichenden Anatomie der Fische 1. Das Cranium ron Amia calva. 1II. Das Cranium der Characiniden. IV. Das Cranium der Cyprinoiden. Morpbol. Jahrbuch. Bd. 9. 1884; Bd. 10. 1885; Bd. 17, 1891.

43. Schauinsland, H., Die Entwickelnng der Wirbelsäule nebst Rippen und Brustbein. Handbuch der Entwickelungslebre, herauggegeben von O. Hertwig. Bd. 3. 1905.

44. Sch neider, H., Über die Augenmuskelnerven der Ganoiden. Jenaische Zeitschrift für Naturwissenschaft. Bd. 15. N. F. 8. 1882.

45. Schreiner, K. E., Einige Ergebnisse über den Bau und die Entwickelung der Occipitalregion con Amia und Lepidosteus. Zeitschrift für wissenschaftliche Zpologie. Bd. 72. 1902.

46. Schwalbe, G., Das Ganglion oculomotorii. Jenaische Zeitschrift für Naturwissenschaft. Bd. 13. N. F. 6. 1879.

47. Sewertz off, A. N., Die Entwickelung der Occipitalregion der niederen Vertebraten im Zusammenhang mit der Frage über die Metamerie des Kopfes. Bulletin de la société impériale des naturalistes de Moscou. anneé 1895. Nouvelle serie. Tome IX. 1896.

48. - Beitrag zur Entwickelungsgeschichte des Wirbeltierschädels. Anatomischer Anzeiger. Bd. 13. 1897.

49. - Die Entwickelung des Solachierschädels. Festschrift für C. v. Kupf fer Jena 1899. 
50. Sewertz off, A. N., Zur Entwickelungsgeschichte des Ceratodus Forsteri. Anatomischer Anzeiger. Bd. 21. 1902.

51. Stöhr, Ph., Zur Entwickelungsgeschichte des Urudelenschädels. Zeitschrift für wissenschaftliche Zoologie. Bd. 33. 1880.

52. - Zur Entwickelungsgeschichte des Anurenschädels. Zeitschrift für wissenschaftlichc Zoologie. Bd. 36. 1882.

53. - Zur Entwickelungsgeschichte des Kopfskeletts der Teleostier. Festschrift zur Feier des dreihundertjährigen Bestehens der Universität Würzburg. Bd. 2. Leipzig 1882.

54. Veit, O., Über einige Besonderheiten am Primordialcranium von Lepidosteus osseus. Anatomische Hefte. Bd. 33. 1907.

55. Virchow, H., Embryologische und angiologische Erfahrungen über nordamerikanische Wirbeltiere. Sitzungsberichte der Gesellschaft naturforschender Freunde zu Berlin. Jalırgang 1894.

56. Voit, M., Das Primordialcranium des Kaninchens unter Berücksichtigung der Deckknochen. Anatomische Hefte. Bd. 38. 1909.

57. va n Wijhe, I. W., Visceralskelett und Nerven des Kopfes der Ganoiden und von Ceratodus. Niederländisches Archiv für Zoologie. Bd. 5. 1882.

58. - Über die Mesodermsegmente und die Entwickelung der Nerven des Selachierkopfes. Verhandelingen der Koninklijke akademie van wetenschappen, Afdeeling Naturkunde, 22. deel. Amsterdam 1883.

59. - Über Somiten und Nerven im Kopfe von Vögel- und Reptilienembry. onen. Zoologischer Anzeiger. Bd. 9. 1886.

60. .-- Über die Entwickelung des Kopfskelettes bei Selachiern. Compterendu des séances du sixième congrès international de Zoologie, à Berne 1904. Genève 1905. 